Portland State University

PDXScholar

$6-2008$

\title{
Physicians Providing Alternative Medicine: Boundary Crossing and the Emergence of Integrative Medicine
}

Richard Scott Lockwood

Portland State University

Follow this and additional works at: https://pdxscholar.library.pdx.edu/open_access_etds

Part of the Alternative and Complementary Medicine Commons, and the Medicine and Health Commons

Let us know how access to this document benefits you.

\section{Recommended Citation}

Lockwood, Richard Scott, "Physicians Providing Alternative Medicine: Boundary Crossing and the Emergence of Integrative Medicine" (2008). Dissertations and Theses. Paper 2273.

https://doi.org/10.15760/etd.2269

This Dissertation is brought to you for free and open access. It has been accepted for inclusion in Dissertations and Theses by an authorized administrator of PDXScholar. Please contact us if we can make this document more accessible: pdxscholar@pdx.edu. 
PHYSICIANS PROVIDING ALTERNATIVE MEDICINE:

BOUNDARY CROSSING AND

THE EMERGENCE OF INTEGRATIVE MEDICINE

\author{
by \\ RICHARD SCOTT LOCKWOOD
}

A dissertation submitted in partial fulfillment of the requirements for the degree of

DOCTOR OF PHILOSOPHY

in

SYSTEMS SCIENCE: SOCIOLOGY

Portland State University

2008 


\section{DISSERTATION APPROVAL}

The abstract and dissertation of Richard Scott Lockwood for the Doctor of Philosophy in Systems Science: Sociology were presented June 3, 2008, and accepted by the dissertation committee and the doctoral program.

COMMITTEE APPROVALS:

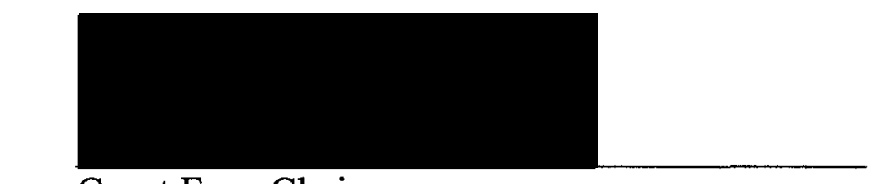

Grant Farr, Chair

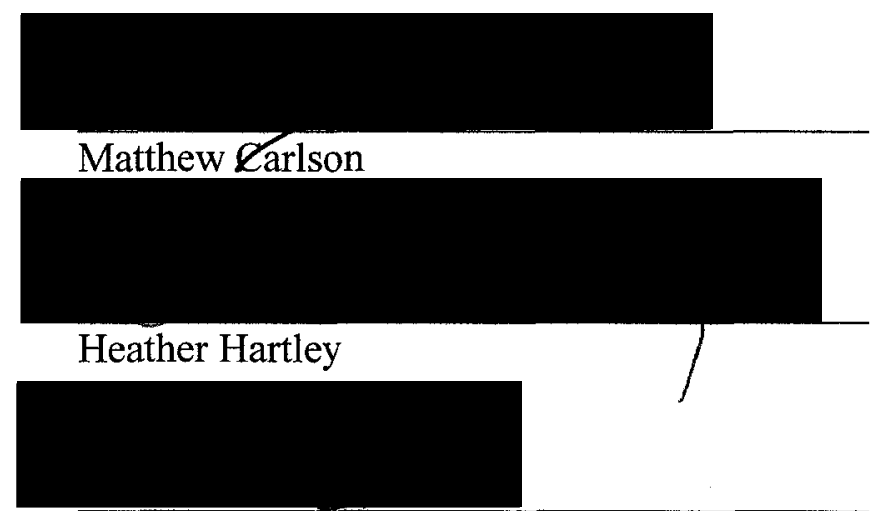

Martin Zwick

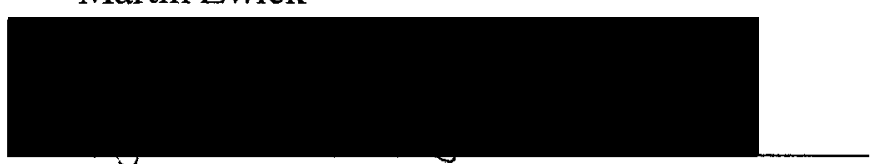

Sherril Gelmon

Representative of the Office of Graduate Studies

DOCTORAL PROGRAM APPROVAL:

George $\mathrm{G}$. Lendaris, Director

Systems Science Ph.D. Program 


\begin{abstract}
An abstract of the dissertation of Richard Scott Lockwood for the Doctor of Philosophy in Systems Science: Sociology presented June 3, 2008.
\end{abstract}

Title: Physicians Providing Alternative Medicine: Boundary Crossing and the Emergence of Integrative Medicine

Integrative medicine (IM) has organized as a new area of specialization in mainstream healthcare. The development of IM is widely attributed to popular demand for the range of therapies known collectively as Complementary and Alternative Medicine (CAM). During the 1990's the rate of acceptance of CAM accelerated among consumers, professions, financing and education. The Medical Expenditure Panel Survey (MEPS) measured CAM utilization and professional service provision during the years 1996 and 1998, but never since. These surveys were unique because they specifically inquired as to whether CAM was provided by a physician, among other types of professionals. This dissertation defines early integrative medicine (MDCAM) as CAM therapies provided by physicians. Because the MDCAM subpopulation is small, MEPS surveys for 1996 and 1998 were combined $(\mathrm{N}=39,314)$ to improve statistical power. 
The theoretical approach employed Abbott's (1988) theory of a system of professions, in which MDCAM represents a professional strategy of client differentiation through the social boundary mechanism of borrowing (Tilly, 2004) specific CAM therapies to satisfy consumer demand. The utility of the theory of a system of professions is discussed for its ability to decouple conceptual-level claims from observable workplace-level behaviors.

Nearly one million Americans received CAM therapies from their physicians during the period, and this professional behavior was found in every region of the country. Services provided by physicians included spiritual healing, massage and acupuncture; national population prevalence estimates are provided. This is meaningful because physicians, at the time, were at risk for disciplinary action for providing CAM.

The MDCAM subpopulation was similar to those who used both conventional and CAM services from other professional sources (BOTH), however, MDCAM reported much higher prescription medication use. The demographic profile of MDCAM was more similar to those who consume health care services frequently, compared to infrequent consumers. The MDCAM group is distinguished from those who use BOTH by increased utilization of the following services: nutritional advice, biofeedback and meditation. MDCAM is characterized by diagnoses of chronic illness. MDCAM recipients used mainstream medicine, yet employed disease management services offered by the CAM domain. 


\section{Dedication}

With solemnity and sincerity I dedicate this dissertation to my family. Deepest thanks are extended to my father, L. Bruce Lockwood, and mother, Edelmira D. Lockwood, for instilling in me the confidence and fortitude for embracing this task. My sisters, Tania Lockwood Schwartz, and Heather Lockwood Taylor have been unwavering in their support of my studies and I would be diminished without them. I hope that this dissertation provides some guiding inspiration to their children. 
Physicians Providing CAM

\section{ACKNOWLEDGEMENTS}

This dissertation has been honed by the attention and contributions of several great people, and I will carry their influence with me henceforth. Thanks to my committee as a whole, I am proud to have submitted my work before such an auspicious team of intellectuals. Special thanks are extended to Dr. Farr for his encouragement and leadership; his support was my touchstone when the future was uncertain. Deepest appreciation is extended to Dr. Zwick. I aspire to develop the same poignant mixture of discernment and curiosity about the sublime qualities of Nature that I witnessed in his classroom. To him, many, many thanks. I attribute my career development and the special opportunities that I have been blessed to receive, to the guidance of Dr. Gelmon. Her mentorship over the years has refined my values for quality, reliability and the pursuit of excellence. It is through her influence that I first wondered what it meant to be professional. I would like to thank Dr. Hartley for introducing me to the sociology of professions; in it I have found a promising theoretical home. Sincere thanks to Dr. Carlson for his attention to, and tacit confidence in my work. His voice of pragmatism encouraged me across the finish line.

I would like to thank Dr. Nathalie Huguet for her friendship, encouragement and tutelage. Her willingness to share her expertise on issues of complex sample design was always paired with both empathy and legitimation. In her I have found a close colleague. 
Early drafts of this dissertation ranged in tone from flourishes of poetry, written at midnight, to the driest of technical reporting. I am deeply indebted to Catherine Thomas, for her contributions as my technical editor, dearest friend and confidant. Ms. Thomas' adherence to the highest standards of professional writing, brought calm to the many voices in the early pages. I appreciate her dedication to my process and the sense of urgency that she shared with me as deadlines loomed. I will be forever grateful.

Finally, I would like to thank Dawn Sharafi for her friendship and heroic dedication to the Systems Science Program at Portland State University. From my first visit to the Department Office, through the last, she has always found the time to talk, connect and listen, despite the harried nature of her position. Her influence, on both the program and the students fortunate enough to make her acquaintance, is cast with a quick smile and sparkle in her eye. It is to her that I hold my glass high. 
Table of Contents

Acknowledgements ii

List of Tables

Acknowledgements viii

Chapter 1. Introduction 1

Contributions of the Study

Background

Professionalization of Integrative Medicine

Problematizing Medicine

Theoretical Approach

Medical Expenditure Panel Survey

Methodological Approach

Rationale

Research Questions

Outline of Chapters

Chapter 2. Theoretical Approach

Systems and Boundaries

Social Boundaries

Sociology of Professions

Internal Differentiation

Medicalization - Creating the Demand for Services

Demand for CAM

Chapter 3. Review of the Empirical Research Literature

CAM Utilization

Variables Associated with CAM Utilization

Prevalence Estimates for Model Variables

Age

Gender

Ethnicity

Education

Economic Status

Insurance Status

Health Status

Utilization of Health Care Services

Geography 
Physicians Provide CAM Services

Chapter 4. Research Methodology

Hypotheses

Model Variables

Dependent Variables

Sociodemographics

Perceived Health Status

Utilization Variables

Physician Awareness Variables

Geographic Variables

Statistical Analyses

Complex Sample Design Variables

Chapter 5. Preliminary Analysis

Data Sources: The Medical Expenditure Panel Survey

Sampling Frame and Response Rates

Study Samples

Preliminary Analyses

Box's M

Bivariate Comparisons of Model Variables

Chapter 6. Results

Characteristics of Respondents

CAM Utilization

Multivariate Analyses

National Projections

Chapter 7. Discussion of Findings

133

Discussion of Tables 6.1-6.13

Chapter 8. Conclusions and Implications

References

Appendix A: Typologies of Complementary and Alternative Medicine 


\section{List of Tables}

Table 1.1 General Research Questions $\quad 22$

$\begin{array}{ll}\text { Table 2.1 Meta Level Theory } & 24\end{array}$

$\begin{array}{ll}\text { Table 4.1 Hypotheses } & 73\end{array}$

$\begin{array}{ll}\text { Table 4.2 CAM Treatments List } & 74\end{array}$

Table 4.3 CAM Providers List $\quad 75$

Table 4.4 Provider Typology: Mutually-exclusive Professional Groups $\quad 76$

Table 5.1 Demographics and Expenditures by Year $\quad 89$

Table 5.2 Demographics, Insurance and Health Status by Year $\quad 90$

Table 5.3 Regional Distributions by Year 91

Table 5.4 Region Distributions by Year for Subpopulation of MDCAM 92

Table 6.1 Meta Table of Methods 93

Table 6.2 Univariate Report $\quad 94$

Table 6.3 Population Characteristics by Professional Group 99

Table 6.4 Type of Unconventional Therapies Among Users of CAM 106

Table 6.5 Type of Unconventional Therapies Among High and Low Users of Conventional Services Compared to MDCAM

Table 6.6 Type of Unconventional Therapies Among High and Low Users of Conventional Services Compared to MDCAM: Ranked Profiles

Table 6.7 Mainstream Health Care Utilization by Specific CAM Modality, Controlling for Population Characteristics

Table 6.8 Mainstream Health Care Utilization by Specific CAM Profession, Controlling for Population Characteristics 
Table 6.9 Financial Characteristics and Utilization by Professional Groups 121

Table 6.10 Utilization Variables and CAM Use 123

Table 6.11 Models of Professional Group Membership: Models $1 \& 2$

Table 6.12 Models of Professional Group Membership: Models $1 \& 3$

Table 6.13 Models of Professional Group Membership: Models 4 \& $5 \quad 130$

Table 6.14 National Projections for CAM Therapies: Detail by Region 132

Table 7.1 Summary Table for Hypotheses 152 
Physicians Providing CAM

List of Figures

Figure 6.1 Number of Prescription Medication by Professional Group 
Introduction

Chapter 1. Introduction

The ten-year period from 1996 to 2006 saw accelerating integration of complementary and alternative medicine (CAM) into mainstream health care systems (Ruggie, 2005; Nahin et al., 2005). CAM ${ }^{1}$ is defined here as a diverse set of treatments and practices that emphasize a general set of values regarding health and healing, which is distinct from allopathic medicine ${ }^{2}$ (Goldstein, 1999). Some argue that the ontological and epistemological differences that underlie both CAM and allopathic medicine are so distinctive that a Hegelian synthesis is required for proper integration (cf., Ritenbaugh et. al., 2003). Other commentators do not shy away from using, specifically, Kuhn's metaphor of the paradigm shift, to describe the impact of CAM upon the health care system of the United States (cf., Achterberg, 1998; Cohen, 1998; Horrigan, 2003). However, the most prominent definition of integrative medicine (IM), proffered by the National Center for Complementary and Alternative Medicine (NCCAM) at the National Institutes of Health (NIH), does not address

\footnotetext{
${ }^{1}$ Complementary and alternative medicine is defined by the National Center for Complementary and Alternative Medicine (NCCAM) as "a group of diverse medical and health care systems, practices, and products that are not presently considered to be part of conventional medicine. Complementary medicine is used together with conventional medicine. Alternative medicine is used in place of conventional medicine." (NCCAM, accessed 032603).

${ }^{2}$ Allopathic medicine treats disease by producing a condition that is incompatible with or antagonistic to the disease or symptom being treated (Dorland 1988, p. 50). This term will be used interchangeably with the terms conventional medicine and mainstream medicine.
} 
Introduction

philosophical differences between allopathic medicine and CAM. The NCCAM definition is: "Integrative medicine combines treatments from conventional medicine and CAM for which there is some high-quality evidence of safety and effectiveness" (NCCAM, 2008). The emergence of IM is worthy of close attention because it is largely credited to novel conceptual arguments by Snyderman and Weil (2002) which predated the general trend of IM clinics or specialty practices (Eisenberg, 2005).

The purpose of this research project is to examine an overlooked aspect of health care service provision which appears to be an early form of integrative medicine. This work will generate population estimates of American citizens who received CAM services from physicians during the years 1996 and 1998. Estimates of this type have not been made previously, and will provide information about workplace-level supply and demand relationships during the period. These measurements will be discussed relative to the conceptual-level claims about IM. This period is significant because of the degree of social change that occurred subsequently, in the health care industry, regarding alternative medicine. The analysis plan includes comparing subpopulations of survey respondents defined by their provider-type relationships. By generating comparative profiles, a more refined understanding of the consumer demand for CAM services will emerge and will aid in describing the market segment involved in early integrative medicine. 
Introduction

\section{Contributions of the Study}

This work contributes to the sociology of professions by providing an illustration of the variation in sociodemographic segments - as market segments that produce differential demand for CAM from different professionals (i.e., consumers, as a countervailing power to professions, are heterogeneous and therefore elicit a range of responses from health care professionals) (Haug \& Sussman, 1969; Abbott, 1988; Light, 1995). This extends Abbott's theory of a system of professions by offering an additional example of the dynamics of internal differentiation. Further, by employing this multilevel theory a more nuanced understanding of the emergence of integrative medicine is possible, by distinguishing between workplace level behaviors and conceptual level claims.

The remainder of this chapter will introduce issues and concepts that will be addressed in the remainder of the dissertation. Sections follow that provide background information about CAM and integrative medicine, address the theoretical approach to the problem, introduce the dataset, describe the rationale for the analysis and outline of the remaining chapters.

\section{Background}

The major driving factors for the integration of CAM and conventional medicine have been consumer demand, the establishment of the National Center for Complementary and Alternative Medicine (NCCAM) at the National Institutes of 
Health (NIH), increasing scientific research on the efficacy of CAM practices and increasing acceptance by physicians (Ruggie, 2005). ${ }^{3}$ This trend in integration has been similar across many industrialized countries (Saks, 2001; Barrett, 2003, Low, 2004), reflecting, in part, the need to address the burden of chronic illness and health care labor shortages associated with demographic transitions. However, the United States has been comparatively reluctant to incorporate alternative therapies into national-level health programs (Trachtenberg, 2002).

During this period, CAM has received increasing attention by the public, private and the not-for-profit sectors as well as the mass media. Popular demand for CAM is widely held to be a primary driving social force for integration (Eisenberg et al., 1993; Eisenberg et al., 1998; Goldstein, 1999, 2000a, 2000b, Goldner, 1999; Burke et al., 2005), yet adaptations of policy, organizational structure and research funding have been uneven. The White House Commission on Complementary and Alternative Medicine Policy (WHCCAMP) summarized the state of regulatory culture at the end of the $20^{\text {th }}$ century as follows: "[u]ntil recently, the primary response of federal, state and local health care regulatory agencies to this phenomenon was to restrict access to and delivery of CAM services to protect the public from unproven and potentially dangerous treatments" (White House Commission, 2002). However, there is evidence of convergence; inclusion of CAM into mainstream health systems has continued to advance. In 1999, Medicaid programs provided coverage for at least

\footnotetext{
${ }^{3}$ While there are many types of physicians (chiropractic physicians, naturopathic physicians, ophthalmic physicians, etc.) I use the term to specify MDs: graduates of a contemporary, mainstream medical education. This view follows Druss and Rosenheck (2003).
} 
Introduction

one alternative therapy in $78 \%$ of 46 states surveyed, although reimbursement expenditures were very small (approximately $\$ 10.00$ for CAM vs. $\$ 199$ for conventional care) (Steyer, Freed \& Lance, 2002). Additionally, this survey found that Oregon and Washington were the only states to reimburse alternative practitioners as primary care providers at that time. Washington State mandated CAM coverage by law in 1996, issuing state-level endorsement for a tax-supported natural medicine clinic embraced by King County (Whorton, 2004; Barrett, 2003). Comparisons of Health Maintenance Organizations (HMO), Preferred Provider Organizations (PPO) and point-of-service organizations indicate that, although CAM utilization was high (less among HMOs), the effect of utilization on insurance expenditures was modest (Lafferty et al., 2006).

There is, however, a gap in the literature about the effect of the CAM movement on the health care division of labor. This is the problem area addressed by this dissertation, primarily by extending the work of both Druss and Rosenheck (1999), and Bausell et al. (2001) and their use of the Medical Expenditure Panel Survey (MEPS) for measuring the health services impact of CAM. By adopting a health services research analytic framework, specific theoretical tools become available for interpreting the malleability of professional boundaries, the social reproduction of expert labor and the processes of internal differentiation within professions. This analytical approach groups survey respondents by professional service utilization as the main organizing principle. Descriptive profiling is then 
Introduction

possible, with attention to demographics, financial characteristics and health status. Analysis of population characteristics by health care provider type has precedent in this research area (cf., Brown, 1991; Cooper et al., 1998a, 1998b; Druss \& Rosenheck, 1999; Mackenzie et al., 1999; Bausell et al., 2001; Druss et al., 2003). Here the possibility presents itself for examining how differential demand for CAM (i.e., differences in consumer characteristics) affects the processes of professional specialization.

\section{Professionalization of Integrative Medicine}

In the United States, the trend toward integration has generated the new professional practice of integrative medicine (IM) (Snyderman \& Weil, 2002; Bell et al., 2002; Barrett, 2003). As alluded to above, some social entities, namely, consumers, are very supportive of CAM. Others are reluctant, if not averse, to CAM, as described by WHCCAMP. Integrative medicine is a relatively new concept in the discourse about health care delivery. Though IM aspires to a form of health care that is inclusive of many modes of healing and treatment beyond pills and surgery, it remains the province of the medical profession. Subdisciplines within health care show varying interest in integration; for example, public health has had a comparatively delayed response to this growing trend (Trachtenberg, 2002). The consumer demand for CAM results in significant discretionary spending, with estimates of out-of-pocket spending ranging from $\$ 10.5-\$ 12$ billion annually, 
Introduction

associated with more visits to CAM practitioners than to primary care providers (Eisenberg et al., 1993, 1998; Ruggie, 2005). These large sums are concrete indicators of the public's interest in health and wellness. However, these financial flows have by-passed the mainstream system. Medicine, as the most autonomous of professions, still sensitively reacts to economic incentives (Haug \& Sussman, 1969; Haug \& Lavin, 1981; Mechanic, 1979:181; The New York Times, 1990; Sullivan, 1993). This has raised alarm from within the system, with charges that the public's foolhardy purchases encourage unproven practices (cf. Angell \& Kassirer, 1998). The challenge of quackery quieted as result of anti-trust contests, and in its place the call for "evidence-based" medicine has emerged (The New York Times, February 9, 1990; Cohen, 1998; Ruggie, 2005). More recently, and ironically, similar concerns have been voiced about the lack of rigorous evidence for conventional care, citing both the paucity of clinical trials and the ubiquity of practice pattern variation (cf., Wennberg, 1984; Borkowski \& Allen, 2003).

Consumer demand for CAM has accelerated markedly since the 1960's (Pizzorno, 1996; Saks, 2001; White House Commission, 2002). This increased demand spurred research interest into the distinction between professionally-delivered alternative therapies and others (Druss \& Rosenheck, 1999). As general popular support for CAM has grown, health care education, in its several forms, has responded. Medical students' attitudes have become more open toward CAM, in part due to consumer interest in becoming active participants in their health care decisions 
Introduction

(Lavin et al., 1987). Krietzer, Mitten, Harris and Shandeling (2002) surveyed 627 faculty and students from the fields of medicine, nursing and pharmacy. Fully $90 \%$ of both faculty and students combined, favored integrating CAM into education and clinical care. In each group, over $80 \%$ favored the addition of CAM to the curriculum. Comparisons between the three professional groups found that nursing favored CAM more. Additionally, a post-residency fellowship in IM at the University of Arizona is producing a "new generation" of physician-CAM specialists (Barrett, 2003), indicating a focused effort on the part of medical education to address the issue of consumer demand (cf., Maizes et al., 2002). Winslow and Shapiro (2002) found that physicians want more CAM education in order to facilitate patient-provider relations. In their study, recommending $C A M$ was strongly correlated with physician self-use and an overall interest in learning. In 2005, the NIH initiated a Continuing Medical Education series on CAM, citing its value for educating both the estimated $62 \%$ of Americans who use CAM, as well as their health care providers (NIH News, 2005). Barrett's erudite review of literature on the degree of integration illustrated a pattern of physician support for more technical therapies, like acupuncture, biofeedback and chiropractic, which represent only a fraction of the CAM modalities popular among consumers (Barrett, 2003). Systematic reviews of research on the practices and beliefs of physicians regarding CAM found that "large numbers" of physicians were referring to, or practicing some forms of CAM, yet there were methodological limitations in the articles under review — primarily, small sample sizes (Astin et al., 1998b). These 
Introduction

authors called for population-based evidence from "rigorous surveys using national, representative samples" to provide more accurate specification of the degree to which physicians supported CAM. This dissertation answers the call by employing the MEPS, a national population-based survey, to investigate the trend toward integration.

\section{Problematizing Medicine}

The development of integrative medicine (IM) has drawn attention to the boundaries between allopathic medicine and CAM on several levels - conceptual, organizational and interactional. Integrative medicine, as a neologism, was described by Snyderman and Weil (2002) in an article entitled "Integrative Medicine: Bringing Medicine Back to Its Roots." This title implies both historical change and a critique of the current state of mainstream medicine. The authors explain that integrative medicine: (1) combines the best of both conventional and evidence-based CAM therapies; (2) emphasizes patient participation (e.g., exercise, diet, stress management) in maximizing health; (3) emphasizes the primacy of the patient-provider relationship and the importance of shared decision-making; (4) emphasizes the contribution of the therapeutic encounter itself; and (5) seeks to optimize an individual's innate healing capacity (Snyderman \& Weil, 2002). This definition has been adopted, in reduced form, by the National Institutes of Health (NIH). "Integrative Medicine... combines mainstream medical therapies and CAM therapies for which there is some high-quality scientific evidence of safety and effectiveness" (NCCAM, 2006). 
Introduction

Recently, David Eisenberg ${ }^{4}$ explained that IM focuses on the reintegration of medicine, by restoring the humanistic and interactive aspects of the medical encounter that once characterized the patient-provider interaction. Integrative medicine is defined by Kligler et al. (2004) as "an approach to the practice of medicine that makes use of the best-available evidence taking into account the whole person (body, mind, and spirit), including all aspects of lifestyle. It emphasizes the therapeutic relationship and makes use of both conventional and complementary/alternative approaches." Integrative medicine represents a restoration of sorts, to a previous culture of medicine, and is required to address a system "in crisis," as defined by two influential Institute of Medicine (IOM) reports (i.e., To Err is Human: Building a Safer Health System (2000), and Crossing the Quality Chasm: A New Health System for the 21st Century (2001)).

Popular demand for CAM continues to grow (Eisenberg, 2005). Populationbased surveys, such as the National Health Interview Survey (NHIS), indicate that Americans are turning to CAM as a strategy to lower personal health care costs (Pagan \& Pauly, 2005). In the NHIS, CAM use was significantly more prevalent among respondents who indicated that they had difficulty obtaining health care because of cost. The authors opined that the increasing ranks of uninsured Americans would drive more CAM consumption, rather than less. These comments are salient for their

\footnotetext{
${ }^{4}$ Dr. Eisenberg is the Director of the Division for Research and Education in Complementary and Integrative Medical Therapies at the Osher Institute, at Harvard University. These comments were made during his lecture at Oregon Health \& Sciences University, April 7, 2005.
} 
Introduction

simultaneous attention to the problems of access to health care and the persistent demand for these marginalized services.

Some authors call for caution as "integration" moves forward, with specific concern about conflating the conceptual organizing principles at play (cf., Astin \& Astin, 2002). Bell et al. (2002) warn that simple combination of alternative medicine with orthodox medicine does not satisfy the label integrative. The practices associated with health and healing are situated in philosophical and conceptual contexts. The paradigmatic distinctions that come to bear on the specialization processes of integration bring several points of contention. At the core of these distinctions is the difference between reductionistic/mechanistic thinking, which focuses narrowly on pathology, versus a holistic approach which considers the environmental, social and psychological aspects of a presenting problem. This paradigmatic difference suggests that thoughtful integration should attend to multiple levels, including theoretical, organizational and interpersonal issues. This concern was echoed by Ritenbaugh et al. (2003) as these authors drew attention to the tendency of previous research on the efficacy of CAM to focus narrowly on mechanisms of action, while diminishing the importance of contextual factors. Their frank discussion of the importance of paradigmatic frames anchored their promotion of "whole systems research" which attends not only to pathology and mechanisms of action, but also to the humanistic milieu, including the effects of institutions on investigation and methodology. 
Introduction

Still, mainstream medicine is responding to this trend as reflected by the behaviors of medical schools. Writing on behalf of the Consortium of Academic Health Centers for Integrative Medicine, Kligler et al. (2004) proposed core competencies in IM for medical school curricula. The competencies included the pursuit of rigorous scientific studies, employing new models of clinical care, and developing innovative educational programs that integrate biomedicine, the complexity of human beings, the intrinsic nature of healing, and the rich diversity of therapeutic philosophies.

Neo-Weberian views on specialization and rationalization specifically emphasize the conflict that can arise from bureaucratic change. Professions in health care and elsewhere are characterized by the "relativity of their positions within the division of labour and the existence of both continuity and change linked to a conflictbased sociopolitical frame of reference" (Saks 2001:120). Within a field of expert labor, redistribution and specialization of professional practices can coalesce to form "protoboundaries" within the jurisdictional field (Abbott, 1995). The development of professional specialty areas involves focused social reproduction of common practices and values. Specialization is an agentic behavior of some professionals to voluntarily limit their scope of work (Klarman, 1963). To some extent, professionalization is an ordered process that produces various levels of professional work, and is sensitively dependent on the degree of bureaucratization (Wilensky, 1964). Given the breadth 
Introduction

and history of the demand for CAM, a question arises as to the influence this has on specialization and the division of health care labor.

The social structure supporting integrative medicine - as a distinctive form of health care - has become increasingly concrete with contributions from mainstream systems in the public, private and nonprofit sectors. Simultaneously, the discourse on integrative medicine has been transformed. Opinion leaders - sympathetic to, if not champions of - integration have addressed the conceptual rationale for integration. This rationale recapitulates a position from the history of medicine, i.e., the desire to promote wellness and contribute to a sophisticated professional relationship with patients (Weil, 2000; Snyderman \& Weil, 2002, Whorton, 2004). A degree of irony has been noted regarding the disconnection between the strategic social messages that are service-oriented or educational (abstractions) and the concrete realities of medical practice (the workplace). Light (2000) points out that the social reproduction of expertise leads to technological specialization. This specialization leads to bureaucratization, which tends to undermine expert judgment; the hallmark of professional autonomy. The drive to technological medicine has the ironic outcome of rescuing the population from early death, yet leaving patients with chronic conditions that cannot be cured by the system that produced them (ibid). Abbott (1988) noted that the drive to expertise generates a phenomenon called professional regression - a state of a profession in which the research agenda becomes increasingly esoteric and 
Introduction

detached from the concrete needs of real people in real situations. Integrative medicine is argued to address more directly the concrete needs of patients.

The logic underlying integrative medicine is not simply reactive, it also offers propositions for a conceptually distinctive professional approach. Snyderman and Weil (2002) recognized that in reaction to the problems of mainstream medicine, a theoretical language has emerged - referencing the ideas of holism and holistic health care - that helps to articulate the multilevel integration required to merge these two disparate approaches of producing, maintaining and restoring health. Their analysis was not limited merely to concrete systems but also recognized the epistemological distinctions between scientific medicine and the various methods of knowledge production associated with CAM (cf., Bell et al., [2002] for a particularly poignant discussion of the need for a systems-oriented epistemology). These views recognize and embrace the dynamic tension between ideology and practice brought by the two paradigms, allopathic and natural medicine, with each domain contributing to the emergence of integrative medicine (Eisenberg, 2005; Ritenbaugh et al., 2003).

\section{Theoretical Approach}

The theoretical approach employed here follows in the tradition of the sociology of work and occupations, and the subspecialty which focuses on professions. Early theoretical approaches accounted for the traits and functions of professions as distinctions from other occupations. This was then supplemented by 
Introduction

conflict theoretical accounts that emphasized the inherent power dynamics in the quest for autonomy. However, these two approaches failed to capture the dynamics of professional emergence, death, merging and adapting. Abbott's (1988) theory of a system of professions argued from an historical/ecological perspective that professions vie for limited jurisdictions within a relatively finite jurisdictional space. Professions are interdependent to greater or lesser degrees and are in constant negotiations with the audiences that grant them privileges. These audiences are the judicial system, the workplace and the public-at-large, and are conceived of as distinctive levels of influence on the status of professions. Professional negotiations take the form of claims-making to their various audiences, based on the abstract knowledge that defines the profession. Audiences respond with settlements of legitimacy. Professions compete for jurisdictions and can respond to challenges either by taking on a fight or by changing internally.

Abbott (ibid) theorized several functional mechanisms that work within the system of professions. One of these, internal differentiation, acts as a mechanism for decoupling the formal (i.e., legal) and informal aspects of professions. Again, the informal aspects are the constructs supported by public opinion and the role-related tasks that occur in the work setting. There are specific consequences that arise from the internal differentiation process and Abbott emphasizes four: (1) differences in intraprofessional status; (2) differences by client; (3) differences by the organization of 
Introduction

work; and (4) differences by career pattern. Abbott characterizes these dimensions as types of buffers that mediate the impact of external disturbances on the system.

For the purposes of this research, the focus is on client differentiation as a means for absorbing system disturbances. As an essential mechanism of the system of professions, internal differentiation helps integrate the effects of workplace dynamics with the conceptual abstractions that define each profession as well as the formal structures that specify interprofessional behavior. Through this lens, it becomes more clear how demand for services structures workplace dynamics. Client differentiation is a pragmatic adaptation to pressures at the level of the workplace. The health care utilization data collected by the MEPS in 1996 and 1998 provide an opportunity to examine the role of client differentiation, as a precursor to internal differentiation within a profession. In this light, physician-provided CAM in the 1990's can be analyzed relative to the emergence of integrative medicine as a new specialty.

To reiterate, the sociology of professions frames this analysis and leads to the general approach of dividing survey respondents into subpopulations based on the type of provider seen for medical need. This is an extension and elaboration on the service utilization approach published by Druss and Rosenheck (1999), and Bausell et al. (2001), using the MEPS data. The data collected by the MEPS reflects providerpatient relations that transpire in the health care workplace and the analysis for this dissertation is limited to this level. The multilevel theory of a system of professions is 
Introduction

useful because it helps place the analysis in context, relative to the theoretical levels of formal legal constraints and public opinion.

\section{Medical Expenditure Panel Survey}

Central to this investigation is a government database created by the Medical Expenditure Panel Survey (MEPS). The MEPS collected unique information about physician-provided CAM during the survey years 1996 and 1998 . While the age of this data is an obvious concern, this dissertation focuses on aspects of the dataset which have remained unexamined. The MEPS is an ongoing project of the U.S. Department of Health and Human Services (DHHS) which captures health behaviors, utilization patterns, and financial burdens created by medical need, along with demographic details (Cohen, 2002). A database of annual samples is maintained for public use. This dissertation employs this population-based survey to examine response patterns among subpopulations of Americans who received CAM from several different types of providers, including physicians. Timing is important here. These survey measurements were taken at a time, an inflection point, in the popularity of CAM in the United States. This period has been discussed broadly in both popular and academic domains. The provision of CAM services by allopathic physicians has been a professional behavior that was geographically widespread and that occurred under risk (Pelletier \& Horrigan, 2003). However, reliable population estimates are missing. 
Introduction

This dissertation draws its importance from its contribution to four main problem areas: (1) the mid- to late- 1990's was a critical period for alternative medicine in the United States (cf., Ruggie, 2005), and detailed understanding of the influence of that period on current trends in health services provision is currently absent; (2) no reliable prevalence estimates exist to describe Americans who received CAM from a physician; (3) strategies for handling the epidemic of chronic illness anticipated to come with the demographic transition faced by the U.S. and other industrialized countries are directly predicated on improvements in prevention and wellness practices - arguably the domain of CAM (cf., Strauss \& Corbin, 1988); and (4) widespread labor shortages are expected within the health services sector, in part due to both demographic transitions (which increased demand) and the increasing rationalization of health care (Health Resources and Services Administration [HRSA], 2003; Northwest Health Foundation, 2001). Evidence of the mainstream acceptance of CAM therapies and practices may reflect favorably on marginalized CAM occupations, creating hope for a new source of expert labor in a time of desperate need. These issues will be expanded upon in the following chapters.

\section{Methodological Approach}

This dissertation employs secondary analysis to generate estimates of health care utilization. Secondary data analysis proceeds in an iterative fashion including preliminary evaluation of the fitness of the data, formulation of the research questions, 
Introduction

preparation of the data, and analysis. The MEPS is an annual population-based survey conducted by the Agency for Healthcare Research and Quality (AHRQ), under the DHHS, and is the data source for this analysis. The MEPS provides the highestquality survey data on national medical expenditures and financing. This stratified cluster sample provides representative annual estimates of health care utilization and expenditures at the national, regional and state levels (Cohen, 2002). Units of analysis are noninstitutionalized citizens of the United States, oversampled for Hispanics and blacks. The data to be analyzed were collected during the years 1996 and 1998 . Sample sizes are: $1996 \mathrm{~N}=21,571 ; 1998 \mathrm{~N}=22,953$.

The mid-1990's was an active period of debate over the role the CAM should play in American health care. At that time, the MEPS included a survey module on Alternative and Preventive Medicine. This module has not been employed since 1998. The data are unique, relative to other surveys on the topic, because of the wide geographic coverage of this population-based survey and because of its attention to health care utilization and financing. Interestingly, the MEPS included a survey question that illuminates the origins of what is now called the integrative medicine movement. The survey inquired as to whether a respondent used CAM during the preceding year. A skip pattern then addressed the type of CAM service consumed and the type of provider involved. Nine different provider types were included as response options. The MEPS specifically asked whether the respondent received alternative medicine from their regular doctor. This dissertation operationally defines integrative 
Introduction

medicine through this response pattern (MDCAM). It should be noted that, to the best of our knowledge, no other data source provides this information with such a large number of potential covariates. While the units of analysis in the MEPS are noninstitutionalized citizens of the United States, the patterns of alternative care consumption will be taken as evidence - i.e., proxy measures - of provider behaviors. This approach emphasizes the boundary relations between supply and demand as recorded in the data. Therefore, the MEPS is a good approach to the problem. These data have been used by others (Druss \& Rosenheck, 1999; Druss et al., 2003; Bausell et al., 2001; McFarland et al., 2002).

\section{Rationale}

The phenomenon of CAM has been theorized to be effected by both the dynamics of consumer demand (as a new social movement) (Goldner, 2000 \& 2001), and as a matter of supply-side policy (regarding professional scope of practice, health care provision and third-party financing) (Cohen, 1998).

Consumer pressures have motivated physicians to adopt alternative health care practices either directly or through their business organizations and educational institutions (Goldstein, 2000b; Schneirov \& Geczik, 2002). This dissertation draws from this view to structure its analysis. By profiling the subpopulations associated with different providers, information about specific similarities or differences between profiles will come to light. Using the analytic framework laid out in Druss and 
Introduction

Rosenheck (1999) of segmenting the population into mutually-exclusive groups (defined by professional type) allows comparisons of the subpopulations who are related exclusively to each type. Results will be interpreted in relation to sociological theories of consumerism in medicine and the ecological conceptualization of professional jurisdictions.

Further, the rationale for this study draws from the fact that the health care industry is facing labor shortages, driven in part by the demographic transition. The Health Workforce Analysis Project of the Bureau for the Health Professions (Health Resources and Services Administration, 2003) projects that if health care consumption patterns and physician productivity remained constant over time, pressure from the aging population from 2000 to 2020 will increase overall demand for MDs and RNs, as well as increase time demands per elderly patient from these workers. Additionally, the health care workforce is aging along with the general population, and workers are retiring without replacement. Increasing pressures on Medicare and Medicaid will create a disincentive to fund additional workers. Solutions to the projected worker shortage can be addressed either by increasing the production of appropriate workers or by labor substitution, i.e., having workers with different training do the work. This raises the question as to whether the broad acknowledgement of the utility of CAM will open doors for previously-marginalized health workers. 
Introduction

Research Questions

Table 1.1 presents general research questions that provide an orientation to this investigation. These are elaborated upon in Chapter 4. The work of Druss and Rosenheck (1999) provides guiding inspiration for the logic of this inquiry.

Table 1.1 General Research Questions

1. What was the prevalence of CAM use by provider type?

2. How does the demographic profile of MDCAM recipients compare to the profile of recipients of CAM from other providers?

3. What is the role of insurance in CAM use by provider type?

4. What is the health status of consumers of CAM by provider type?

5. What was the geographic distribution of CAM use by provider type?

6. What specific CAM services were provided by MDs and other providers?

7. How does the demographic profile of MDCAM recipients compare to the profiles of frequent and infrequent mainstream health care users?

8. How does the CAM therapy utilization pattern compare between MDCAM and frequent and infrequent mainstream health care users?

\section{Outline of Chapters}

Following this introduction, Chapter 2 reviews theoretical issues and the literature on CAM consumption. Chapter 3 reviews the literature on the set of variables under consideration. Chapter 4 presents the analytic methodology. Chapter 5 is dedicated to the preliminary analysis of the datasets from the MEPS. Of primary concern is whether the two datasets are appropriate for addressing the research questions. Chapter 6 presents the results. Chapter 7 discusses the results, and Chapter 8 provides conclusions and statements on the limitations and indications of this research. 
Theoretical Approach

Chapter 2. Theoretical Approach

At an introductory level, medical sociology offers a grand narrative of its scope and purview (cf., Straus, 1957; Brown, 1991; Weitz, 2004). Medical sociological work comes in two forms according to this orientation script - the sociology in medicine, and the sociology of medicine. This dissertation seeks conceptual advancement and understanding in the latter form, yet applies focused study of survey data to that end, as in the former form. This is not an unusual position for medical sociological work. Blane (2003), in a systematic review of the publication history of The Sociology of Health and Illness, (1979-2002), found that quantitative research on the social structure within the journal has provided a minor but theoretically substantive contribution. This emergent corpus is located between sociology proper and social epidemiology, with, for example, contributions to theory on social class in the former, and the relation between income distribution and health status in the latter. Blane concluded that a period of growth in theoretical contributions should be expected, specifically related to the increase in the number of large-scale survey projects like the MEPS.

Large-scale population surveys are necessary to monitor financing and expenditures because, as a "dispersed model" of health care, the U.S. health care 
Theoretical Approach

system is funded and regulated in a noncentralized manner (Bodenheimer \&

Grumbach, 1995). Health care is subject to regulation from government at the federal, state, county and city levels, making for a noncohesive mixture of strategies (Straus \& Corbin, 1988; Reinhardt, 1992). The variety of concrete operations at work in the U.S. health care system, is reflected by a similar variety of theoretical treatments of these relations.

This chapter addresses several theoretical issues that pertain to the phenomenon of physician-provided CAM (Table 2.1).

Table 2.1 Meta Level Theory

Theoretical Contribution

Countervailing Powers System of Professions Social \& Symbolic Boundaries Social Boundary Mechanisms
Author

Light Abbott

Lamont \& Molnar Tilly
Purpose

Polarization of Autonomy Competition for Jurisdictions Boundaries as Social Facts Borrowing Changes Boundaries

At issue, is the complexity that surrounds the phenomenon of integrative medicine. While the origins of the theories included here are quite different, they are grouped with a meta-level organizing principle into sections on supply-side issues, boundary issues and demand issues.

This chapter opens with a discussion of systems theoretic ideas that aid in the conceptualization of interprofessional competition. This is followed by an account of the theoretical development of the sociology of professions, offered as an orientation 
Theoretical Approach

to the situated lexicon. Sections then follow on medicalization as a strategy for creating demand for services, the demand for CAM and patterns of CAM utilization.

\section{Systems and Boundaries}

Fundamental to the discussion of systems is the primary distinction between a system and its environment. This distinction implies boundaries. Hall and Fagen (1956) define a system as "a set of objects together with relationships between the objects and their attributes." This definition is plain, set theoretic and reflects a objectivist bent. It provides a positivistic specification of the system, and the environment to the system is implied. Lendaris (1986) defines a system as "(1) a unit with certain attributes perceived relative to its (external) environment, and (2) that unit has the quality that it internally contains subunits, and these subunits operate together to manifest the perceived attributes of the unit." While systemic relations occur in nature, the Lendaris definition is particularly helpful for studying problems at the human scale. It explicitly calls for an external "perceiver" of a system, which opens the door to subjectivity, social constructions of reality and the scientific challenge to demonstrate objectivity.

Both of these definitions can contribute to the conceptualization of the differences between types of medicine. Ideological ${ }^{1}$ systems are sets of conceptual elements that operate together in relationship (from the "eye of the beholder"). The

\footnotetext{
${ }^{1}$ Doctrines/opinions
} 
Theoretical Approach

organizing principles of various ideological systems can employ disparate ontological and epistemological assumptions. This appears to be the case when comparing the ontologies of scientific medicine and alternative medicines (cf. Appendix 1:

Typologies of CAM). Scientific medicine is predicated on a mechanistic material reality as a byproduct of the Cartesian split, while alternative medicine (largely derived from indigenous healing traditions) springs from a vitalistic view of reality. The epistemologies employed by these two approaches are also different, with scientific medicine employing the rational skepticism of the scientific method and the practical utility of probability theory. Alternative medicines (broadly and historically speaking) employ an epistemology based on case study. The close historical relation between alternative medicines and spiritual traditions has led critics to label associated clinical decision-making strategies as casuistry (i.e., morality and health are held in correspondence, and treatment decisions reflect the distinction between right and wrong regarding spiritual development). Some authors are forthright in describing these differences as paradigmatic (cf., Bell et al., 2002; Ritenbaugh et al., 2003). This assertion of a profound difference in intellectual style is supported by examining the content of the conceptual-level claims advanced by these two ideological schools. Allopathic medicine succeeded in marketing itself as an applied science (Starr, 1982), oriented to solving specific health problems through the use of technology (e.g., immunization), while natural medicine advances a mentoring role in the patientprovider relation, where professionals should lead by example. To illustrate, 
naturopathic medicine follows six fundamental dicta: (1) Vis medicatrix naturae, which means, "the healing power of nature or the vital force as the driving impetus behind healing disease"; (2) Primum non nocere, which means, "first do no harm"; (3) Tolle Causam, which means, "to identify and treat the underlying cause of the disease"; (4) Tolle Totum, which means, "to treat the whole person"; (5) Principiis obsta: sero medicina curator, which means, "prevention is the best cure"; and, (6) Docere, which means, "the doctor as teacher". This final dictum sets the naturopathic philosophy apart from the allopathic philosophy by explicitly defining the physician as one who is physically, emotionally and spiritually balanced. This difference can be summarized with the role concepts of applied scientist (in the case of allopathic medicine) and teacher (in the case of naturopathic medicine) (National College of Natural Medicine, 2008).

If the reader accepts these ideological systems as distinct from one another then each will be considered to exist in the external environment of the other, i.e., CAM exists externally from the system of scientific medicine - it is outside the boundaries of the system. To the extent that scientific medicine exhibits normative concrete behaviors (e.g., procedures and treatments), these can be taken as manifestations of the encompassing ideological system (cf. Wight, 2004 for elaboration). Similarly, a set of concrete behaviors emerges from the ideological system underlying alternative medicine. Following this logic, an observer external to both systems can empirically account for the frequency with which one system 
Theoretical Approach

employs the concrete behaviors of the other system. This accounting would provide an empirical measurement of the overlap of ideological systems. The tension between competition and cooperation between these disparate health systems is instantiated in the phenomenon of integrative medicine (IM). The influence of professional power becomes central in the cost-to-benefit calculus of clinical problem-solving from the mixed strategy of IM. This issue has been addressed by Abbott's theory of a system of professions, in which power plays occur at multiple levels. This theory will be discussed below.

\section{Social Boundaries}

This section addresses the system-boundary-environment distinctions within the context of the social sciences. Social boundary analysis has recently attracted attention for its enduring application by several different disciplines. A review of the social science literature (Lamont \& Molnar, 2002) revealed a vast and differentiated history of attention to the generalized concept of boundaries. Both symbolic and social boundary concepts have been employed in various studies of the differences between personal identities, groups and social locations, including the intersections of professions, knowledge and science (Shuval \& Mizrachi, 2004; Ajrouch, 2004).

"Symbolic boundaries are conceptual distinctions made by social actors to categorize objects, people, practices, and even time and space. They are an essential medium through which people acquire status and monopolize resources....Social boundaries 
Theoretical Approach are objectified forms of social differences manifested in unequal access to and unequal distribution of resources (material and nonmaterial) and social opportunities" (Lamont \& Molnar, 2002). By analyzing citation patterns for a few salient key words, Lamont \& Molnar discovered compelling evidence of the utility of this conceptual framework. Common themes in the literature include "the general social processes of boundary work, boundary crossing, boundary shifting and the territorialization, politicization, relocation, and institutionalization of boundaries." The disciplines employing these concepts include anthropology, history, political science, social psychology and sociology. The popularity of this conceptual approach argues for its theoretical utility and applicability, especially with regard to relational processes. As argued by Lamont and Molnar, the boundary concept has explanatory value in matters of "(a) social and collective identity; (b) class, ethnic/racial, and gender/sex inequality; (c) professions, knowledge, and science; and (d) communities, national identities, and spatial boundaries. It points to similar processes at work across a range of institutions and social locations" (ibid.).

The boundary concept has broader interdisciplinary value, and it is worthwhile to point out its generality in three distinctive applications. Boundary concepts are present in the discipline-specific theories of economic markets, biological speciation and the study of dynamic physical systems. The concept is encountered in the field of economics, exemplified by its attention to "externalities" and the requisite specification of salient variables (i.e., endogenous v. exogenous variables) during the 
Theoretical Approach

theoretical model building (cf., Sterman, 2002: 541-543). Here boundary construction occurs through public debate over the responsibilities that must be included in cost calculations. This boundary is malleable and responsive to the dynamics of legitimate authority to operationally define economic parameters as salient or otherwise. A second example can be taken from cladistics, the branch of biology, which strives to classify organisms according to evolutionary relationships. Problems here include the determination of boundaries between antecedent and descendent forms based on empirical evidence, such as ultrastructure and transitions in character states (cf., de Quieroz \& Gauthier, 1992; de Quieroz, 2005). This example illustrates the general problem of generating taxonomy (or typology) in the context of development. Thirdly, the discipline of engineering addresses problems of "free and moving boundaries," which attend to dynamics in such diverse areas as hydrology, metallurgy, chemical engineering, soil science, molecular biology, materials science, and steel and glass production (cf., Crank, 1987; McClelland, 2004). This illustrates the boundary problem in the context of dynamic systems.

The boundary concept is very general and, as such, it exemplifies the orientation of the systems field. The Society for General Systems Theory, founded in 1954, began as a special interest group within the American Association for the Advancement of Science (von Bertalanffy, 1968:15). The Society's formative declaration explained that many disciplines were converging on a common approach to problems in their disparate fields, and called for the study of the system 
Theoretical Approach

phenomenon as sui generis. Central to this early form of the systems field was the search for isomorphisms, i.e., formalisms of equivalent structure. Among the major functions of this interest group were: “(1) [to] investigate the isomorphy of concepts, laws and models in various fields, and to help in useful transfers from one field to another; ... (3) [to] minimize the duplication of theoretical effort in different fields; (4) [to] promote the unity of science through improving communication among specialists" (ibid.). Systems science, as a subdiscipline of the systems field, was described by Bunge (1973) as the pursuit of an exact and scientific metaphysics, i.e., the pursuit of portable, mathematical and testable hypotheses about the natural world. The pursuit is inherently transdisciplinary.

A relatively recent special issue of the journal Philosophy of the Social Sciences (Volume 34(2), 2004) was dedicated to the social philosophy of Mario Bunge and his ideas about social boundary mechanisms (Bunge, 1997; Mahner \& Bunge, 2001; Bunge, 2004a; Bunge, 2004b). Bunge shares accolades from both domains science and philosophy not only for his prolific production, but also for his incisive commentary (Pickel, 2004). This special issue has generated increasing activity in sociology and other fields (cf., Whitley, 2006; Norkus, 2005; Giesler, 2005; Sadovnikov, 2004).

Tilly $(2001,2004)$ elaborated on social boundary mechanisms and described the fecundity of this approach for generating testable hypotheses. The formation, transformation, activation, and suppression of social boundaries are general processes 
Theoretical Approach

that operate across a range of social sites. Explanation of social boundary change is facilitated by recognizing three classes of robust mechanisms: those that precipitate change; those that consist of boundary change; and those that produce the consequences of change. More generally, Tilly's theory addresses the antecedents of change, what change looks like when it happens, and the results of change. Social boundary mechanism theory is relevant to this investigation by contributing the idea of precipitators of boundary change, which Tilly names encounter, imposition, borrowing, conversation and incentive shift. Borrowing is the precipitator of change which seems most reasonable for explaining the emergence of IM. Borrowing does not construct a new boundary per se, but rather moves a familiar boundary to a new social location. In this case, the boundary of authority surrounding medical culture is moved to include behaviors and techniques associated with CAM.

This approach establishes a plausible theoretical framework for interpreting empirical observations of boundary crossing, in the form of physician-provided CAM. The discussion of boundary crossing will be conceptualized within the theoretical framework of the sociology of professions, and will employ the concepts of professional borrowing as a mechanism that precipitates boundary changes (Tilly, 2004) and the process of internal differentiation within professions (Abbott, 1988) as a precipitator of change. A fuller description is provided below; however, it is important to emphasize that this dissertation will primarily focus on the role of internal differentiation as a mechanism to absorb system disturbances. These disturbances can 
Theoretical Approach

arise from the countervailing forces of consumer demand and the professional interests of health care providers (cf., Light, 1995, 2000). Allopathic and CAM providers engage in interprofessional competition (cf., Halpern, 1990; Sullivan, 1993 for illustrations of these types of competitions), and it is hypothesized that consumer pressures sensitively affect the boundary maintenance processes between them (e.g., competition for consumers).

\section{Sociology of Professions}

In the United States, the sociology of professions has experienced four distinct approaches, which have followed sequentially (Borgatta \& Borgatta, 1992:1553), and their influences can be found in contemporary theory. These approaches are the process approach, the structural-functionalist or trait-based approach, the power/conflict approach, and the historical/ecological approach.

The process approach to professionalization identifies general stages of development. Caplow (1954) envisioned four stages that occupations move through to become professions: (1) establish a professional association; (2) a change of name in order to dissociate from previous nonprofessional status and to provide a title that represents an exclusive domain of practice; (3) develop a code of ethics; and, (4) engage in political agitation to gain popular and legal support, and develop a mechanism for training new members. Wilensky (1964) described the process of professionalization in a different order: (1) people working full time at a specific set of 
tasks that form a new occupation's core jurisdiction; (2) this group establishes a university-based training program and some from within the group begin training a new generation of workers; (3) practitioners and teachers combine to form a professional association which delineates the core tasks and makes claims regarding skill jurisdiction; (4) efforts are made to protect their jurisdictional claims through political processes, including the pursuit of legal protection in the form of licensure and other entry-restricting regulations; and, (5) a professional code of ethics is developed regarding the protection of clients, the exclusion of those that are unqualified and the promotion of the ideal type of service provision. Process approaches have been critiqued due to their limited attention to the actions (i.e., strategies and tactics) of the professionalizing group and their underestimation of the effects of the political process (Ritzer \& Walczak, 1986:66)

The trait approach, aligned with the functionalist school, was common after World War II and involved attempts to categorize professions as distinct from nonprofessions, based on exhaustive lists of characteristics. Assessments were made by comparison to ideal types of professions, emphasizing the role of expertise (Borgatta \& Borgatta, 1992:1553). Ritzer and Walczak (1986) described six core traits that are engendered by a profession and which are important to this theoretical approach: claims of general/systematic knowledge; autonomy; altruism; authority over clients; a distinctive occupational culture; and recognition by the community and law that the occupation is a profession. The traits of professions were studied as a special 
Theoretical Approach

case in the broader scope of occupational sociology. "Idea" or "innovative"

occupations were viewed as an emergent phenomenon of urbanization and came to prominence after the 1860s (Taylor, 1968:476-488). From this theoretical view, ideas held a special directive power in urban cultures. The progenitors and guardians of this idea work are the professionals, executives and artists. The social space of innovative occupations is defined in relation to others in the workplace. Innovative occupations are characterized by research and systematic or rational analysis, and this work is granted social space for creativity, privilege and practice. To the extent that these occupations develop highly organized internal structures, their boundary maintenance enables them to become, in effect, communities within larger society (Taylor, 1968:486). Community characteristics are: (1) practitioners are bounded by a sense of occupational identity; (2) with the admission to practitionership, there is little outmobility; (3) common values, both occupational and social, are widely shared; (4) appropriate roles for both members and non-members are widely agreed upon; (5) an occupational language or jargon is commonly understood by practitioners; (6) collective control over practitioners is maintained; (7) the boundary maintenance of the occupational community is social rather than physical or geographical; and (8) through recruitment and training, selection is made of subsequent generations (ibid). As professionalization advances, the characteristics of distinctive communities become more pronounced. This trait-based approach provided positive description of 
Theoretical Approach

the social structure of professional work, but, as discussed below, gave little attention to the importance of strategy and power.

The power/conflict approach gained popularity in the 1960s and saw the professionalization process as a product of dominance and submission, coercions and settlements (Borgatta \& Borgatta, 1992:1554; Ritzer \& Walczak, 1986). In response to the structural-functionalist characterization of professions, the power approach argues that emphasizing qualitative differences between professions and nonprofessions based on expert knowledge is artificial and reflects more the establishment of barriers to access of that knowledge. To the degree that claims of autonomy reflect a desire for a profession to "police" itself by exercising sanctions outlined in a code of ethics, the power approach suggests that this is more a means to obfuscate malpractice from public scrutiny (cf., Abbott, 1988:62). The functionalist characterization of the altruistic claims of professions is critiqued for ignoring the effect of these claims on professional status, (i.e., their utility for distracting the public away from challenges to monopoly, privilege and power) (Ritzer \& Walczak, 1986:74). The conflict approach questions whether professionals ever gained authority over their clients, citing the agency that prospective clients have in defining their needs, the ability for clients to terminate business relationships at-will, and the cooperative nature of professional-client relationships required for successful outcomes. This view opens the discourse to the dynamics of consumerism. Claims of authority are seen, in this view, as a strategy to pacify the consumers of services. 
Theoretical Approach

Though it is recognized that elaborate professional cultures emerge which delineate collegial and training relationships, the functionalist view overemphasizes this feature. Finally, the distinction between the functionalist characterization and the conflict characterization, regarding the public, is essentially a matter of degree. The conflict perspective emphasizes how professions strategically manage public impressions for their best interests.

Scholarly differences in the study of professions reflect cultural origins. Ritzer and Walczak (1986:203-206) recognize differences between the European and American approaches. The Europeans have followed closely in the Weberian tradition, by characterizing professional development as a natural sequel of the rationalization of Western civilization. Weber saw the professionalization process as occurring primarily within bureaucracies. The American tradition has held the processes of professionalization and bureaucratization as largely antithetical. Ritzer and Walczak opine that this theoretic difference is related to two explanatory factors: (1) American occupational sociologists tended to study these phenomena in isolation, thereby missing the linkages; and (2) the disproportionate attention given to one particular occupation - the physician in private practice. These authors suggest that physicians in private practice are better considered an outlier to the general professionalization process, because they existed outside formal organizations through much of the late 1800 s and early 1900 s (c.f., Starr, 1982 for elaboration). During this time, the medical profession developed an ethic of autonomy which put them at odds 
Theoretical Approach

with the bureaucracies that eventually employed them. The next general approach to professionalization to be discussed is interesting because it is derived from international and historical comparisons of the role of professions within health care systems of European industrialized countries. Across these comparisons, physicians hold varying degrees of professional autonomy (Light, 1995).

The countervailing powers model developed by Light $(1995,2000 ;$ Hafferty \& Light, 1995) was designed to provide a theoretical framework for professions in transition. This theory was developed in critical response to antecedent theories that took a narrower scope and were limited in their explanatory power. Subsumed within the countervailing powers model are the dynamics related to consumerism in medicine described by Haug and Lavin (1983), along with the general discussion of dominance and autonomy. Arguing for an ecological view, Light recognized the multidimensional pressures that lie external to the actions of the professions themselves.

Professions are both a special kind of occupation, with elements of a collective social movement, and a population of organizations. They are memic by intent, by professional policy (DiMaggio \& Powell, 1983), yet located in and interdependent with one or more clustered networks of organizations that form the client base (Flood \& Fennell, 1995). They are also strongly tied to the state, both exploiting and being subject to its regulatory and financial powers. Finally, they usually have clients who care very much about services and can be both dependent and very critical. In these ways, professions operated within a field force of countervailing powers (Light, 1993). (Light, 2000). 
Theoretical Approach

The countervailing powers model describes a fully connected system of

elements (i.e., stakeholders) that define a state-space. The power relations between

stakeholders lie along continua of influence in which absolute dominance is polarized

at extremes. This model envisions a continuum of control across a tetrahedral space

with relations between the state, capitalism (in the form of the medical-industrial

complex ${ }^{2}$ ), the professions and consumers. While others have argued that the

medical-industrial complex is simply a projection of institutions that emerge from

each of the macroeconomic sectors (i.e., public, private, and not-for-profit), there is

another more salient level of conceptualization to which this label alludes. Light uses

this designation in keeping with the original precautionary tone set by Eisenhower, as

he warned against a military-industrial complex. This conceptualization connotes that

the alignment of interests, in the pursuit of profit, seriously challenges the advocacy

role that is subsumed in the professionalism of said institutions. The countervailing

powers theory contributed a new and useful lens for describing alignments of interests

between nodes in the system (cf., Hartley, 2002).

${ }^{2}$ The medical industrial complex is a concept derived from the famous phrase popularized by Eisenhower in his Farewell Address to the Nation, January 17, 1961. In it, he warned: "in the councils of government, we must guard against the acquisition of unwarranted influence, whether sought or unsought, by the military-industrial complex. The potential for the disastrous rise of misplaced power exists and will persist." The first use of the adapted term was advanced by Ehrenreich \& Ehrenreich (1970) and further elaborated by Relman (1980) to describe an historic transition in health care delivery. "Corporations have begun to integrate a hitherto decentralized hospital system, enter a variety of other health care businesses, and consolidate ownership and control in what may eventually become an industry dominated by huge health care conglomerates." (Starr, 1988:428). 
Theoretical Approach

The historical approach is associated with Abbott's (1988) theory of a system of professions vying for jurisdiction in a relatively finite jurisdictional space. This is the fifth general theoretical approach to be discussed.

Abbott's analytical approach developed in response to functionalist conceptions of the professionalization process. It was guided by a very general research question: How do modern societies institutionalize expertise? (ibid:xii). Preceding research identified the traits of professionals but none had addressed the messiness of the actual, observable squabbles that are inevitable in a complex organization. Abbott's theoretical approach grew from participant observation in many organizational settings. Abbott aspired to illustrate the professions "growing, splitting, joining, adapting, dying" (ibid:xiii). He acknowledged that although he aspired to synthesis and generality, this result would lack sophistication to experts of any one profession. As such, he avoided the popular topics within the academic study of professions; medicine and law. The present study hopes to contribute to the discussion of internal differentiation specifically within the domain of health care.

Emphasizing the actual work performed (i.e., functions rather than traits), Abbott developed an ecological model of how professions establish and maintain jurisdictions of practice through cybernetic processes. This occurs through the social actions taken in reaction to claims of jurisdiction made by each profession. Iterative feedback loops control the scope of professional jurisdiction. Professions make claims of expertise to specific audiences. Audiences respond by offering settlements, or 
Theoretical Approach agreements to cooperate, of greater or lesser degree, and, in this way, the parties are structurally coupled. The audiences discussed by Abbott are the judicial system, the domain of public opinion and the workplace. This view recognized the value of both functionalist and conflict theoretic analyses of professional development but challenges their emphasis on professional autonomy and authority, because of the connotation that professions arise independently from one another (Abbott, 1988:18). Further, functionalist and conflict theoretic approaches overlooked the sticky problem of internal differentiation within professions, which is particularly salient when analyzing the actual work that is performed. Abbott recognized a theoretical distinction between overarching claims of professional status and the functional realities. "Psychiatry is officially part of the medical profession, but I have followed the functional reality in calling it a profession here. To say that it is not a profession but a specialty is simply to define the interesting questions about it out of existence" (Abbott, 1988:81).

The theory of a system of professions envisions an identifiable set of professions that maintain a struggle for jurisdiction. Professions are organized around, and continue to develop, formal systems of conceptual (abstract) knowledge. As asserted by Abbott (ibid:53), “[A profession's formal knowledge system] ...is not organized from common to esoteric or from treatable to recalcitrant. Rather it is organized along logically consistent, rationally conceptualized dimensions." 
Theoretical Approach

To clarify, two examples of the settlements process are offered. To illustrate claims-making at the level of conceptual knowledge, one can imagine a debate between the professions of law and psychiatry on matters of heinous crime, e.g., patricide. Both knowledge systems can convincingly advance arguments that such an act would fall within their respective jurisdictional domains. The settlement is the tendency for such acts to treated as criminal, while psychiatric explanations are accepted as exceptions. These arguments are made to the audiences of the judicial system and of public opinion.

With respect to internal differentiation, a well-documented case from pediatric medicine illustrates how technological advances prompted a division within the professional ranks (Pawluch, 1983; Halpern, 1990). A transition occurred, in the early 1950 s, related to the success of treating childhood infectious disease and resulting decreases in infant and child mortality rates. "Worried about their declining status and possible disappearance as primary care specialists, pediatricians sought a new mission in ministering to the psychosocial and behavioral needs of children" (Pawluch, 1983). Using an historical approach for examining professional development, Halpern explained the expansion of pediatrics. Practitioners, who dominated the profession at the time, were challenged by academicians within the discipline who had turned their attention to a larger sphere of influence. They argued to their colleagues and to the public for legitimate authority over a larger segment of social life. The boundary expansion process was successful and the effects manifested as a control function 
Theoretical Approach

within health care delivery where pediatricians became "the architects and coordinators of psychosocial care and by redefining medically uninteresting behavioral deviance as an intellectually challenging problem" (Halpern, 1990). This observation led to a more general insight. "...[E]fforts for medicalization need not result in treatment of new disorders by physicians. The outcome might be a new redistribution of tasks across professions whereby physicians assume new investigatory and managerial roles and delegate service delivery to less prestigious occupations" (ibid). This boundary shift serves as an illustration of the process of claims-making to the audience of the workplace.

The assertion that there are a relatively fixed number of professional jurisdictions is derived from the power approach to studying professions. "Power theorists viewed professions as monopolistic organizations intent on gaining and retaining professional control and ensuring their status in the stratification system" (Borgatta \& Borgatta, 1992:1554). Boundary work is performed by professions to control professional scope and profits (Gieryn, 1983; Gieryn et al., 1985). Here, boundary work connotes an ideological style that is employed strategically to create a public image of a profession by contrasting it favorably against other professions and nonprofessions. Through examining the demarcation of science from non-science, Gieryn (1983) notes that limiting analysis to ideological distinctions provides little descriptive value. Boundary demarcation is accomplished materially, by educational institutions, funding agencies and publishers. Gieryn added to the list of potential 
Theoretical Approach evidence for identifying professional boundaries by emphasizing analysis of rhetorical style, i.e., the analysis of symbolic formulations and figurative languages. This research approach aspired to "identify specific social conditions in which an ideology might be expected to take one or another stylistic form" (Gieryn, 1983:783). Allen (2000) used this theoretical construct to illustrate the way nurse managers established professional identities in a large district general hospital in the United Kingdom. The context for the study was the air of concern for the agentic adaptation of nurses, doctors and support workers in the face of organizational change. Allen's study advanced the understanding of the social reproduction of divisions of labor by reconceptualizing the relationship between formal and social organization of hospital work. Faced with increased labor demand due to legislative changes in doctors' hours, nurses employed a "discourse of holism" (i.e., caring for the needs of the whole person, not just medical needs) to differentiate themselves from physicians. Simultaneously, "doctors' accounts were linguistically assembled in order to cast nurses in the subordinate role of technician" (ibid:349).

\section{Internal Differentiation}

This section is devoted to explaining the development of the internal structure of professions. While the discussion of jurisdictions addresses professions atomistically, attention is now turned to the empirical differences within professions, recognizing that the work occurs in a variety of workplaces with a variety of clients. 
Theoretical Approach

Abbott discusses internal differentiation as an essential mechanism for integrating the effects of workplace dynamics, with both the conceptual abstractions that define each profession and the formal (i.e., legal) structures that specify interprofessional behavior. Demand for services, in Abbott's view, structures workplace dynamics.

How does internal differentiation affect the system of professions? Like other properties of professions, it has its effects through a profession's position in the system. Thus, internal differentiation can generate or absorb system disturbances; a challenged profession can respond not only by fighting a contest or by changing its level of abstraction, but also by changing internally. Conversely, internal changes can generate such system disturbances (Abbott, 1988:117).

As introduced in Chapter 1, internal differentiation generates specific consequences within professions and, hence, within the system of professions. Client differentiation is among the outcomes. In Abbott's view, the functional reality of formally equivalent professionals cultivating different client bases is a strategy for maintaining the external appearance of cohesion within the profession, by allocating different clients to nascent subdivisions of the profession.

The following subsection examines the demand for CAM services, and begins with a discussion of medicalization. In an attempt to explicate the role and dynamics of the consumption side of the boundary relation, attention is given to the characteristics associated with CAM consumption. A central question posed in this section is whether the client base self-organizes into subgroups with differing demand interests. 
Medicalization - Creating the Demand for Services

An operating assumption of this dissertation is that professional interests and consumer interests interact in a complex and sensitive manner. The process of boundary construction has been elaborated upon for medical work, with the theory of medicalization/demedicalization. "Medicalization describes a process by which nonmedical problems become defined and treated as medical problems, usually in terms of illnesses or disorders" (e.g., cosmetic surgery, childhood hyperactivity) (Conrad, 1992). Demedicalization refers to a problem that no longer retains its medical definition and for which medical treatments are no longer deemed appropriate (e.g., homosexuality, included in the DSM from 1952 to 1973). Definitional claims are made at multiple levels and are the social locations of contests for jurisdiction and resources.

At a conceptual level, boundary disputes focus on language and operationalization. ${ }^{3}$ The level of institutionalization concerns the rationalization ${ }^{4}$ and bureaucratization of the social sphere. "Organizations may adopt a medical approach to treating a particular problem in which the organization specializes" (ibid:211). The

${ }^{3}$ (cf., Foucault, 1973:xii-xviii) Foucault argues that the development of sophisticated lexicons for describing individuals (and, in the case of medicine, to diagnose) is an historical process that represents the establishment of boundaries. The very ability to issue commentary on a problem is divisive and represents objectification.

4 "The process of rationalization is said by [Max] Weber to affect economic life, law, administration, and religion. It underpins the emergence of capitalism, bureaucracy, and the legal state. The essence of the rationalization process is the increasing tendency by social actors to the use of knowledge, in the context of impersonal relationships, with the aim of achieving greater control over the world around them. However, rather than increasing freedom and autonomy, rationalization makes ends of means (slavish adherence to the rules within modern bureaucracies are an obvious example), and imprisons the individual within the 'iron cage' of rationalized institutions, organizations and activities." (Marshall, 1998). 
Theoretical Approach

interactional level concerns the micro-dynamics of roles, authority and status.

"Medicalization occurs here as part of doctor-patient interaction, when a physician defines a problem as medical (i.e., gives a medical diagnosis) or treats a 'social' problem with a medical form of treatment (e.g., prescribing tranquilizer drugs for an unhappy family life)....Subcultures, groups, or individuals may vary in their readiness to apply, accept, or reject medicalized definitions" (ibid:211). The "engines" of medicalization have expanded beyond professional associations and state regulation to include biotechnology, consumerism and managed care as a financing strategy (Conrad, 2005). Further, Conrad argues that the economic environment of the past two decades has shifted the driving forces of medicalization away from professional claims-making, to external construction by vested commercial interests. These changes correspond with physicians' attitudes towards managed care reaching their nadir (Simon et al., 1999).

The power of consumerism was vigorously championed during the 1990s by Paul Ellwood and many others (Ellwood, 1988; Ellwood \& Enthoven, 1995). They believed that health care policy missed subtle issues that, if changed, would improve the delivery of personal health care. Consumer advocacy in policy making was promoted. The problems generated from a system guided by the government and professional interests, include wide variations in both access and quality. Among the causes are the relationships between third-party payers, the providers and the regulators, which together obfuscate the cost of health care and, thereby, the supply 
Theoretical Approach

and demand relation. Consumerism, as a driver of medicalization, seeks participation in the clinical decision-making process, thereby acknowledging an extant structure to which the consumer wishes to be added. This is a very different connotation from the desire for self-care, arguably a demedicalizing interest.

\section{Demand for CAM}

This section lays groundwork for addressing the structure of the consumer demand for CAM services provided by physicians. Specifically, it makes the case, along with Goldstein, that the desire for spirituality applies pressure for these services.

Astin (2000) revisited his findings from his 1998 survey and supplemented with a review of the literature for the main theoretical components. This national survey indicated that there were, essentially, three explanations for why people used CAM: (1) dissatisfaction with conventional medicine; (2) desire for personal control; and (3) philosophical or value congruence. It is worth reporting on Astin's review of the literature because it provides the rationale for some basic hypotheses to be addressed with the MEPS data.

Dissatisfaction is a complex construct that includes disenchantment with conventional medical care, dissatisfaction with specific treatment approaches or practitioners, and lack of symptom relief. Components of dissatisfaction include: decreased trust; disappointment with conventional treatment; impersonal care; poor communication; and cost of care. Dissatisfaction is higher among CAM users 
Theoretical Approach compared to non-users, and criticism has been leveled at mainstream health care from middle-class suburban participants in non-traditional healing groups (ibid).

Individuals seek CAM in order to gain personal control and are attracted by freedom of choice, clearer explanations and a holistic approach to care. They hold an interest in self-help CAM modalities. Anti-authoritarian views of CAM users frame doctors as "knowledgeable resource persons for self-aware patients", as opposed to all-knowing experts (ibid).

Regarding philosophical/value congruence, CAM is held to be consistent with personal worldviews. There is a perceived alignment of CAM beliefs (e.g. vital energy) and spiritual beliefs. CAM consumption is viewed as a component of a more general interest in personal growth and development (ibid).

A more recent exploration of motives for CAM use suggests that economics is more of a driving force than personal politics (Pagan \& Pauly, 2005). That is, consumers of CAM view their consumption as an effort to save money. Further, within the subpopulation of chronic illness sufferers, trust in future health care mitigates the use of CAM. Those with less trust are more likely to use CAM, although they generally hold CAM practitioners as less trustworthy than regular health professionals (Van den Brink-Muinen \& Rijken, 2006).

This chapter has addressed the theoretical approach to the analysis by emphasizing the concept of boundaries within social systems. The social actors relevant to professional service in health care were discussed. Special consideration 
Theoretical Approach was given to the social theories of both professional interests and consumer interests. The chapter ended with a discussion of the influence that consumers have on the boundaries between professions, specifically addressing allopathic medicine and CAM. The next chapter turns to the literature on variables associated with CAM consumption. 
Chapter 3. Review of Empirical Research Literature

This chapter reviews the empirical research addressing CAM utilization. Attention is focused on the relationships between CAM utilization and sociodemographics, health status, and financial status. The chapter begins with literature on the population prevalence of CAM, and is followed by sections of relevant modeling variables. The chapter concludes with attention to the political climate of the period in which the data were collected and studies of physician attitudes towards CAM.

\section{CAM Utilization}

Several population estimates have been made regarding popular use of CAM in the United States. Eisenberg et al. (1998) reported a rise in prevalence of use from $33.8 \%$ to $42.1 \%$ in a six-year period. Astin (1998a) found $40 \%$ prevalence of use, while the Landmark Health care survey of 1998 found a $42 \%$ prevalence estimate (Jayaraman, 1998; The Landmark Report II, 2003). Low and high estimates were provided by the Consumer Reports subscriber survey $(n=34,000)$, which estimated $47 \%$ utilization in a two year period (Devitt, 2005). Kessler et al. (2001) estimated a $50 \%$ utilization rate among those with anxiety or depression. Bausell et al. (2001), and Druss and Rosenheck (1999) found smaller estimates in the MEPS data (9\% and 
Empirical Research Literature $6.5 \%$ respectively); Barnes et al. (2004) examined NHIS data from 2002 and found an overall CAM utilization estimate of $36 \%$, which grew to $62 \%$ when the definition of CAM included prayer specifically for health reasons. Wolsko (2002), using the 1997 survey data from the Eisenberg (1998) follow-up study, estimated that $44 \%$ of the population had used at least one CAM therapy in the preceding year. The White House Commission on CAM reported prevalence estimates that ranged from $6.5 \%$ to 43\%, referencing Druss et. al. (1999) and Eisenberg et al. (1998), respectively.

According to Mackenzie et al. (2003), our current understanding of who uses CAM is derived, from 3 widely-cited national surveys: Eisenberg et el. (1993); Astin (1998a); and Eisenberg et al. (1998). As these studies did not endeavor to unpack the sociodemographic relations with CAM utilization, the impression given is unrefined and possibly misleading because of a lack of specificity. Mackenzie et al. developed their study in critical response to the preceding surveys. Given the origins of CAM therapies, it was likely that the findings of the Eisenberg and Astin studies could be elaborated upon by close scrutiny of sociodemographic variables. The Mackenzie study defined CAM as a set of five items: herbal medicine; acupuncture; chiropractic; visits to traditional healers; and use of home remedies. The variables chosen for analysis were ethnicity, gender, age, education, income, insurance status and being foreign born. Their secondary analysis was conducted on survey data that included oversampling of several minority groups and was conducted in six languages: English; Spanish; Mandarin; Cantonese; Korean; and Vietnamese. 
Empirical Research Literature

Mackenzie et al. found that $43.1 \%$ of all respondents in their survey had used CAM therapies in the preceding year, an estimate that was consistent with previous surveys. This study found evidence of both the importance of conducting culturallycompetent survey research, and the need to honor the complex social differences between the modalities commonly grouped together as CAM. While use of any CAM therapy within the preceding year did not differ by ethnicity, subgroup analysis illuminated more subtle relationships. When ethnicity was analyzed with each specific CAM therapy, statistically significant differences were found across ethnic groups. The authors concluded that the process of analyzing CAM modalities separately produces different prevalence estimates by demographic segment, and provides a different picture of consumption as compared to an undifferentiated population of CAM users. These conclusions inform the study proposed here by suggesting that the integration of allopathic medicine and CAM will occur by modality.

Mackenzie et al. noted that the sociodemographic picture provided by Eisenberg and Astin is counterintuitive because so much of the knowledge base underlying the various CAM therapies has been developed by indigenous cultures and folk practices - practices embraced by subcultures within the larger society. This view is provided some validation by the World Health Organization (WHO) with their Traditional and Alternative Medicines Initiative, which began in 1985 (WHO, 1987). This program was an effort to meet and enlist indigenous healers from around the 
Empirical Research Literature

world to assist with local public health work (Bodeker \& Kronenberg, 2002;

Trachtenberg, 2002). The American Public Health Association (APHA) embraced the WHO initiative in 1994, and the Office of Alternative Medicine at the NIH issued similar support in 1996. The APHA explained their interests in CAM: "The public health imperative for the study of these health practices was their sheer prevalence, which had been brought to major public attention by...Eisenberg." The public health interest in global alternative health practices stems from the ability of holistic practice to improve health care by taking a larger view than conventional care, one that incorporates cultural competence as an important value in primary health care (Trachtenberg, 2002). It is interesting to note that these pro-CAM messages were being produced by national and global public health organizations at a time when physicians were at risk of disciplinary action by state medical boards for providing CAM services. This point will be developed in the next section.

Wolsko et al., (2002) further analyzed the Eisenberg et al. (1998) survey data for the effects of insurance coverage. Among those who used a CAM therapy, factors independently associated with seeing a provider were: having been in the upper quartile of visits to conventional providers in the last year; female sex; and having used the therapy to treat diabetes, cancer, back or neck problems. Factors independently associated with frequent use of a CAM provider included partial insurance coverage; having used the therapy for wellness; and having seen the provider for back or neck problems. This analysis found that a small subpopulation 
Empirical Research Literature

$(8.9 \%$, or 17.5 million adults) was responsible for more than $75 \%$ of the 629 million visits made to CAM providers in 1997.

To summarize, CAM utilization estimates from population-based surveys affirm the popularity of alternative health care. This section addressed the importance of sociodemographic variation and the role of insurance coverage. CAM utilization was explored at both the micro- and macro-levels through inquiries about why people used CAM, as in the former, and the public policy acceptance of the knowledge claims associated with CAM, as in the latter.

\section{Variables Associated with CAM Utilization}

A relatively recent review of the literature on the sociodemographic relations with various CAM services found wide variety (Conboy et al., 2005). This article provides a useful summary of patterns of sociodemographic variation. Medline ${ }^{\circledR}$ searches for measures of sociodemographic status yielded 35 articles. Demographic profiles were mixed across publications. The patterns for variables in the present study are discussed below.

Regarding Age, nine of 17 research articles (53\%) found younger people more likely to use CAM. Five of 17 articles (29\%) found middle-aged people more likely to use CAM, while one article found older age to be associated with CAM use. Two articles found no association between CAM use and Age. Regarding gender, eight of 13 articles (61.5\%) found that women were more likely to use CAM. Five of 13 articles (38.5\%) found no gender effect. Regarding Higher Education, 15 of 16 
Empirical Research Literature

articles $(93.8 \%)$ showed a relation with higher levels of education. Regarding Ethnicity, five of 11 articles (45.5\%) showed a significant effect of race/ethnicity. Regarding Economic status, nine of 10 articles (90\%) showed differences by higher income. Conboy et al. (2005) also performed a secondary analysis on the data from Eisenberg et al. (1998), specifically to focus on the sociodemographic variability in CAM utilization.

\section{Prevalence Estimates for Model Variables}

This section lists parameter estimates for the following traits: Age, Gender, Ethnicity, Education, Economic Status, Health Status and Geography. Age

Conboy et al. (2005) found mixed estimates for the relation between Age and CAM utilization. Sixteen of 23 types of CAM showed significant differences by Age. Relaxation and Self-Help was associated with the 35-49 age group. Prayer was associated with this age group and older. Chiropractic and acupuncture was associated with being older. Older age was also associated with using practitioner-based CAM. Imagery and aromatherapy were inversely related to older age.

Bausell et al. (2001) found that the 40-49 age group was $85 \%$ more likely than the 18-29 age group to use CAM $(O R=1.85)$. Druss and Rosenheck (1999) found that the average age for exclusive CAM use was 38 , while the age for users of both CAM and conventional care was 46. Eisenberg et al. (1993) found that CAM use was more 
Empirical Research Literature common in the 25-49 years of age segment. The 1998 follow-up survey by this group found a statistically significant increase in use in the 35-49 age group, over both the younger and older segments of the study population (Eisenberg et al., 1998). Lafferty et al. (2006) reported that the age group 31-50 was associated with CAM use in an insured population.

\section{Gender}

Eisenberg et al. (1993) reported no differences by gender. However, Conboy et al., (2005) found women were more likely than men to use CAM in the Eisenberg data (49\% vs. $37.8 \%$ ). Also, using the same data, Wolsko et al. (2002) report an adjusted odds ratio of 1.67 for females for $A n y C A M U$ Use; however, gender was not associated with Frequent CAMUse.

Mackenzie et al. (2003) found an increased likelihood for CAM use among females ( $O R=1.29)$. Results from Bausell et al. (2001) reported females as $75 \%$ more likely to use CAM (OR=1.75). Druss and Rosenheck, (1999) reported a 68\% prevalence of CAM use for females. Lafferty et al. (2006) reported female gender was associated with CAM use in an insured population.

\section{Ethnicity}

Regarding race, African Americans were less likely than other ethnicities to use CAM in the Eisenberg data (33.1\% vs.44.5\%) (Conboy et al., 2005). 
Empirical Research Literature

Mackenzie et al. (2003) found that CAM utilization was equally prevalent by ethnicity in their aggregate sample; however, characteristic profiles changed with CAM modality.

Results from Bausell et al. (2001) found that CAM use was more prevalent among whites (65.5\%); while blacks and Hispanics were less likely ( $O R=0.46$ and $\mathrm{OR}=0.58$ ), respectively, to use CAM. Druss and Rosenheck (1999) found an $86.5 \%$ prevalence among whites for any CAM.

Conboy et al. (2005) found that whites were more likely than non-whites to use CAM, with the exception of prayer. Non-Hispanic Blacks were more likely to use on one CAM modality - self-prayer, more than non-Hispanic whites. Seven of 23 modalities showed differences by ethnicity. Users of acupuncture tended to identify as Asian. Users of massage and self-care tend to identify as Hispanic. Users of homeopathy tended to identify as Asian and Hispanic. Hispanics were more likely to use massage, prayer by others and herbal remedies. They were less likely to use chiropractic therapies. Asians were more likely to use acupuncture, lay midwives, lifestyle diet and yoga; they were less likely to use prayer. Native Americans were less likely to use chiropractic care than non-Hispanic Whites.

\section{Education}

Mackenzie et al., (2003) found that those with a High School Education or higher were more likely to use $\mathrm{CAM}\left(\mathrm{OR}_{\mathrm{HSgrad}}=1.27, \mathrm{OR}_{\text {Collegegrad }}=1.43\right.$, 
Empirical Research Literature

$\mathrm{OR}_{\text {Postgrad }}=1.50$ ). Bausell et al., (2001) showed that having greater than High School Diploma was associated with a $26 \%$ greater likelihood of CAM utilization $(\mathrm{OR}=1.26)$. Astin (1998a) found that more education was associated with and increased likelihood of CAM use (OR=1.2). Druss and Rosenheck (1999) found an $84.2 \%$ prevalence among high school graduates.

Conboy et al. (2005) found that 17 of 23 types of CAM showed differences by education. Users of CAM had more education than nonusers, most pronounced for acupuncture and homeopathy. The variables Prayer by Others and Use of a Lay Midwife were inversely related to High Education. Self Prayer and Prayer by Others were most strongly related to having less than a College Education.

\section{Economic Status}

With respect to the variable Income, only Chiropractic showed differences between Users and Non-users. Only Self-Prayer and Prayer by Others was inversely associated with high income, (Conboy et al., 2005)

Eisenberg et al., (1998) found a positive association between CAM use and those with incomes above $\$ 50,000$ per year. Wolsko (2002) found no association between CAM use and economic status. However, Astin (1998a) found higher income to be correlated with CAM use $(r=0.06, p<.05)$.

Regarding expenditures, Lafferty et al., (2006) found the median per visit expenditure was $\$ 39.00$ for CAM and $\$ 74.40$ for conventional care. Total 
Empirical Research Literature expenditures for this sample were $\$ 2,589.00$ per enrollee, of which $\$ 75.00(2.9 \%)$ was spent on CAM.

Insurance status

Eisenberg et al. (1993) reported that insurance coverage was most common for visits to herbal therapists, biofeedback providers, chiropractors and providers of megavitamins. These results were supported by Pelletier et al. $(1997,1999)$, in which they found that most managed care organizations (MCOs) and insurers provided at least some coverage for nutritional counseling, biofeedback, psychotherapy, acupuncture, preventive medicine, chiropractic, osteopathy, and physical therapy. These authors were careful to mention that consumer demand was the explanation given for offering CAM coverage. In an analysis of the proportion of the population with insurance coverage for CAM, Eisenberg et al. (1998) saw increases across a seven-year period; in the numbers of respondents with both full or partial coverage, however, the trend did not reach statistical significance, owing to small sample sizes.

Regarding insurance status in this population, $87 \%$ of users were covered; however, no indication of difference between Users and Non-users was given (Conboy et al., 2005).

Mackenzie et al. (2003) found that being uninsured was predictive of CAM use $(\mathrm{OR}=1.52)$, compared to insured respondents. Druss and Rosenheck (1999) analyzed the 1996 MEPS for insurance coverage within professional service groups. Among the four groups, the percentage of uninsured was lowest among those that used both 
Empirical Research Literature CAM and Conventional services (11.8\%, [95\% C.I.: 9-14]), and was highest among those who used neither CAM nor Conventional services (i.e., None) (33\%, [95\% C.I.: 31-35]). Among those that used CAM Only the percentage of uninsured was $31.6 \%$, (95\% C.I.: 25-38), and finally, among those that used Conventional services only the prevalence was $13 \%$ (95\% C.I.: 12-14). Wolsko et al. (2002) found that frequent use of specific CAM therapies was associated with both full insurance coverage of CAM $(\mathrm{AOR}=5.06)$ and partial insurance coverage of CAM $(\mathrm{AOR}=3.26)$. Lafferty et al. (2006) analyzed utilization patterns across three large health insurance companies. Utilization was less likely within an HMO model as compared to both a Preferred Provider Organization or point-of-service model.

Health status

Regarding Self-Rated Physical Health, Druss and Rosenheck (1999) found that fewer respondents identified as having poor health in the CAM Only group $(11.1 \%$ CAM v. $16.7 \%$ BOTH). Bausell et al. (2001) found that $3.8 \%$ of the sample had poor health, and that lower health status predicted CAM use $(\mathrm{OR}=1.21$, [95\% C.I.: 1.141.30]). Astin (1998a) found that poorer health was associated with increased CAM use $(\mathrm{OR}=1.32$, [95\% C.I.: $1.1-1.5])$.

Regarding Self-Rated Mental Health, Druss and Rosenheck (1999) found prevalence rates of $3.1 \%$ for CAM vs. $7.3 \%$ for BOTH. Bausell et al. (2001) found that $1.3 \%$ of their sample self-identified as having Poor Mental Health. This was not predictive of CAM use. 
Empirical Research Literature

Regarding the need for help with Activities of Daily Living (ADLs), Druss and Rosenheck (1999) found rates of $0.9 \%$ impaired compared to BOTH at $2.8 \%$. The need for help with Instrumental Activities of Daily Living (IADLs) is proportionate to the ADLs, with roughly double the prevalence in each category (1.7\% CAM compared to $\mathrm{BOTH}$ at $4.5 \%$ ).

\section{Utilization of Health Care Services}

Druss and Rosenheck (1999) found that respondents in the Upper Quartile of mainstream health care utilization were more likely to use CAM than those in the Bottom Quartile (58.8\% vs. $40.5 \%$; p<.001). Similarly, Wolsko et al. (2002) also found that respondents in the Upper Quartile of mainstream health care utilization were more likely to use CAM (AOR=2.0 [95\% C.I.:1.33-3.01]). Astin (1998a) found that frequent health care utilization was associated with poorer health.

\section{Geography}

Regarding the regional distribution of CAM utilization, Druss and Rosenheck (1999) found that CAM use was more likely in the West (38.2\%). Similarly, Bausell et al. (2001) found that respondents in the West were $119 \%$ more likely to use CAM compared to respondents in the South. Eisenberg et al. $(1993,1998)$ found that CAM use was more common in the West compared to other regions (1990: 44\% vs. $31 \%$; $\mathrm{p}<0.05 ; 1997: 50.1 \%$ vs. $42.1 \% ; \mathrm{p}=0.004)$

Regarding urban/rural geographic distinctions in CAM utilization, Albert and Butar (2004) described the geographic distributions of naturopathic physicians (NDs) 
Empirical Research Literature

in Washington and Arizona. Using GIS mapping, these authors examined the relation between practice locations of NDs relative to both Health Professional Shortage Areas (HPSA) and distance from the nearest naturopathic medical school. While ND practice location was not different by HPSA category, there was a statistically significant inverse relation with distance from school. There was a similar correlation with high population density, indicating that NDs have similar preferences to MDs for locating their practices in urban, rather than rural, areas.

\section{Physicians Provide CAM Services}

From the supply-side perspective, the main research interest lies in the investigation of the proportion of physicians who provide alternative therapies. This dissertation contributes to that investigation. However, another approach is to hold the total amount of CAM utilization as a dependent variable, to be explained by the professional mix within a social milieu. Weiss (1997:100) described a utilization survey of this type conducted by Lerner and Kennedy (1992) of a national random sample of cancer patients, focusing on the therapies they used. Of primary interest was the prevalence of "questionable" therapies for which there were no FDA approval. Regarding this set of health treatments, the researchers found that physicians were the major purveyors, with patients reporting that one-third of the time they learned of these treatments from their doctors. Weiss commented, "In an additional 15 percent of cases, the patient's physician had approved the alternative treatment. Even more interesting is the finding that fully 60 percent of those actually administering 
Empirical Research Literature

alternative cancer treatments were physicians." These results inform the present study in two ways. First, the Lerner and Kennedy study is a methodological example of using consumer reports to infer physician behavior. Second, this study raises a conceptual question of whether physician referrals for CAM would increase before actual CAM service provision by physicians. Increases in physician referrals could be taken as indicators of future physician behavior.

The prevalence of physician-provided CAM is historically interesting given the risks that faced those physicians who did so. One such risk was posed by a nationallevel organization with guiding influence over all 50 states. "The Federation of State Medical Licensing Boards (FSMB) is the national entity that represents all State Medical Licensing Boards. They are charged with issuing guidelines or recommendations to State Boards that cover every conceivable aspect of medical practice" (Pelletier \& Horrigan, 2003). In April 1997, the FSMB issued its first White Paper on alternative medicine, which was extremely negative and equated CAM with "fraudulent and deceptive practices" (Federation of State Medical Boards, 1997). This paper avoided the challenge of defining CAM; however, the authors cited the Eisenberg et al. (1993) study as a foundation for their concern. As such, any practicing physician who provided alternative medicine, or "questionable health practices", ought to have legal action taken against him or her. The FSMB paper recommended that a standard of scientific evidence be advanced which promotes clinical trials and eschews anecdote. Further, the FSMB White Paper suggested that 
Empirical Research Literature state medical boards solicit the assistance of any of the following organizations for disciplinary action, as appropriate: Federal Trade Commission; State Attorney General; State Insurance Board; Health Care Financing Administration; U.S. Postal Service; U.S. Customs Service; Food and Drug Administration; and District Attorney. Simultaneously, the FSMB raised concerns about medical education, focusing on new CME courses about CAM, which were viewed as lacking content validity and possibly promoting dangerous practices (American Medical News, 2000). Interestingly, the FSMB's position paper occurred at about the same time that Congress increased funding to the OAM thereby creating the NCCAM. A few years later, the FSMB changed its position. In 2002, the FSMB approved a revised version of its guidelines, which was disseminated to all 50 states. Two fundamental changes were adopted in the new document. The definition of CAM was taken directly from the NCCAM website, thereby deferring to the expertise of the NIH. Rather than characterizing CAM as inherently negative, the revised document presented these therapies as ethically neutral. The FSMB recommended guidelines to states which include the language, "The (name of board) recognizes that the practice of medicine consists of the ethical application of a body of knowledge, principles and methods known as medical science and that these objective standards are the basis of medical licensure for physicians of the state of (name of state). These standards allow a wide degree of latitude in physicians' exercise of their professional judgment and do not preclude the use of any methods that are reasonably likely to benefit patients without undue risk" 
Empirical Research Literature (FSMB, 2002). Further, the document explicitly stated that a physician would not be subject to disciplinary action solely on the basis of providing alternative therapies. By continuation, the revised FSMB document allows physicians to refer patients to alternative care providers, whereas the initial document considered these referrals as grounds for disciplinary action (ibid.).

Challenges also emerged from the profession of medicine. The AMA Council on Scientific Affairs has given special attention to alternative medicine (AMA, CSA Report 12, 1997), alternative therapies for menopause (AMA, CSA Report 4, 1996), and folk remedies among ethnic subgroups (AMA, CSA Report 13, 1997). A general theme is presented across these three reports that emphasizes the lack of scientific evidence. The report on alternative medicine states that observers from outside the CAM sector see little commonality across alternative therapies. They "find no common or unifying theory or basis for its use; indeed, it may be that the variety of treatments in itself enhances their popularity. Many such therapies are characterized by a charismatic leader or proponent, and are driven by ideology; some spring from folk practices or quasi-religious groups, while others are recognized elements of religions such as those practiced by Native Americans." The alternative medicine report calls for the use of randomized clinical trials to establish efficacy, and admonishes physicians to educate patients as to the hazards that might result from postponing or stopping conventional medicine. 
Empirical Research Literature

The historical timing of these documents is meaningful. These AMA-CSA reports were produced as Congress deliberated the expansion of the OAM to become the NCCAM (in October, 1996). Together with the FSMB reports, these political position statements are a salient message to professionals, but how did they respond?

The literature on physician attitudes toward CAM is large and growing (Hirschkorna, 2005). Astin et al. (1998b) conducted an extensive and influential review of the literature on physician attitudes toward specific CAM therapies and physician's various professional practices, referral patterns and reasoning behind advocating for specific CAM therapies. This review of the literature provides some insight into the complexity of the physician's point-of-view. There were two motivating factors for Astin's review: (1) prevalence estimates of CAM utilization ranging from $30 \%$ to $50 \%$; and (2) the volume of the extant literature on physician attitudes toward CAM. Astin et al. found that physicians had a range of responses to patient interests in CAM, both positive and negative. "Three of the most common arguments used by opponents are as follows: (1) alternative therapists do not have the extensive knowledge that is required to diagnose an illness properly; (2) there is a lack of evidence of the efficacy of CAM; and (3) CAM is potentially harmful owing to its adverse effects or indirectly through the failure of patients to seek appropriate medical care" (ibid). These arguments are well understood within the theoretical framework established by Abbott on the ecological nature of professional strategies for managing their jurisdictions. The arguments are stereotypical of the challenges asserted by 
Empirical Research Literature professions against other professions, for the purpose of eroding social perceptions of exclusive expertise. However, Astin et al. (1998b) also acknowledged, "By contrast, clinicians have become strong proponents of particular types of CAM, regardless of whether or not there is scientific evidence of efficacy." Astin's review of the literature from 1982 to 1995 yielded 25 surveys that examined the practices and beliefs of physicians regarding five of the more prominent CAM therapies: acupuncture; chiropractic; homeopathy; herbal medicine and massage. Results were wide-ranging and discriminating.

Again, regarding physician acceptance of CAM, acupuncture had the highest rate of physician referral (43\%), followed by chiropractic (40\%) and massage (21\%). Regarding actual practice of CAM therapies by physicians, both chiropractic and massage therapies had $19 \%$ prevalence rates, and the lowest prevalence was associated with homeopathy (9\%). Regarding beliefs about CAM therapies, over half of physicians thought chiropractic and acupuncture to be efficacious (53\% and 51\%, respectively); massage was similarly believed to be efficacious among $48 \%$ of the respondents. Fewer physicians believed in the efficacy of homeopathy (26\%) and herbal remedies $(13 \%)$.

This research by Astin et al. is particularly salient because of the period reviewed. Astin's findings illustrate the degree of acceptance of CAM in the years immediately preceding the MEPS surveys that form the central data component of this dissertation. 
Empirical Research Literature

The previous two sections have shown that more research needs to be done regarding the characterization of both the consumers of CAM services and the physicians who provide CAM services. The popular demand for CAM, as measured by Eisenberg et al. $(1993,1998)$, coupled with the work of Astin et al. (1998b), provides converging evidence of social change during the period.

The tension between consumer demand, professional ethics and professional oversight raises the question of the degree of constraint that conceptual-level boundaries have on workplace-level behaviors. Additional structural constraints on the patient-provider interaction come from the legal environment.

In large part, constraint is placed on the scope of practice, by legal protections established (i.e., sought and won) across the various strata of the judicial system. States have primary authority for defining the scope of practice, and the federal and local levels of government have influence by defining rewards and punishments for licensed professionals (e.g., access to Medicare business), and also through zoning and building permits.

To understand the structure of legal constraint on health professionals, close attention to the definition of medicine provides a description of where jurisdictional contests focus. The following is an abstracted description from Cohen (1998). States develop medical practice statutes pursuant to their police power. Police powers are those associated with protecting the public good, including health. The legal basis for licensure derives from the Tenth Amendment of the U.S. Constitution, which gives 
Empirical Research Literature authority to the states to regulate health, safety, welfare and morals. Licensure varies by profession, scope of practice, training and education, and by types of licensure. The variety in this legal approach creates a complex patchwork of prerogatives and restrictions not only for professionals, but also for the treatments and therapies that are employed by mainstream and marginalized health workers. Although states differ in their statutes, there are some common elements in their definitions of medicine: (1) diagnosing, preventing, treating and curing disease; (2) holding oneself out for, or compensation for, the above; (3) intending to receive a gift, fee or compensation for the above; (4) attaching such titles as M.D. to one's name; (5) performing surgery; and (6) using, administering or prescribing drugs or medicinal preparations. With respect to each of these elements, there are states whose policies constitute outlier cases. For example, concerning element (1), Michigan and Arkansas have broad definitions, including: "relieving...a...complaint...by...advice constitutes practicing medicine," and "suggesting....any form of...healing for the intended palliation constitutes the practice of medicine," respectively. Similarly, concerning (2), holding one's self out to the public expands the definition of medicine beyond diagnosis and treatment. Regarding (3), in Hawaii, Louisiana and Utah, one can be legally accused of practicing medicine irrespective of compensation; this legal sanction reinforces a separation between the conceptual/technical aspects of healing work and economic activity and reinforces the importance of expert knowledge as a distinctive, debatable arena. Regarding (4), (attaching a title to one's name) about half of states conclude 
Empirical Research Literature that an individual is practicing medicine if they entitle themselves doctor, or $\mathrm{Dr}$. Delaware includes the use of the word healer in its definition of medicine, while Ohio, Oklahoma, Oregon and Vermont include the use of the word professor. Other criteria for distinguishing the practice of medicine include maintaining an office "to receive, examine, and treat patients," performing surgery, administering or prescribing drugs, and being evaluated as appropriate for malpractice insurance coverage.

To summarize, this chapter covered empirical research on CAM utilization and physician attitudes towards CAM. It provided some context for these measures by discussing political challenges faced by CAM providers and by reviewing the various definitions of the practice of medicine. The next chapter introduces the research methodology for the study. 
Chapter 4. Research Methodology

The methodological approach for this study was a descriptive analysis of secondary data taken from a nationally representative, large-sample survey. This chapter presents the variables selected for analysis from the MEPS datasets HC-012 and HC-028. The analysis plan calls for these datasets to be combined in order to increase statistical power. In this chapter the research questions are presented, descriptions of model variables are provided and the statistical approach is described. Chapter 5 is dedicated to the initial step in secondary analysis, which is to determine whether the datasets have sufficient observations in the variables of interest and whether the datasets are amenable to combination.

The approach for this analysis is closely modeled after two publications that employed MEPS data from 1996. Bausell et al. (2001) investigated the sociodemographic and health variable relations between mainstream and CAM utilization. Druss and Rosenheck (1999) used MEPS data to discern whether CAM consumption was a substitute for or adjunctive to mainstream health care utilization. This was accomplished by grouping respondents into mutually-exclusive categories of health care utilization. The present study extends this approach by further subdividing the mutually-exclusive categories, creating a subpopulation of respondents who 
Research Methodology

received CAM from their mainstream, allopathic physician. Again, a main objective was to determine which of the sociodemographic and health variables were associated with the utilization of alternative therapies provided by physicians. The following hypotheses guide the analysis:

Table 4.1 Hypotheses

1. Demographic profiles of subpopulations of survey respondents, classified into mutually-exclusive categories of health professions, are hypothesized to be distinctive. [Table 6.3]

2. Utilization of unconventional therapies by three different professional groups: users of CAM services only; users of both CAM and Conventional services; and users of MDCAM are hypothesized to be distinctive. [Table 6.4]

3. Utilization of conventional health care services, differentiated into high- and lowfrequency users, along with MDCAM, will receive different types of unconventional therapies. This places MDCAM in relation to consumers and nonconsumers of health care services. [Tables 6.5, 6.6]

4. Comparisons between Conventional Care Only use and MDCAM for the average number of visits for conventional health care by specific CAM therapy, controlling for population characteristics, is hypothesized to be different [Table 6.7]

5. Comparisons between Conventional Care Only use and MDCAM for the average number of visits for conventional health care by specific CAM profession, controlling for population characteristics, is hypothesized to be different [Table $6.8]$

6. Comparisons of five mutually-exclusive professional groups will differ in their profiles of financial characteristics and utilization. [Table 6.9]

7. Comparisons of three mutually-exclusive professional groups with some CAM use will differ in their profiles of financial characteristics [Table 6.10] 
Research Methodology

8. After controlling for possible confounders, statistically significant bivariate relations will remain statistically significant in multivariate modeling [Tables 6.11, $6.12,6.13]$

\section{Model Variables}

This section describes the variables chosen for analysis. Variables are presented as conceptual sets: Dependent Variables; Sociodemographics; Perceived Health Status; Utilization; Physician Awareness Variables; and Geographic Variables. Dependent Variables

Respondents were asked whether they had consumed alternative medicine in the preceding year. If so (ALTCAR=1), they were to identify from a list the types of treatments they received (Table 4.2).

Table 4.2 CAM Treatments (exact wording and presentation order)

Acupuncture

Nutritional advice or lifestyle diets

Massage therapy

Herbal remedies

Biofeedback training

Training or practice of meditation, imagery or relaxation techniques

Homeopathic treatment

Spiritual healing or prayer

Hypnosis

Traditional medicine such as Chinese, Ayurvedic, American Indian, etc.

Other treatments

Source: Codebook MEPS FAMES Panel 1 Round 3 Alternative/Preventative Care (AP) Section. February 15, 1998 
Following this, respondents were asked to identify the type of professional that delivered the service. The dependent variable for this analysis is derived from the following survey question: "You told me that (PERSON) consulted someone who practices alternative care. What type of practitioner(s) (was/were) used?" Respondents were shown a flash card that listed the CAM providers from which they selected the type of practitioner (Table 4.3).

Table 4.3 CAM Providers (exact wording and presentation order)

Massage therapist
Acupuncturist
Physician
Nurse
Homeopathic or naturopathic doctor
Chiropractor
Clergy, spiritualist or channeler
Herbalist
Other

Source: Codebook MEPS FAMES Panel 1 Round 3 Alternative/Preventative Care (AP) Section. February 15, 1998

Because the primary objective is to compare the characteristics of survey respondents who received CAM therapies from allopathic physicians to those who received services from other types of providers, service utilization was categorized into a typology of mutually-exclusive groups, based on the intersection of 
Research Methodology

Conventional Care and Alternative Care (Table 4.4). This typology reproduces the approach taken by Druss and Rosenheck (1999).

Table 4.4 Provider Typology: Mutually-exclusive Professional Groups

\begin{tabular}{lll}
\hline Variable & \multicolumn{2}{c}{ Alternative Care } \\
\hline Conventional Care & No & Yes \\
No & No Prof Visits & CAM Only \\
Yes & Conventional Only & Both \\
& &
\end{tabular}

Additionally, the MDCAM group was identified and removed from the BOTH group to complete a set of five mutually-exclusive categories of Professional Types. This typology was the basis for the derived variable PROFGRP, the primary dependent variable, and was coded: $1=$ Conventional Only; $2=$ Both; $3=$ CAM Only; 4=No Professional Visits (NONE); and 5=MDCAM.

\section{Sociodemographic Variables}

AGE is recorded as a continuous variable. AGECATK is a derived ordinal level variable coded $(1=0-17,2=18-29,3=30-39,4=40-49,5=50-59,6=60-69,7=70-$ $79,8=80-89,9=90+)$.

SEX is a dichotomous variable coded $1=$ male, $2=$ female.

The concept of race is represented with the categorical variable RACED, where $0=$ White, and $1=$ Nonwhite.

The concept of education is represented with two categorical variables. EDUCR is coded $0=$ never attended school, $1=$ grades 1 through $11,2=$ high school 
Research Methodology

diploma, 3=any college. HIDEGCAT collects data on the highest degree earned and is coded $1=$ no degree, $2=$ high school diploma /GED, 3=other degree, 4=Bachelor's degree, $5=$ Graduate degree.

The concept of income is represented with three variables. TTLPNX2 is a continuous variable that represents a person's total income, limited to respondents with positive values. POVCAT is a categorical variable that represents family income as a percent of poverty line, coded $1=$ less than $100 \%$ of poverty line, $2=$ between 100 $124 \%$ of poverty line, $3=$ between $125-199 \%$ of poverty line, $4=$ between $200-399 \%$ of poverty line, and $5=$ greater than $400 \%$ of poverty line. WAGEP is a continuous variable that represents a person's wage income.

Employment Status (EMPST) 1=employed, 2=job waiting, 3=job during sampling period, $4=$ not employed during sampling period.

The concept of insurance status is represented with three variables. INSCOV indicates health insurance coverage and is coded $1=$ any private, $2=$ public only, $3=$ uninsured. INSALT indicates whether insurance paid for alternative care in the past year, coded $1=$ yes, $2=$ no. The estimated percentage paid for CAM by insurance (PERINS) is a continuous variable.

Total expenditures (TOTEXP) includes the sum of direct payments for care provided during the year, including out-of-pocket payments and payments by private insurance, Medicare, Medicaid and other sources. Payments for hospital and physician services, ambulatory physician and nonphysician services, prescribed 
Research Methodology

medicines, home health services, dental services and various other medical equipment and services that were purchased or rented during the year are included. Total charges (TOTTCH) includes the total health care charges, excluding prescription medications. Total expenditures for CAM (ALTCRE) is a continuous variable. Total expenditures for prescriptions (RXEXP) is a continuous variable.

\section{Perceived Health Status}

Perceived health status, RTHLTH, is an ordinal variable coded 1=excellent, 2=very good, 3=good, 4=fair, 5=poor. MNTHLTH2 reflects subjective mental health status and is coded $1=$ excellent, $2=$ very good, $3=$ good, $4=$ fair, $5=$ poor. ADLs is a dichotomous variable, coded $1=y e s, 2=$ no, reflecting the need for help with Activities of Daily Living (i.e., those activities required to maintain the basic level of life, such as getting in or out of bed or a chair, walking, eating, going to the bathroom, bathing or showering, or dressing). IADLs is a dichotomous variable, coded $1=y e s, 2=$ no, reflecting the need for help with Instrumental Activities of Daily Living (those activities that enhance life but are not required to maintain the basic level of life, such as using the telephone, paying bills, going shopping, housework, preparing meals, taking medications, or doing laundry). 
Research Methodology

\section{Utilization Variables}

EVENTS is a count variable derived from the MEPS office-based medical provider visits event files for 1996 and 1998. An interval-level variable, EVENTS records the number of office-based medical provider visits a person had during the period. Number of Events with a Diagnosis and Treatment (NUMDXTX) is a derived continuous variable, as is Number of Events with a General Checkup (NUMGENCHK), and Number of Visits with a Diagnosis (NUMBEST). Number of Visits for CAM (ALTCVE) is a continuous variable, as is Number of Prescription Medicines (RXTOT).

Respondents were asked what condition or conditions were responsible for each contact with the health care system. Conditions reported by the respondent were assigned three-digit diagnostic codes, according to the International Classification of Diseases, Ninth Revision (ICD-9), by trained coders (less than $2.5 \%$ error rate, MEPS workbook p.94). The list of disease conditions surveyed by the MEPS is exhaustive $(n>1000)$. The list of ICD-9 disease codes are reduced to mutually-exclusive clinical classification categories (CCC). Two variables are provided by the MEPS that reflect diagnoses, ICD9CODX, the ICD-9 code proper, and CCCODEX, a variable that groups diagnoses into clinical categories ( $n=260$ categories). 
Research Methodology

\section{Physician Awareness Variables}

Referred by MD for CAM Therapies (REFMD) is a dichotomous variable coded $1=$ yes, $2=$ no.

Discussed CAM with Regular MD (DSCALT) is a dichotomous variable coded $1=$ yes, $2=$ no.

\section{Geographic Variables}

REGION is a categorical variable coded $1=$ Northeast, $2=$ Midwest, $3=$ South, 4=West. Metropolitan service areas (MSA) were identified. MSA is a categorical variable coded $0=$ nonMSA, $1=$ MSA.

\section{Statistical Analyses}

Cross tabulations, likelihood estimate chi-squares tests of statistical inference, ordinary least-squares regression and logistic regressions (using maximum likelihood estimates for the standardized slope parameters, their respective Wald chi-square tests of statistical significance, odds ratios, and $95 \%$ confidence intervals) were used. Cross tabulations and chi-square tests were used to compare the sociodemographic characteristics of the respondents, and to compare the prevalence of use of each CAM provider. Variables with statistically significant bivariate relationships with the DV were included in the modeling stage of analysis. Logistic regression was used to 
Research Methodology

assess the significance of these independent variables in explaining the likelihood of visiting physicians for CAM therapy as compared to visits to nonphysicians, while controlling for other salient independent variables. The general model included sociodemographic variables, geographic variables, insurance variables, and medical condition variables.

\section{Complex Sample Design Variables}

Analyses were conducted with the Statistical Program for the Social Sciences (SPSS v13.0) which includes procedures for complex samples. Where appropriate, the design effect and the square root of the design effect will be presented to provide a measure of the effect of the complex sampling strategy on the estimates precision. Complex samples use at least two levels of adjustment to the data matrix. In the present case, MEPS provides two weighting variables, designed for different units of analysis: individuals and households. The analysis described here employed only the individual level weighting. The second design variable accounts for variance in the cluster sampling procedure. The sampling strategy employed by both the NHIS and the MEPS is staged and clustered by region of the country.

Version 13 of the SPSS statistical analysis package includes procedures to both generate and manage complex samples. An investigation into the reliability of these procedures was undertaken by generating standard error estimates in bivariate comparisons using both SPSS13 and SUDAAN (a product of Research Triangle 
Research Methọdology

Institute). Standard error estimates matched to the second decimal position

(hundredths). Further, personal communication with MEPS staff found matching

precision in creating univariate estimates of demographic variables using SUDAAN,

Stata, SAS and SPSS13 (Zodet, 2005). 
Preliminary Analysis

Chapter 5. Preliminary Analysis

This chapter focuses on the dataset for the study. Secondary data analysis begins with preliminary explorations of the data to determine whether a sufficient number of observations are present for meaningful analysis (Lee \& Forthofter, 2006). This is particularly important when assessing subpopulations with small sample sizes. The focus of this dissertation is an investigation into a set of survey response options that provide a quantitative measurement of a unique pattern of health care utilization: CAM provided by physicians (MDCAM). The Medical Expenditure Panel Survey (MEPS) inquired specifically about this professional behavior in the 1996 and 1998 surveys, but never afterwards.

\section{Data Sources: The Medical Expenditure Panel Survey}

The MEPS is an annual survey conducted by the Agency for Health care Research and Quality (AHRQ), and is the source of data for this analysis. The MEPS is specifically designed to produce annual national and regional estimates of health care utilization and expenditures. It is very reliable at doing so for the entire U.S. civilian noninstitutionalized population, and large subpopulations (Machin et al., 2003). The units of analysis available from this survey are persons, families, medical 
Preliminary Analysis

events, tax filing units and health insurance eligibility units (Cohen, 2002). This stratified cluster sample oversamples for Hispanics and blacks and provides representative estimates at the level of census region or higher (Druss \& Rosenheck, 1999; Cohen, 2002; Druss et al., 2003). Extrapolations to the state level are also possible. The specific data files that include CAM questions are: HC-012 and HC028, reflecting years 1996 and 1998, respectively. The 1996 dataset has been used previously to investigate CAM use in the United States (Druss \& Rosenheck, 1999; Bausell et al., 2001; McFarland et al., 2002; Druss et al., 2003). In October 2006, MEPS released a linking file (HC-36), which provided the appropriate design variables for analysis of combined datasets across survey years.

The particular strengths of the MEPS are that it allows national and regional (census categories) estimates of "the impact of changes in financing, coverage, and reimbursement policy as well as estimates of who benefits and who bears the cost of a change in policy.... No other survey provides a foundation for estimating the impact of changes on different economic groups or special populations of interest..." (Cohen, 2002). MEPS interviews take place in person using a computer-assisted-personalinterview system, and all respondents are asked a set of questions about visits to practitioners of unconventional therapies (Druss \& Rosenheck, 1999). Results can be correlated with other data on, for example, demographics, geography, education, income, health insurance (including coverage for CAM), urban/rural divide, employment, and number of health conditions (ibid). 
Preliminary Analysis

Secondary data analysis comes with both costs and benefits. A common challenge to secondary analysis focuses on the responsibility to match the theoretical reasoning of the research question to the data set, which has preexisting limits. The primary/initial purpose for data collection may be quite different from the purpose of the secondary research effort. As such, measurement items may not be ideal in terms of wording, focus, scope, or depth. In this sense, there is less control over the conceptual frame of the research. This imparts more importance to operationalization and to addressing the limits of the utility of the data for a specific research purpose. In exchange, government-sponsored large sample surveys provide measurement rigor, geographic breadth, statistical power, and documentation on validity and reliability. Indeed, it is the application of such a large research program that enables quantification of rare events like MDCAM.

Sampling Frame and Response Rates

The MEPS uses the National Health Interview Survey (NHIS) - conducted by the National Center for Health Statistics - for its sampling frame, from which a probabilistic subsample is drawn (Druss \& Rosenheck, 1999; MEPS Statistical Brief $\# 9$, 2003). Design variables are provided which adjust for nonresponse, oversampling, stratification in sampling, and clustering in sampling. Weighting variables are provided for generating national estimates for either individuals or households. The datasets employed here are the 1996 MEPS (raw file $\mathrm{N}=22,601 ; \mathrm{N}=17,704$ after 
Preliminary Analysis

cleaning) and the 1998 MEPS (raw $1998 \mathrm{~N}=24,072 ; \mathrm{N}=21,610$ after cleaning).

Response rates were $77.7 \%$ for the 1996 survey (Egede et al., 2002) and 67.9\% for the 1998 survey (MEPS Statistical Brief \#9, 2003). Preliminary analysis of missing data in the original datasets indicates that there are no outstanding differences by study year.

\section{Study Samples}

Sample sizes for the 1996 and 1998 MEPS were, respectively, 17,704 and 21,610 noninstitutionalized, civilian respondents. The main dependent variable of interest, MDCAM, while represented in both datasets, is a relatively rare event (weighted $n=86,(0.2 \%$ of the entire sample and $4.8 \%$ of the subpopulation who used CAM)). Combining these two datasets represents a strategy for maximizing multivariate statistical power and reducing the effects of extreme values, yielding increased reliability (Machlin et al., 2003). Direction is taken from both Druss and Rosenheck (1999) and Bausell et al.'s (2001) approach to the 1996 MEPS data, which focused on CAM use. This is to provide some external validation. One distinction from Bausell et al. is the application of Taylor series linearization to adjust for complex samples. Another distinction from the Bausell paper comes from the increased precision available from the analysis package employed here (i.e., SPSS v13). Bausell et al.'s analysis employed a version that permitted weighting adjustments only (SPSS v10). As such, the Bausell estimates are unreliable because 
Preliminary Analysis

they did not account for stratification within the sample, related to post hoc adjustment to Census data.

\section{Preliminary Analyses}

Preliminary analysis of the changes in the point-estimates of service utilization, over the 1996-98 biennium, indicate some interesting trends. Definitions of the variables discussed here can be found in Chapter 6. Survey respondents were asked whether they used alternative care in the preceding year. Those respondents who used CAM were then asked to identify the CAM therapies that they used. For each therapy, respondents were asked what type of provider provided the services. The options included allopathic physicians. The opportunity to analyze CAM utilization patterns associated with physicians is the focus of this dissertation.

In order to determine whether sufficient cases of the DV MDCAM were available for analysis, both survey years were compared. In the 1996 dataset, 29 (3.7\%) cases of MDCAM were distributed across 14 of $24(58.3 \%)$ primary sampling units (PSUs) (unweighted). For the 1998 dataset, 45 (5.8\%) cases of MDCAM were distributed across 9 of 37 (24.3\%) PSUs (unweighted). There was a 51\% increase in the number of visits to allopathic physicians for CAM from 1996-1998. This analysis indicates that there is sufficient representation of the main DV in both datasets. 


\section{Box's M}

One strategy for determining whether two datasets are comparable is to measure the multivariate covariance. Box's $M$ is a multivariate inferential statistic that tests the hypothesis that the covariance structure of two matrices are homogeneous. A lack of statistical significance indicates that the matrices are indeed comparable. Box's M tends to be oversensitive when sample sizes are large (greater than $\sim 16,000$ cases), as is the case here. Age, Sex and Region were analyzed and found to have no differences in their covariance structure across years $(N=38,804$ weighted, $\mathrm{F}=1.49, \mathrm{p}=.202$ ). This adds confidence that the datasets are comparable, especially because the test was biased against this result.

\section{Bivariate Comparisons of Model Variables}

Pairwise comparisons across study years (1996 and 1998) of variables in the model can help establish the similarity of the datasets. 
Preliminary Analysis

Table 5.1 Demographics and Expenditures by Year (N=37,465)

\begin{tabular}{llll}
\hline Variable & 1996 & 1998 & $P$ Value* \\
\hline & $\mathrm{n}=16,876$ & $\mathrm{n}=20,589$ & \\
& & $\mathrm{~N}(\mathrm{SE})$ & $\mathrm{N}(\mathrm{SE})$ \\
Age & $35.3(0.34)$ & $35.4(0.27)$ & .823 \\
Total Income & $\$ 24,456(372)$ & $\$ 27,382(370)$ & $<.001$ \\
CAM Expenditures & $\$ 242.46(29.3)$ & $\$ 264.63(67.8)$ & .446 \\
CAM \% covered & $79.4 \%(2.9)$ & $79.7 \%(2.4)$ & .940 \\
& & & \\
\hline
\end{tabular}

Weighted values, analysis adjusted for complex sampling design

*One sample t-test (test value is 1996 value for each variable)

Across 1996 and 1998 surveys (Table 5.1), Age, Expenditures for CAM and, the Percentage of CAM Expenditures Covered by Insurance were not different. Total income increased by nearly $\$ 3,000$, a statistically significant increase (one sample $t=$ 5.85 , test value $\$ 24,456 ; \mathrm{p}<.001)$.

No statistically significant differences were observed across 1996 and 1998 surveys (Table 5.2) for Sex, Race/Ethnicity, Educational Attainment, the Proportion of Respondents with Insurance Coverage, nor Self-Rated Health Status. This indicates that the datasets are comparable regarding the majority of respondent characteristics. The proportion of respondents whose CAM utilization was Covered by Insurance was statistically significantly different, with a greater percentage of respondents being covered in 1998 (Likelihood ratio $\mathrm{X}^{2}=6.52, \mathrm{df}=1, \mathrm{p}=.042$ ). 
Preliminary Analysis

Table 5.2 Demographics, Insurance and Health Status by Year $(\mathrm{N}=37,465)$

\begin{tabular}{llll}
\hline Variable & 1996 & 1998 & $P$ Value* \\
\hline & $\mathrm{n}=16,876$ & $\mathrm{n}=20,589$ & \\
& $\mathrm{~N}(\%)$ & $\mathrm{N}(\%)$ & .836 \\
Sex & & & \\
Female & $9,320(51.1)$ & $3,995(53.6)$ & .454 \\
& & & \\
Race/Ethnicity & & & \\
Hispanic & $1,887(10.3)$ & $2,441(11.6)$ & \\
Black & $2,314(12.7)$ & $2,699(12.8)$ & \\
Other & $14,043(77.0)$ & $15,930(75.6)$ & \\
& & & \\
Education & & & \\
None & $738(4.4)$ & $780(4.0)$ & .307 \\
No Diploma & $5,355(31.9)$ & $6,126(31.3)$ & \\
Diploma & $4,564(27.2)$ & $5,254(26.8)$ & \\
G.T. Diploma & $6,150(36.6)$ & $7,424(37.9)$ & \\
& & & \\
Insurance Coverage & & & \\
Private & $13,421(73.6)$ & $15,242(72.3)$ & \\
Public Only & $2,613(14.3)$ & $3,320(15.8)$ & \\
Uninsured & $2,210(12.1)$ & $2,507(11.9)$ & \\
& & & \\
CAM Insured & & & \\
Yes & $102(12.3)$ & $138(17.2)$ & \\
Perceived Health Status & & \\
Excellent & $6,264(34.7)$ & $6,901(33.6)$ & \\
Very Good & $5,715(31.6)$ & $6,558(31.9)$ & \\
Good & $4,219(23.4)$ & $5,029(24.5)$ & \\
Fair & $1,387(7.7)$ & $1,534(7.5)$ & \\
Poor & $479(2.7)$ & $523(2.5)$ & \\
& & & \\
\hline
\end{tabular}

Weighted values, analysis adjusted for complex sampling design

*Likelihood ratio Chi-Square 
Preliminary Analysis

Similarly, the geographic distribution of respondents was compared (Table

5.3). No statistically significant difference was found between survey years. This indicates that the datasets are comparable regarding geographic location of respondents.

Table 5.3 Region by Year

\begin{tabular}{llll}
\hline Variable & 1996 & 1998 & $P$ Value $^{*}$ \\
\hline & $\mathrm{N}=18,070$ & $\mathrm{~N}=20,866$ & \\
& $\mathrm{n}(\%)$ & $\mathrm{n}(\%)$ & \\
Region & & & .865 \\
Northeast & $3,457(19.1)$ & $3,995(19.1)$ & \\
Midwest & $4,074(22.5)$ & $4,851(23.2)$ & \\
South & $6,704(37.1)$ & $7,345(35.2)$ & \\
West & $3,834(21.2)$ & $4,675(22.4)$ & \\
\hline
\end{tabular}

Weighted values, analysis adjusted for complex sampling design

Values are frequencies and percentages

*Likelihood ratio Chi-Square

Finally, the geographic distribution of physician-provided CAM was compared (Table 5.4). This bivariate comparison reflected a statistically significant change in the pattern in the cell distributions of Region, when controlling for physician-provided CAM (Likelihood ratio $\mathrm{X}^{2}=12.5, \mathrm{df}_{1}=1.8, \mathrm{df}_{2}=1.8, \mathrm{p}<.001$ ). This indicates that there is some variability to be explored regarding the DV of interest, MDCAM. 
Table 5.4 Region by Year (subpopulation of MDCAM; $\mathrm{n}=86$ )

\begin{tabular}{llll}
\hline Variable & 1996 & 1998 & $P$ Value $^{*}$ \\
\hline & $\mathrm{N}=35$ & $\mathrm{~N}=51$ & \\
& $\mathrm{n}(\%)$ & $\mathrm{n}(\%)$ & \\
Region & & & $<.001$ \\
Northeast & $5.5(15.8)$ & $2.1(4.2)$ & \\
Midwest & $7.9(22.7)$ & $4.2(8.4)$ & \\
South & $5.7(16.4)$ & $26.9(53.2)$ & \\
West & $15.8(45.1)$ & $17.3(34.2)$ & \\
\hline
\end{tabular}

Weighted values, not adjusted for complex sampling design

"Likelihood ratio Chi-Square

To summarize, this chapter explored the 1996 and 1998 MEPS datasets to determine if there were sufficient cases to conduct a meaningful analysis. The DV of interest represents a small subpopulation; however, data is distributed across all regions of the country. The covariance structure of the datasets does not differ in terms of three core theoretical variables, even though the test tends to be overly sensitive with large population sizes. Bivariate analysis similarly showed that the response patterns within variables did not differ significantly across survey years. Taken together, it is reasonable to combine datasets for the specific purpose of increasing multivariate power relative to the small subpopulation of MDCAM. 
Results

Chapter 6. Results

This chapter begins with univariate descriptive statistics of model variables and a series of tables covering bivariate analyses through the lens of Professional Consumptions Groups. Groups are compared for differences in demographics, health status, geographic location, finances, insurance status, and patterns of health care consumption. Table 6.1 introduces the methods used in this chapter, along with their associated purposes.

Table 6.1 Meta Level Methods

\begin{tabular}{ll} 
Method & Purpose \\
\hline Univariate Analyses & Distributions, Population Comparisons \\
Bivariate Analyses & Identify Discriminating Variables \\
Nonparametric Ranking & Profile Respondents \\
Multiple Regression & Calculate Average Health Care Visits \\
Logistic Regression & Examine Contributions of Discriminating Variables \\
Weighted Projections & Generate National Estimates \\
\hline
\end{tabular}

Below, Table 6.2 reports on univariate statistics for model variables $(\mathrm{N}=39,314$ unless otherwise specified). The table is presented in two sections, distinguishing between categorical and continuous variables. The table includes breakdowns of variable attributes by percentage or mean, as appropriate, accompanied by the standard error of the measure. 
Results

Table 6.2 Univariate Report $(\mathrm{N}=39,314)$

\begin{tabular}{|c|c|}
\hline Variable & Percentage (SE) \\
\hline \multicolumn{2}{|l|}{ Sex } \\
\hline Female & $51.1 \%(0.2)$ \\
\hline Male & $48.9 \%(0.2)$ \\
\hline \multicolumn{2}{|l|}{ Race } \\
\hline White & $76.2 \%(0.9)$ \\
\hline Nonwhite & $23.8 \%(0.9)$ \\
\hline \multicolumn{2}{|l|}{ Education } \\
\hline Never to $11 \mathrm{yrs}$ & $35.7 \%(0.5)$ \\
\hline HS diploma & $27.0 \%(0.4)$ \\
\hline Any college & $37.3 \%(0.6)$ \\
\hline \multicolumn{2}{|l|}{ Insurance Coverage } \\
\hline Any private & $72.9 \%(0.7)$ \\
\hline Public Only & $15.1 \%(0.5)$ \\
\hline Uninsured & $12.0 \%(0.4)$ \\
\hline \multicolumn{2}{|l|}{ Region } \\
\hline Northeast & $19.1 \%(1.0)$ \\
\hline Midwest & $22.9 \%(1.1)$ \\
\hline South & $36.1 \%(1.5)$ \\
\hline West & $21.9 \%(1.6)$ \\
\hline \multicolumn{2}{|l|}{ MSA } \\
\hline Non-MSA & $20.8 \%(1.1)$ \\
\hline MSA & $79.2 \%(1.1)$ \\
\hline \multicolumn{2}{|l|}{ Self-Rated Physical Health } \\
\hline Excellent, Very Good, Good & $88.2 \%(0.3)$ \\
\hline Fair, Poor & $11.8 \%(0.3)$ \\
\hline \multicolumn{2}{|l|}{ Self-Rated Mental Health } \\
\hline Excellent, Very Good, Good & $93.0 \%(0.2)$ \\
\hline Fair, Poor & $7.0 \%(0.2)$ \\
\hline \multicolumn{2}{|l|}{ Needs Help with ADLs } \\
\hline Yes & $2.3 \%(0.1)$ \\
\hline No & $97.7 \%(0.1)$ \\
\hline \multicolumn{2}{|l|}{ Needs Help with IADLs } \\
\hline Yes & $4.2 \%(0.1)$ \\
\hline No & $95.8 \%(0.1)$ \\
\hline \multicolumn{2}{|l|}{ CAM Use During Previous Year } \\
\hline Yes & $4.6 \%(0.2)$ \\
\hline No & $95.4 \%(0.2)$ \\
\hline \multicolumn{2}{|l|}{ Referred to CAM by $\mathrm{MD}(\mathrm{n}=1,762)$} \\
\hline Yes & $12.3 \%(1.0)$ \\
\hline No & $86.8 \%(1.0)$ \\
\hline \multicolumn{2}{|l|}{ Discussed CAM with MD $(n=1,756)$} \\
\hline Yes & $32.5 \%(1.6)$ \\
\hline No & $67.5 \%(1.6)$ \\
\hline
\end{tabular}


Results

$\begin{array}{cl}\text { Yes } & 13.7 \%(1.2) \\ \text { No } & 79.6 \%(1.3) \\ \text { CAM for Specific Problem (n=1,759) } & 61.3 \%(1.8) \\ \text { Yes } & 38.7 \%(1.8) \\ \text { No } & \\ \text { Employment Status } & 65.0 \%(0.5) \\ \text { Employed } & 31.6 \%(0.5) \\ \text { Not Employed During Sampling } & \\ \text { Professional Consumption Category } & 64.5 \%(0.4) \\ \text { Conventional Only } & 3.6 \%(0.2) \\ \text { Both CONV + CAM } & 0.8 \%(0.1) \\ \text { CAM Only } & 30.8 \%(0.4) \\ \text { No Professional Visits } & 0.2 \%(0.0) \\ \text { MDCAM } & \end{array}$

The following are means and standard errors for continuous variables.

\begin{tabular}{ll} 
Variable & Mean (SE) \\
\hline Age & $35.34(0.23)$ \\
Number of Provider Visits with a Diagnosis & $5.72(0.069)$ \\
Number of Events with Dx \& Tx & $4.34(0.068)$ \\
Number of Events with General Checkup & $2.18(0.022)$ \\
Total Spent on CAM Remedies ( $\mathrm{n}=1,693)$ & $\$ 115.53(10.33)$ \\
Total Expenses for Rx & $\$ 264.05(5.52)$ \\
Number of Prescription Meds & $7.03(0.13)$ \\
Total Conventional Visits (office-based+outpatient) & $3.42(0.046)$ \\
Total Health care Expenses & $\$ 2,029.23(48.89)$ \\
Total Health care Charges (excludes Rx) & $\$ 2,845.08(70.80)$ \\
Total Income & $\$ 26,024.96(319.11)$ \\
Annual Personal Income from Wages & $\$ 14,625.01(229.69)$ \\
Excluding Ss with 0 wage ( $\mathrm{n}=21,986)$ & $\$ 26,151.39(309.16)$
\end{tabular}

As shown in Table 6.2, an estimated $51.1 \%$ of the sample was female. The dichotomized measure of Race described $76.2 \%$ white. Nearly equal proportions were seen in the measure of Education for Grades 1-11 31.5\%, HS diploma 27\%, and any college $37.3 \%$. Insurance Coverage reflects that a majority of respondents hold private insurance $72.9 \%$; the percentages are similar for holding public insurance only $(15.1 \%)$ or for being uninsured $(12.0 \%)$. The geographic variable Region reflects that the percentage of respondents from the South is nearly double the region of smallest 
Results

percentage, the Northeast (Northeast 19.1\%, Midwest 22.9\%, South $36.1 \%$ and West 21.9\%). The geographic variable MSA reflects an predominantly urban sample (NonMSA 20.8\%, MSA 79.2\%). Regarding health measures, Self-Rated Physical Health reflected that $89.9 \%$ of the sample were in Good health or better, with only $7.6 \%$ reporting Fair and $2.6 \%$ reporting Poor. Similarly, $94.6 \%$ of the sample reported their Self-Rated Mental Health as Good or better. Only 2.3\% Need Help with ADLs, and only $4.2 \%$ Need Help with IADLs. A small proportion of the sample affirmed CAM use during the previous year (4.6\%). Regarding physician participation in CAM consumption, $12.3 \%$ indicated that they were Referred to CAM by MD $(n=1762)$. Further, $30.2 \%$ Discussed CAM with their MD $(n=1756)$. Regarding the financing of CAM consumption, $13.7 \%$ of CAM consumers indicated that Insurance Paid for CAM. CAM for Specific Problem yielded a majority: Yes 61.3\%, No 38.7\%. Regarding Employment Status, 65\% were Employed, and 31.6\% were Not Employed During Sampling. Finally, Professional Consumption Category reflects the relative proportions of respondents within the following professional subgroups: Conventional Only (64.5\%), Both CONV + CAM (3.6\%), CAM Only (0.8\%), No Professional Visits (30.8\%), and MDCAM (0.2\%).

The subpopulation of MDCAM is a very small proportion of the entire data set $(\mathrm{n}=86$, weighted). However, it should be noted that the expansion ratio of the sample size to population estimates is $1: 11,617$. The national projection for the number of persons who received CAM from a physician is 992,097 (SE 149,353). The Regional 
Results

distribution of MDCAM recipients, again from national projections, is: Northeast = 89,096, Midwest $=141,084$, South $=37,8597$, and West $=383,322$. However, the likelihood ratio chi-square test on the sample distribution of MDCAM by REGION (not the national projections, discussed above) is not statistically significant $\left(X^{2}=4.114, p=0.307\right)$.

The following are the estimated means and standard errors for continuous variables. The estimated average Age for the sample is $35.34(0.23)$ years. Additionally, the Age group $0-17$ comprised $27.1 \%$ of the sample, and $8.7 \%$ were aged 70 or above (not shown in table), yielding an approximate dependency ratio of 0.55. Regarding health care utilization, the estimated average Number of Provider Visits with a Diagnosis was $5.72(0.069)$. The Number of Events with a Diagnosis and/or Treatment (DXTX) was $4.34(0.068)$. The average Number of Events with a General Checkup was 2.18 (0.022). The estimated Total Spent on CAM Remedies $(n=1,693)$ was $\$ 115.53(10.33)$, while the estimated Total Expenses for Pharmaceuticals was $\$ 264.05$ (5.52). The average Number of Prescription Meds held by the overall population was $7.031(0.13)$. The average Total Conventional Visits (office-based + outpatient) was $3.42(0.046)$, while the average amount of Total Health care Expenses was $\$ 2,029.23$ (48.89). Total Health care Charges (excluding $\mathrm{Rx}$ ) averaged $\$ 2,845.08(70.80)$. Regarding personal income, the estimated average Total Income was $\$ 26,024.96$ (319.11), and the estimated average Annual Personal Income from Wages was $\$ 14,625.01$ (229.69). When persons with zero wages were 
Results

excluded $(n=21,986)$, the estimated average Annual Personal Income from Wages rose to $\$ 26,151.39(309.16)$.

\section{Characteristics of Respondents}

Addressing Hypothesis 1, survey respondents were examined for differences across subpopulations. Following Druss and Rosenheck (1999), Table 6.3 compares population characteristics, health status and geographic distribution by five mutuallyexclusive professional service provision groups: (1) Both CAM and Conventional services (BOTH, $\mathrm{n}=1,373$ ); (2) Conventional Only (CONV, $\mathrm{n}=24,898$ ); (3) CAM Only (CAM, n=320); (4) No Professional services (NONE, $n=11,898$ ); and (5) Physicianprovided CAM (MDCAM, $\mathrm{n}=86$ ). For all comparisons, alpha was set at $\mathrm{p}=.05$ unless otherwise specified.

Most notably, MDCAM and BOTH differed on only one measure, Total Number of Prescriptions. These two groups were not different for any of the remaining population characteristics, measures of health status, nor measures of geographic distribution. Upon inspection, the ranges for the number of prescription medicines proved to be interesting. For the MDCAM group the maximum was 80 , with the second largest number of prescriptions being 56 . The Both group had a maximum of 213 prescription medications, with the second highest value being 146 meds. The medians for all five groups were: $\mathrm{MDCAM}=17.36$, Both=6, Conventional $=4, C A M=0$ and None $=0$. The interquartile range for all five groups 
Results

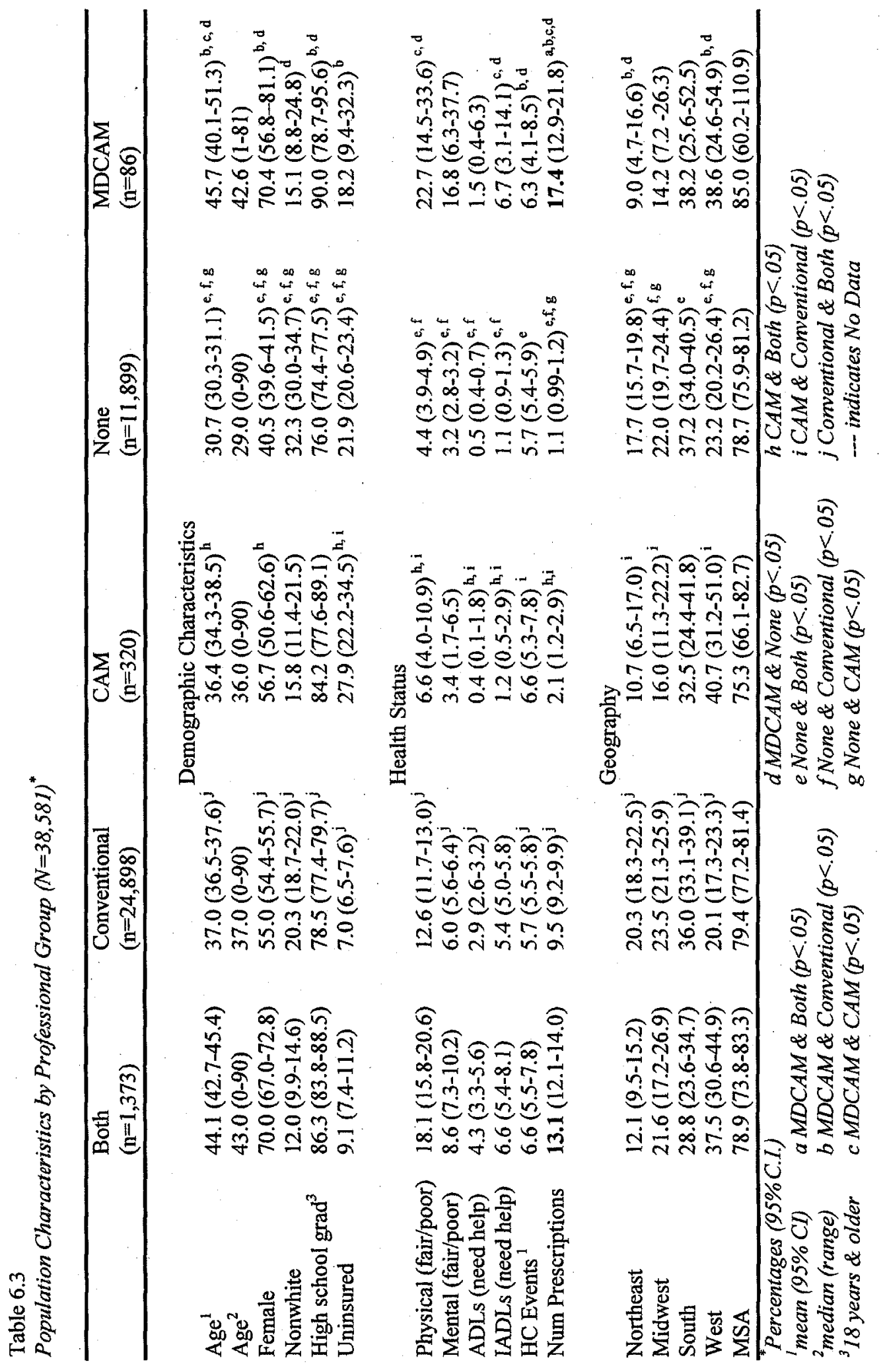


were: $\operatorname{MDCAM}=25$, Both $=14$, Conventional $=10, \mathrm{CAM}=1$ and None $=0$. The distributions of these groups values are illustrated in the box plots of Figure 6.1. Box plots present the medians, interquartile ranges and outliers for categories within a variable.

Figure 6.1 Box Plot of Number of Prescription Medications by Professional Group

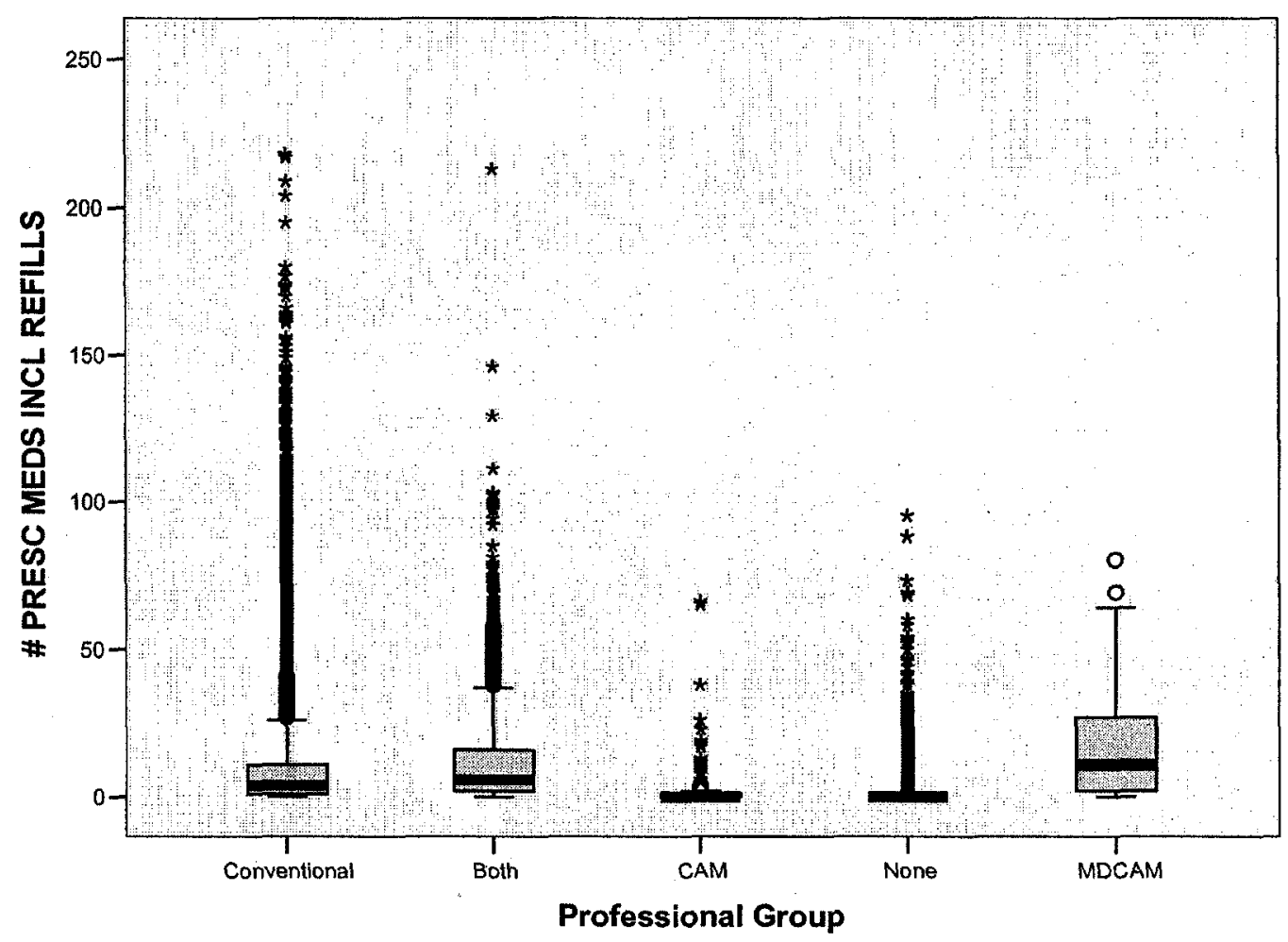

Because the average and median number of prescription medicines were highest in the MDCAM group, an additional analysis was conducted to investigate which diagnoses were associated with this level of prescription use. The range of 
Results

prescription medications was halved at GE 17 prescriptions. The upper half was examined for diagnoses $(n=28)$. The maximum number of diagnoses for a single respondent in the entire MEPS data set was 46. Each respondent in the MDCAM group had several diagnoses and the first two diagnoses were listed to determine the types of health challenges experienced by this group. This resulted in a list of 35 distinct disease categories and these are listed in Appendix 2. Because the MDCAM group tended to be less insured than other groups, this group was explored further for its insurance relationships. The variables Ever have Medicare, Ever have Medicaid and Ever have Champus were examined. When this group $(n=33)$ was binned into quartiles, the top quartile of prescription medication use was strongly associated with an attachment to at least one of these entitlements ( $29.6 \%$ of 27 chances). In fact, the two highest prescription counts were associated with Medicaid.

Comparing MDCAM and CONV, there were no differences in the percentage of respondents who were Nonwhite, in all measures of health status, nor the likelihood of living in the South, in the Midwest or in MSAs. The percentage of respondents receiving MDCAM compared to CONV were more likely to be older (Wald F=9.4, $\mathrm{p}=.002)$, female $\left(\mathrm{X}^{2}=7.89, \mathrm{p}=.022\right)$, uninsured $\left(\mathrm{X}^{2}=12.8, \mathrm{p}=.019\right)$, have at least a high school education $\left(X^{2}=6.58, p=.028\right)$, and be located in the West $\left(X^{2}=12.4, p=.004\right)$. Respondents receiving MDCAM were less likely than CONV to be located in the Northeast $\left(X^{2}=7.6, p=.002\right)$. MDCAM recipients had statistically significantly more health care events during the period $(t=-7.13, p>.0001)$. 
Comparing MDCAM to CAM Only, there were no differences in the percentage of respondents regarding the following: female; nonwhite; high school educated; uninsured; need help with ADLs; geographic distribution; and average number of health care events. The percentage of respondents receiving MDCAM compared to CAM Only were more likely to be older (Wald $F=9.24, p=.003$ ), to have poor Self-Rated Physical Health $\left(X^{2}=9.95, p=.002\right)$, and to need Help with IADLs $\left(X^{2}=6.01, p=.004\right)$.

Comparing MDCAM to respondents who used no professional services (NONE), there were no differences in the percentage of respondents regarding the following: Uninsured; Self-Rated Mental Health; need for Help with IADLs; and likelihood of living in the Midwest, South or within MSAs. MDCAM recipients were more likely to be Older (Wald $F=27.8, p<.0001$ ), Female $\left(X^{2}=30.92, p<.0001\right.$ ), High School Educated $\left(X^{2}=9.52, p=.01\right)$, have poor Self-Rated Physical Health $\left(X^{2}=18.1\right.$, $\mathrm{p}<.0001)$, need Help with IADLs $\left(\mathrm{X}^{2}=11.14, \mathrm{p}=.001\right)$ and live in the West $\left(\mathrm{X}^{2}=10.1\right.$, $p=.022)$. MDCAM recipients were less likely to be Nonwhite $\left(X^{2}=13.13, p<.0001\right)$ and to live in the Northeast $\left(\mathrm{X}^{2}=5.2, \mathrm{p}=.013\right)$. MDCAM recipients had statistically significantly more Health Care Events during the period $(t=-4.47, p<.0001)$.

Comparing NONE to BOTH, respondents who did not use any professional health services were statistically significantly Younger (Wald $F=354.01, p<.0001$ ), less likely to be Female $\left(\mathrm{X}^{2}=426.5, \mathrm{p}<.0001\right)$, less likely to have a High School Education $\left(X^{2}=66.0, p<.0001\right)$ and less likely to live in the West $\left(X^{2}=121.4\right.$, 
Results

$p<.0001)$. They were not different in their percentages of those who that lived in the Midwest nor in MSAs. Those respondents who consumed no professional services were statistically more likely to be Nonwhite $\left(X^{2}=277.45, p<.0001\right)$, Uninsured $\left(X^{2}=166.06, p<.0001\right)$ and healthier by all measures: Physical $\left(X^{2}=171.8, p<.0001\right)$; Mental $\left(X^{2}=45.18, p<.0001\right)$; ADLs $\left(X^{2}=115.53, p<.0001\right)$; IADLs $\left(X^{2}=138.45\right.$, $\mathrm{p}<.0001)$; and number of Health Care Events $(\mathrm{t}=-\mathbf{7} .14 . \mathrm{p}<.0001)$.

Comparing NONE to CONV, respondents who did not use any professional health services were Younger (Wald $F=371.7, p<.0001$ ), less likely to be Female $\left(X^{2}=651.69, p<.0001\right)$, less likely to have a High School Education $\left(X^{2}=19.8\right.$, $\mathrm{p}<.0001)$ and less likely to live in the Northeast $\left(\mathrm{X}^{2}=35.04, \mathrm{p}<.0001\right)$, or the Midwest $\left(X^{2}=10.64, p=.015\right)$. They were not different in the percentages of those who lived in the South or in MSAs, nor in the average number of Health Care Events. Those respondents who consumed no professional services were more likely to be Nonwhite $\left(X^{2}=591.16, p<.0001\right)$, Uninsured $\left(X^{2}=1,539.85, p<.0001\right)$, healthier by all measures: Physical $\left(X^{2}=285.64, p<.0001\right) ;$ Mental $\left(X^{2}=76.6, p<.0001\right) ; \operatorname{ADLs}\left(X^{2}=246.45\right.$, $\mathrm{p}<.0001)$; IADLs $\left(\mathrm{X}^{2}=440.14, \mathrm{p}<.0001\right)$; and living in the West $\left(\mathrm{X}^{2}=43.69, \mathrm{p}<.0001\right)$.

Comparing NONE to CAM Only, there were no differences by health status, nor by the percentages of respondents who lived in the South or within MSAs. Respondents who did not use any professional health services were Younger (Wald $\mathrm{F}=27.1, \mathrm{p}<.0001)$, less likely to be Female $\left(\mathrm{X}^{2}=33.57, \mathrm{p}<.0001\right)$, less likely to have a High School Education $\left(X^{2}=10.4, p=.014\right)$ and to be Uninsured $\left(X^{2}=10.77, p=.048\right)$. 
Results

They were less likely to live in the West $\left(\mathrm{X}^{2}=47.8, \mathrm{p}<.0001\right)$. They were more likely to be Nonwhite $\left(X^{2}=45.24, p<.0001\right)$ and to live in the Northeast $\left(X^{2}=12.01, p=.022\right)$ and Midwest $\left(X^{2}=6.997, p=.049\right)$.

Comparing respondents who received CAM Only professional services to BOTH, there were no differences in percentages of Nonwhite, Education level, nor in percentages of those living in the Northeast, West or South. CAM Only recipients were Younger (Wald $F=43.6, p<.0001)$, less likely to be Female $\left(X^{2}=17.76, p<.0001\right)$ and healthier by all measures: Physical $\left(X^{2}=21.57, p<.0001\right)$; Mental $\left(X^{2}=12.76\right.$, $\mathrm{p}<.0001) ; \operatorname{ADLs}\left(\mathrm{X}^{2}=14.98, \mathrm{p}<.0001\right)$; IADLs $\left(\mathrm{X}^{2}=17.14, \mathrm{p}<.0001\right)$, with one exception. These two groups had the same average number of Health Care Events. CAM Only recipients were more likely to be Uninsured $\left(X^{2}=62.4, p<.0001\right)$ and less likely to live in the Midwest $\left(X^{2}=4.59, p=.026\right)$.

Comparing CAM Only to Conventional Only, there were no differences in Age, Gender, Race, Education, or likelihood of living in the South or within an MSA. CAM Only recipients were more likely to be Uninsured $\left(X^{2}=126.44, p<.0001\right)$ and to live in the West $\left(\mathrm{X}^{2}=65.98, \mathrm{p}<.0001\right)$. They were healthier by all counts: Physical $\left(X^{2}=10.6, p=.004\right) ; \operatorname{Mental}\left(X^{2}=8.78, p=.046\right) ;$ ADLs $\left(X^{2}=10.1, p<.0001\right) ;$ IADLs $\left(X^{2}=14.33, p<.0001\right)$, and they were less likely to live in the Northeast $\left(X^{2}=21.1\right.$, $\mathrm{p}=.002)$ and Midwest $\left(\mathrm{X}^{2}=10.14, \mathrm{p}=.011\right)$. CAM Only recipients had statistically significantly more Health Care Events during the period $(t=-9.96, p<.0001)$. 
Results

Finally, comparing CONV to respondents who consumed BOTH, there were no differences in the need for Help with IADLs, or in the likelihood of living in the Midwest or within MSAs. Respondents who used conventional services only were Younger (Wald $F=98.7, p<.0001)$, less likely to be Female $\left(X^{2}=119.7, p<.0001\right)$, High School Educated $\left(X^{2}=45.1, p<.0001\right)$ and Uninsured $\left(X^{2}=28.6, p<.0001\right)$. They were healthier as measured by Self-Rated Physical $\left(X^{2}=24.4, p<.0001\right)$ and Mental Health $\left(X^{2}=7.59, p=.003\right)$, with less need for Help with ADLs $\left(X^{2}=7.9, p=\right.$ $.009)$, and they had on average fewer Health Care Events for the year $(t=-10.76$, $p<.0001)$. They were more likely to be Nonwhite $\left(X^{2}=61.1, p<.0001\right)$. Users of conventional services only were more likely to live in the Northeast $\left(\mathrm{X}^{2}=61.2\right.$, $p<.0001)$ and South $\left(X^{2}=29.7, p<.004\right)$ and less likely to live in the West $\left(X^{2}=202.6\right.$, $p<.0001)$ 
Results

\section{CAM Utilization}

Table 6.4 Type of Unconventional Therapies among Users of CAM $(N=1,516)$

\begin{tabular}{|c|c|c|c|}
\hline & $\begin{array}{l}\text { Both } \\
(n=1,373) \\
\end{array}$ & $\begin{array}{l}\text { CAM Only } \\
(\mathrm{n}=320)\end{array}$ & $\begin{array}{l}\text { MDCAM } \\
(\mathrm{n}=86)\end{array}$ \\
\hline & \multicolumn{3}{|c|}{ Use of Practitioner-Based CAM } \\
\hline Acupuncture & $9.7(7.7-12.2)$ & $6.1(3.4-10.7)$ & $5.6(2.2-13.1)$ \\
\hline Massage & $34.5(30.4-38.8)$ & $31.2(24.9-38.3)$ & $20.2(11.9-31.2)^{3}$ \\
\hline Herbal & $29.9(26.7-33.4)$ & $33.4(24.1-44.2)$ & $35.3(21.4-52.2)$ \\
\hline Biofeedback & $2.0(1.3-3.2)$ & $0.2(0.0-1.4)^{2}$ & $10.9(4.8-23.0)^{4,6}$ \\
\hline Meditation & $8.4(6.3-11.2)$ & $10.4(4.9-20.5)$ & $16.8(9.2-28.6)^{3}$ \\
\hline Homeopathy & $9.4(7.2-12.1)$ & $12.4(7.6-19.5)$ & $6.2(2.2-16.3)$ \\
\hline Spiritual & $22.9(19.9-26.3)$ & $36.2(28.4-44.7)^{2}$ & $20.7(12.0-33.4)^{5}$ \\
\hline Hypnosis & $1.3(0.7-2.5)$ & -...- & $2.1(0.3-13.2)$ \\
\hline Traditional & $5.1(3.7-6.9)$ & $7.4(4.0-13.3)$ & $8.8(3.9-18.8)$ \\
\hline Nutritional & $21.1(18.6-23.9)$ & $17.9(12.1-25.5)$ & $74.2(62.5-83.2)^{4.6}$ \\
\hline \multirow[t]{2}{*}{ Other } & $26.1(23.1-29.4)$ & $28.9(21.2-38.1)$ & $10.6(4.5-23.1)^{4.6}$ \\
\hline & \multicolumn{3}{|c|}{ Physician Involvement in CAM } \\
\hline Physician referred & $13.7(11.5-16.1)$ & $6.5(3.8-10.7)^{2}$ & \\
\hline Physician aware & $34.2(31.2-37.4)$ & $12.5(7.9-19.3)^{2}$ & \\
\hline
\end{tabular}

Note: Values are percentage $\left(95 \%\right.$ C.I.), tested by Likelihood ratio $\mathrm{X}^{2}$

${ }^{I}$ Comparison between Both \& CAM $(p<.05)$

${ }^{2}$ Comparison between Both \& CAM $(p<.01)$

${ }^{3}$ Comparison between Both \& MDCAM $(p<.05)$

${ }^{4}$ Comparison between Both \& MDCAM $(p<.01)$

${ }^{5}$ Comparison between CAMonly \& MDCAM $(p<.05)$

${ }^{6}$ Comparison between CAMonly \& MDCAM $(p<.01)$

Addressing Hypothesis 2, subpopulations of respondents are compared for patterns of CAM utilization. Table 6.4 compares the use of unconventional therapies by three mutually-exclusive subpopulations: users of CAM services only (CAM Only, $\mathrm{n}=320$ ), users of both CAM and Conventional services (BOTH, $\mathrm{n}=1,373$ ) and users of CAM from allopathic physicians (MDCAM, $n=86$ ). These groups did not differ with 
respect to consumption of Acupuncture, Herbal Therapies, Homeopathy, and Traditional Medicines.

MDCAM differed from BOTH with respect to Massage $\left(X^{2}=7.6, p=.014\right)$ and Other CAM Therapies $\left(\mathrm{X}^{2}=11.45, \mathrm{p}=.007\right)$, with MDCAM using less in both cases. MDCAM differed from Biofeedback $\left(X^{2}=16.72, p<.0001\right)$, Meditation $\left(X^{2}=5.8\right.$, $\mathrm{p}=.044)$, and Nutritional Therapies $\left(\mathrm{X}^{2}=101.7, \mathrm{p}<.0001\right)$ with MDCAM using more in all three cases.

MDCAM differed from CAM Only in Spiritual Healing $\left(X^{2}=21.8, p<.0001\right)$ and Other CAM $\left(\mathrm{X}^{2}=12.4, \mathrm{p}=.006\right)$ therapies, with MDCAM being less prevalent. MDCAM also differed from Biofeedback $\left(\mathrm{X}^{2}=21.8, \mathrm{p}<.0001\right)$ and Nutritional Therapies $\left(\mathrm{X}^{2}=86.2, \mathrm{p}<.0001\right)$, with MDCAM being more prevalent.

Comparisons between BOTH and CAM Only services illuminated few differences. Chiropractic services $\left(X^{2}=5.57, p=.023\right)$ and Biofeedback services $\left(X^{2}=6.83, p=.001\right)$ were less prevalent among CAM Only users. Spiritual Healing $\left(X^{2}=20.1, p=.001\right)$ was more prevalent among CAM Only users.

Two groups were also compared for the degree of physician involvement in CAM consumption. The subpopulation receiving BOTH compared to CAM Only was statistically significantly more likely to report that a physician was aware $\left(\mathrm{X}^{2}=81.6\right.$, $\mathrm{p}<.0001$ ) of their CAM utilization as well as having referred them to CAM providers $\left(X^{2}=13.1, p=.004\right)$ 
Table 6.5 Type of Unconventional Therapies Among High and Low Users of Conventional Services Compared to MDCAM: Subpopulation of CAM Users

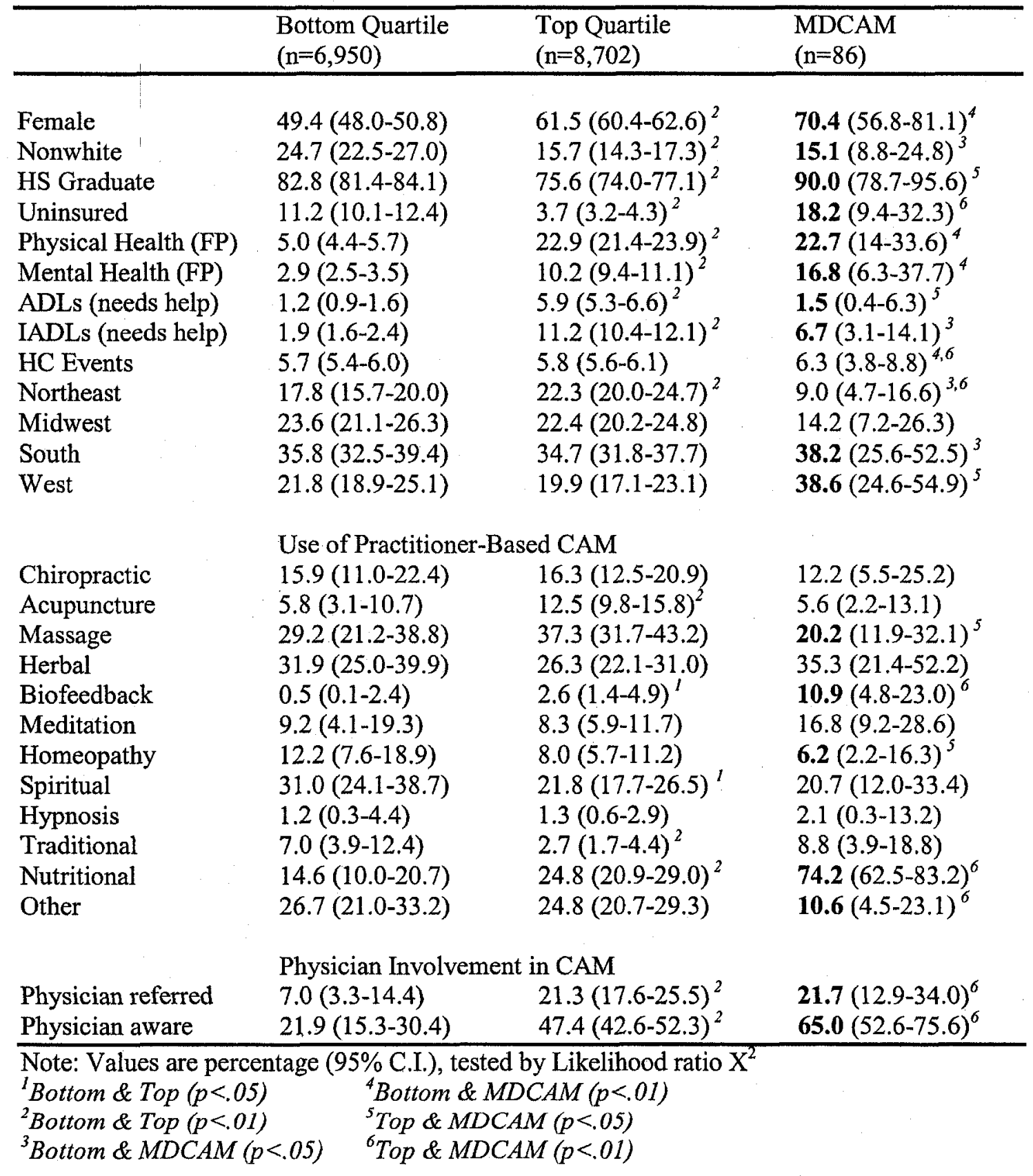


Results

Addressing Hypothesis 3, again profiles are compared, however this analysis examines whether MDCAM uses health care resources frequently or infrequently. Table 6.5 compares subpopulations of respondents grouped by their frequency of conventional health care consumption. The frequency of health care consumption was divided into quartiles. The top quartile (6 or more visits) and bottom quartile (one visit) were compared for demographic measures, use of CAM therapies and physician involvement in their CAM consumption. Both of these groups were compared to the subpopulation MDCAM. This analysis was limited to those who visited a mainstream health care provider at least once.

Comparing the bottom and top quartiles of $\mathrm{HC}$ consumption for demographic patterns lays the groundwork for additional comparisons to the group of interest, MDCAM. There are many differences by utilization pattern. The top quartile of health care consumers had a statistically significantly higher percentage of Females, and a statistically significantly lower percentage of Nonwhites, High School Graduates and Uninsured persons. Statistically significant differences were found in all measures of health status with respondents in the top quartile of utilization more often reporting poor Self-Rated Health, poor Self-Rated Mental Health, and a need for Help with both ADLs and IADLs. When comparing the estimates across geographic regions, there were generally no differences in the percentages represented in the bottom and top quartiles, with one exception. In the Northeast Region, there were statistically significantly fewer respondents in the bottom quartile. By design, the 
Results

quartiles are equivalent proportions of the overall population, so this finding is curious. By inspection, we see that a relatively large proportion of the bottom quartile comes from the South region, but this is not statistically significantly different from the proportion in the top quartile.

Comparisons for CAM therapies are, of course, limited to those who used CAM. Continuing with the comparisons of the bottom and top quartiles, a plurality of the CAM therapies exhibited greater patronage by the respondents in the top quartile of health care utilization. However, this was not a simple pattern. The respondents in the top quartile consumed statistically significantly more Acupuncture $\left(X^{2}=7.9, p=.01\right)$ Biofeedback $\left(X^{2}=4.3, p=.017\right)$, and Nutritional Advice $\left(X^{2}=9.8, p=.004\right)$. They consumed statistically significantly less Spiritual Healing $\left(X^{2}=6.76, p=.21\right)$ and Traditional Medicine $\left(\mathrm{X}^{2}=6.7, \mathrm{p}=.008\right)$. There were no differences between the top and bottom quartiles with respect to Chiropractic services, Massage, Herbal Remedies, Meditation, Homeopathy, Hypnosis or "Other" nonspecified CAM therapies.

Finally, regarding physician involvement in CAM, all measures exhibited statistically significant differences across quartile groups. Among the respondents in the top quartile of health care utilization, physicians were reported to have discussed CAM with their patients $\left(\mathrm{X}^{2}=71.3, \mathrm{p}<.0001\right)$, to have referred patients for CAM therapies $\left(\mathrm{X}^{2}=26.5, \mathrm{p}<.0001\right)$ and to have provided CAM therapies directly to their patients $\left(\mathrm{X}^{2}=15.7, \mathrm{p}<.0001\right)$. 
Results

Moving to comparisons between those survey respondents who received CAM from their physicians (MDCAM) and the top and bottom quartiles of health care utilization, the first result of note is the absolute number of statistically significant differences that exist between these three groups. There were fewer differences between MDCAM and the bottom quartile ( $\mathrm{n}=7$ differences) than between the MDCAM group and the top quartile ( $\mathrm{n}=12$ differences). By this simple criterion, MDCAM seems to hold more in common with those who consume less health care.

Comparing respondents who received MDCAM to those in the bottom quartile of health care utilization, we see no statistically significant differences in the use of practitioner-based CAM therapies, nor in the level of physician involvement with CAM consumption. Differences were exhibited among demographics, health status and geographic variables. MDCAM had a statistically significantly higher percentage of Females $\left(X^{2}=15.05, p=002\right)$, respondents with poor Self-Rated Health $\left(X^{2}=12.5\right.$, $\mathrm{p}<.0001)$, and respondents who needed Help with their IADLs $\left(X^{2}=5.9, p=.011\right)$. The MDCAM group was statistically significantly less likely to be Nonwhite $\left(X^{2}=4.59\right.$, $\mathrm{p}=.031)$. There were no differences relative to Education, Insurance status, Mental Health status, nor the ability to execute their ADLs. The MDCAM group was less likely to live in the Northeast $\left(\mathrm{X}^{2}=5.29, \mathrm{p}=.012\right)$, and more likely to live in the West $\left(\mathrm{X}^{2}=12.25, \mathrm{p}=.01\right)$. There were no differences between the MDCAM group and the bottom quartile respondents in their distributions in the Midwest or the South. 
Results

Comparing respondents who received MDCAM to those in the top quartile of health care utilization, we see several differences. However, there were no differences in Gender or Race proportions. The percentage of MDCAM respondents with a High School or greater level of education was statistically significantly higher than the top quartile group $\left(X^{2}=8.24, p=.014\right)$, and the MDCAM group was the most educated of all three groups. Insurance status also differed, with the MDCAM group being more Uninsured $\left(\mathrm{X}^{2}=20.04, \mathrm{p}=.002\right)$ than the top quartile group. MDCAM was the most uninsured group of the three. There were no differences in Physical and Mental Health ratings, nor the perceived need for Help with IADLs between the MDCAM group and those in the top quartile of health care utilization. Further, the MDCAM group was statistically significantly less likely to need Help with ADLs $\left(X^{2}=3.09\right.$, $\mathrm{p}=.032$ ). Regarding geography, the MDCAM group had a much smaller representation in the Northeast region $\left(\mathrm{X}^{2}=7.996, \mathrm{p}=.001\right)$, and this was the smallest percentage of all three groups across all four regions (range 9\%-38.6\%).

Comparing MDCAM to those in the top quartile of health care utilization regarding CAM therapy consumption, we also see several differences. The MDCAM group was statistically significantly more likely to consume Biofeedback $\left(\mathrm{X}^{2}=14.8\right.$, $\mathrm{p}=.001)$, and Nutritional Advice $\left(\mathrm{X}^{2}=98.6, \mathrm{p}<.0001\right)$, and statistically significantly less likely to consume Massage $\left(X^{2}=7.8, p=.016\right)$, Homeopathy $\left(X^{2}=4.94, p=.015\right)$, and "Other" non specified CAM therapies $\left(\mathrm{X}^{2}=10.15, \mathrm{p}=.011\right)$. There were no differences in consumption of Chiropractic care, Acupuncture, Herbal Remedies, Meditation, 
Results

Spiritual Healing, Hypnosis, or Traditional Medicine. The MDCAM group was statistically significantly more likely to have been Referred by a Physician $\left(X^{2}=22.05\right.$, $\mathrm{p}<.0001)$ and to report that their regular Physician was Aware that they were using CAM therapies $\left(X^{2}=67.3, p<.0001\right)$. 
Table 6.6 Type of Unconventional Therapies Among High and Low Users of Conventional Services Compared to MDCAM: Ranked Profile (N=15,737)*

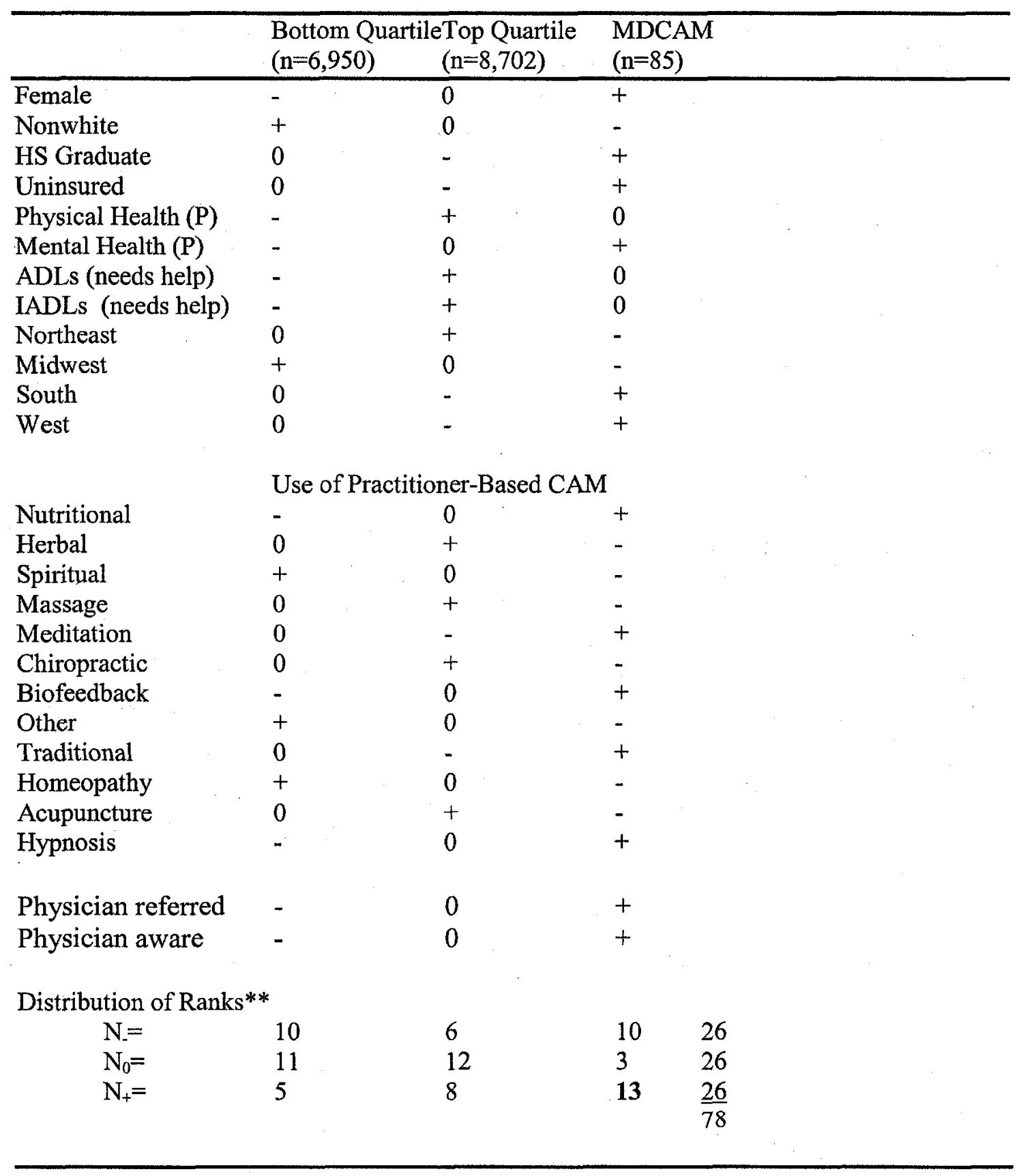

$*$ Ranks reflect population proportions; $+=$ largest, $0=$ intermediate, $-=$ smallest

** Likelihood ratio $\mathrm{X}^{2}=11.76, \mathrm{df}=4, \mathrm{p}=.019$ 
Addressing Hypothesis 3, again profiles are compared in an effort to determine the distinctiveness of subpopulations by aggregating evidence. As Table 6.6 illustrates, the patterns of differences across quartiles are more readily appreciable when percentages are coded as ordinal measures. Again, the subpopulation under analysis is CAM users, limited to the top and bottom quartiles of mainstream health care utilization. This nonparametric, data reduction analysis creates profiles by ranking the population distributions for each variable, and follows the logic of the Wilcoxon Summed-Ranks Test. This approach imposes a difference structure on the data and explores whether any distinctive subgroups patterns exist within the combination of variables: demographics; practitioner-based CAM therapies; and physician awareness. The symbols $(+, 0,-)$ are used to indicate the largest proportions in the row, the intermediate sized proportions, and the smallest proportions, respectively. A measure of the overall profile is produced by summing the count within each rank. The group with the greatest number of $(+)$ signs represents a polarized group with a positive "valence". The groups with the greatest number of $(-)$ signs represents a group with the opposite valence. The expected value for cells, in this 3 by 26 analysis, is 8.7 , under the null hypothesis. The distribution of ranks was nonrandom (Likelihood ratio $X^{2}=11.76, d f=4, p=.019$ ).

From this analytical approach, we see that the MDCAM had the greatest number of $(+)$ signs as a group $(n=13$ variables $)$ and was more Female, Educated, Uninsured, Mentally Unhealthy, lived in the South and West, consumed Nutritional 
Therapies, Meditation, Biofeedback, Traditional Therapies and Hypnosis. Not surprisingly, this group had more Physician Involvement in the form of Referrals and overall Awareness.

The group with the greatest number of $(0)$ signs represents an intermediate position in these three groups. This was the top quartile group. It exhibited an intermediate level of Gender, Race, Mental Health, and living in the Midwest. It had intermediate levels of CAM consumption for these modalities: Nutrition, Spiritual, Biofeedback, Other, Homeopathy and Hypnosis. It also had intermediate levels of Physician Involvement in both measures.

The group with the greatest number of $(-)$ signs was the bottom quartile of mainstream health care utilization. It is characterized by Male Gender, Nonwhite, less frequently poor Physical and Mental Self-Rated Health, and less need for Help with ADLs and IADLs. This group had low consumption of Nutritional Therapies, Biofeedback, and Hypnosis, and the lowest level of Physician Awareness. 
Table 6.7 Mainstream Health Care Utilization by Specific CAM Modality, Controlling for Population Characteristics*

$\frac{\text { All CAM Users }}{\text { Mean } \mathrm{R}^{2} \quad \mathrm{~N}_{1}}$
$\begin{aligned} & \text { \# Visits } \\ & \text { \#ean } \mathrm{R}^{2}\end{aligned}$

$\begin{array}{lllllll}\text { Hypnosis } & 16.28 & - & 19 & 76.00 & -- & 2 \\ \text { Biofeedback } & 12.60 & .973 & 29 & 18.74 & -- & 9 \\ \text { Acupuncture } & 10.87 & .338 & 141 & 10.71 & -- & 5 \\ \text { Other Alt } & 10.38 & .334 & 122 & 9.00 & - & 1 \\ \text { Nutritional } & 9.91 & .226 & 305 & 10.91 & 0.43 & 63 \\ \text { Chiropractic } & 9.63 & .200 & 205 & 16.61 & -- & 11 \\ \text { Meditation } & 9.19 & .325 & 121 & 19.66 & -- & 14 \\ \text { Massage } & 8.16 & .180 & 500 & 13.90 & -- & 17 \\ \text { Homeopathy } & 7.53 & .379 & 136 & 5.97 & -- & 4 \\ \text { Herbal } & 7.30 & .206 & 434 & 11.57 & 0.32 & 30 \\ \text { Spiritual } & 6.46 & .278 & 332 & 10.02 & -- & 18 \\ \text { Traditional } & 4.99 & .575 & 73 & 5.86 & -- & 8\end{array}$

* Controlling for Age, Sex, Race, Education, Insurance Coverage, Region, and SelfRated Physical Health

-- Indicates insufficient sample size for multivariate modeling

Addressing Hypothesis 4, Table 6.7 compares the mainstream health care utilization for the All CAM Users compared to MDCAM users; within subpopulations defined by each CAM therapy. This analysis is conceptually guided by Druss and Rosenheck (1999: Table 5) and examines whether mainstream health care use is associated with specific CAM therapies. Where the sample size was sufficient, the average number of mainstream health care visits was calculated by Least Significant Difference regression, adjusting for sampling design. Otherwise, a simple average was calculated, also with adjustment for complex sample design. The regression model solved for total number of mainstream health care visits controlling for Age, 
Results

Sex, Race, Education, Insurance Coverage, Region of the country and level of SelfRated Physical Health. The model performed well according to the range of $\mathrm{R}^{2}$ values (.18 to .97). The $\mathrm{R}^{2}$ value reflects the proportion of explainable variation accounted for by the model. The range reflects that the control variables contribute meaningfully to the variation in the Average Number of Visits to Mainstream Care.

For comparison, it is interesting to note that within the All CAM Users, the average number of visits was $4.86\left(n=24,829 ; R^{2}=0.119\right)$. When subdivided by specific CAM therapy, the range in the number of $\mathrm{HC}$ visits was 11.29 visits (4.99 to 16.28). Within the subpopulation of MDCAM, the range was 70.14 (5.86 to 76$)$. In general, the MDCAM group had more mainstream health care visits. Within the All CAM Users group, the range in the number of visits to conventional HC services was high in the Hypnosis subpopulation (mean \# of visits = 16.28) and low in the Traditional Medicines subpopulation (mean \# of visits $=4.99$ ). Within the MDCAM group, the highest level of mainstream health care consumption was exhibited by the Hypnosis subpopulation (mean \# of visits $=76$ ) and low in the Traditional Therapy subpopulation (mean \# of visits $=5.97$ ). The Hypnosis group should be taken as an outlier, as it reflects a single respondent (weighting generates a population estimate of 2 people). Similarly, the value for Other Alternative Therapies reflects only one respondent. When Hypnosis is dropped, the range is 12.88 (5.86 to 18.74), indicating that the MDCAM group consumes more health care, as measured by number of visits. 
Results

Table 6.8 Mainstream Health Care Utilization by Specific CAM Profession, Controlling for Population Characteristics*

\begin{tabular}{ll}
\multicolumn{2}{c}{ All CAM Users } \\
$\begin{array}{l}\text { Mean R } \mathrm{R}^{2} \\
\text { \# Visits }\end{array}$ & $\begin{array}{l}\text { Mean } \mathrm{R}^{2} \\
\text { \# Visits }\end{array}$
\end{tabular}

\begin{tabular}{|c|c|c|c|c|c|}
\hline Acupuncturist & 10.44 & .421 & 121 & 7.84 & -- \\
\hline Chiropractor & 9.63 & .200 & 205 & 16.61 & -- \\
\hline Nurse & 8.67 & -- & 28 & 10.85 & -- \\
\hline $\begin{array}{l}\text { Homeopathic or } \\
\text { Naturopathic Docto }\end{array}$ & 8.55 & .468 & 102 & 4 & -- \\
\hline Other Professional & 8.30 & .251 & 379 & 10.26 & -- \\
\hline LMT & 7.83 & .209 & 456 & 13.07 & -- \\
\hline Herbalist & 6.92 & .273 & 176 & 37.04 & -- \\
\hline Clergy, Spiritualist & 6.65 & .265 & 253 & 12.12 & -- \\
\hline
\end{tabular}

or Channeler

* Controlling for Age, Sex, Race, Education, Insurance Coverage, Region, and SelfRated Physical Health

-- Indicates insufficient sample size for multivariate modeling

Addressing Hypothesis 5, Table 6.8 compares the mainstream health care utilization for the All CAM Users group compared to MDCAM users; within subpopulations defined by each CAM Profession. This analysis examine whether mainstream health care use is associated with specific CAM Professionals. The average number of Conventional health care visits was calculated by Least Significant Difference regression, adjusting for sampling design. The model solved for total number of mainstream health care visits accounting for Age, Sex, Race, Education, Insurance Coverage, Region of the country and level of Self-Rated Physical Health. The control variables accounted for a range of $R^{2}$ values, all indicating a good fit of 
Results

the model (.20 to .47$)$. Among all survey respondents, the average number of visits, controlling for confounders, was $4.86\left(n=24,829 ; R^{2}=0.119\right)$. When identified by CAM Professional visits, respondents exhibited different levels of mainstream health service utilization, and the MDCAM group tends towards more visits. The range in the average number of visits for mainstream $\mathrm{HC}$ services, listed in Table 6.8, was high among those who visited Acupuncturists (mean \# of visits = 10.44) and low among those who visited Clergy, Spiritual Healers, or Channelers (mean \# of visits $=6.65$ ), for a range of 3.79. Within the MDCAM population, the range was 33.04. The highest average number of mainstream $\mathrm{HC}$ visits was associate with MDCAM respondents who also visited Herbalists, at 37.04 visits. The lowest number came from a single respondent who also visited either a Homeopathic or Naturopathic Physician four times. 
Results

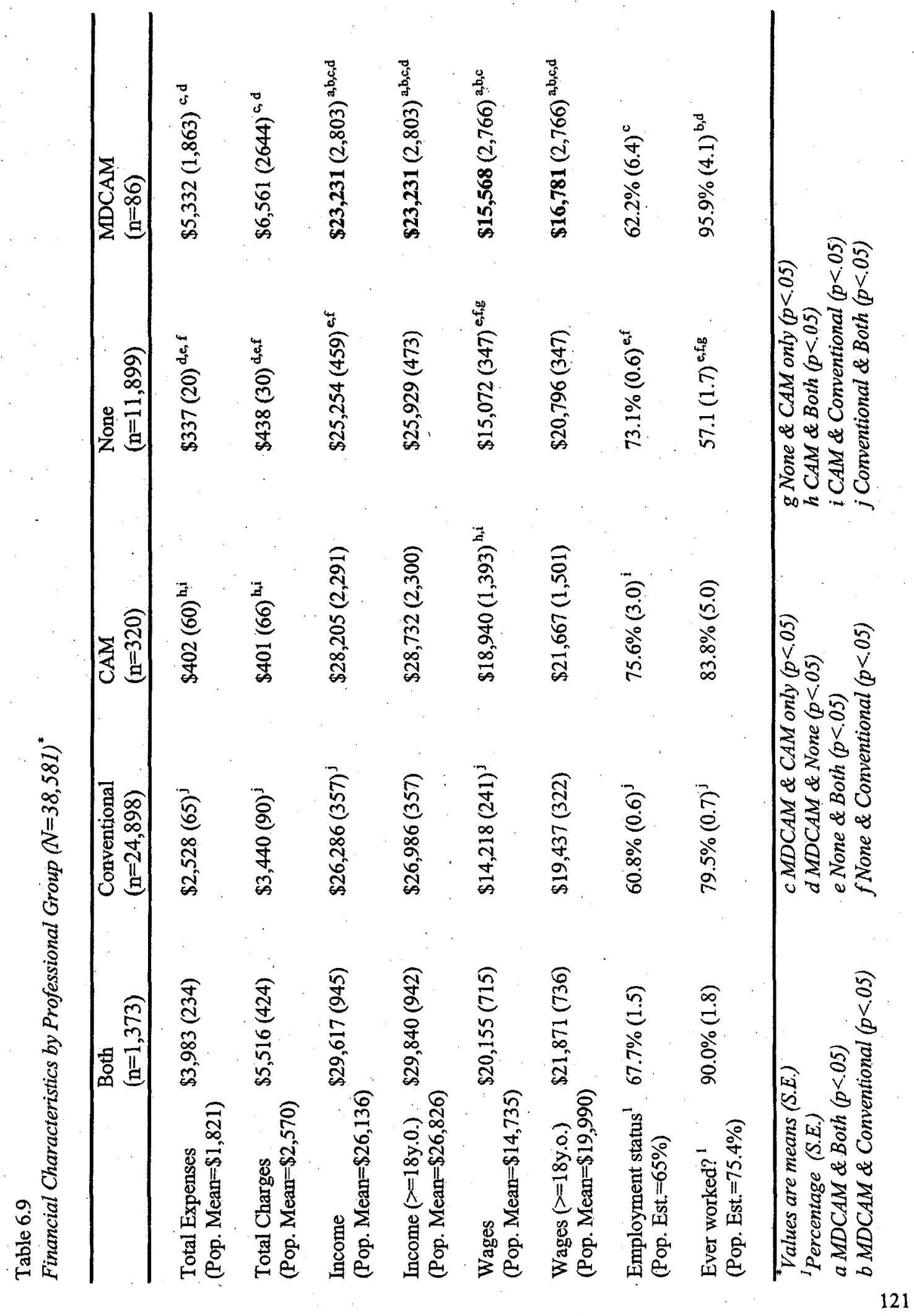


Results

Addressing Hypothesis 6, Table 6.9 compares the five mutually-exclusive professional groups by a set of financial variables to determine if MDCAM is distinctive. Total expenditures (mean $\$ 1,892.54$ [SE \$44.25]) includes the sum of direct payments for care provided during the year, including out-of-pocket payments and payments by private insurances, Medicare, Medicaid, and other sources.

Statistically significant differences were found for the following comparisons: BOTH to CONV (Wald F=37.07, $\mathrm{p}<.0001$ ). However, the groups BOTH and MDCAM were not different. The groups CONV and MDCAM were also not different.

Statistically significant differences were found for the following comparisons: CAM ONLY to MDCAM (Wald F=7.02, $\mathrm{p}=.009$ ); CAM ONLY to BOTH (Wald $\mathrm{F}=258.62, \mathrm{p}<.0001$ ); and CAM ONLY to CONV (Wald $\mathrm{F}=649.64, \mathrm{p}<.0001$ ).

Statistically significant differences were found for the following comparisons: NONE to MDCAM (Wald $F=7.19, \mathrm{p}=.008$ ); NONE to BOTH (Wald $\mathrm{F}=238.52$, $\mathrm{p}<.0001$ ); and NONE to CONV (Wald $\mathrm{F}=981.64, \mathrm{p}<.0001$ ). The groups NONE and CAM Only were not different. 
Table 6.10 Utilization Variables and CAM Use

\begin{tabular}{llll}
\hline & $\begin{array}{l}\text { Both } \\
(\mathrm{n}=1,273)\end{array}$ & $\begin{array}{l}\text { CAM Only } \\
(\mathrm{n}=303)\end{array}$ & $\begin{array}{l}\text { MDCAM } \\
(\mathrm{n}=73)\end{array}$ \\
\hline & & & \\
Total spent on CAM* & & & \\
& $(176.39-356.33)$ & $\begin{array}{l}\$ 148.43^{1} \\
(93-203.87)\end{array}$ & $\begin{array}{l}\$ 454.83^{5} \\
(199.54-710.12)\end{array}$ \\
Est \# CAM Visits* & 12.2 & $17.45^{2}$ & $9.6^{3.5}$ \\
& $(9.8-14.7)$ & $(10.6-24.3)$ & $(11.9-31.2)$ \\
Specific Problem** & $\begin{array}{l}64.5 \\
(60.9-68.0)\end{array}$ & $\begin{array}{l}46.7^{2} \\
(39.3-54.2)\end{array}$ & $\begin{array}{l}72.3^{6} \\
(59.3-82.4)\end{array}$ \\
\hline
\end{tabular}

* Values are Averages, tested by Independent Samples t-test

** Tested by Likelihood ratio Chi-Square

${ }^{I}$ Comparison between Both \& CAM $(p<.05)$

${ }^{2}$ Comparison between Both \& CAM $(p<.01)$

${ }^{3}$ Comparison between Both \& MDCAM $(p<.05)$

${ }^{4}$ Comparison between Both \& MDCAM $(p<.01)$

${ }^{5}$ Comparison between $C A M$ \& MDCAM $(p<.05)$

${ }^{6}$ Comparison between $C A M \& M D C A M(p<.01)$

\#Population size 203

Addressing Hypothesis 7, Table 6.10 presents utilization variables for three mutually-exclusive groups: those who consumed BOTH CAM and Conventional care; those who consumed CAM Only; and MDCAM. Total adjusted sample size for this subpopulation is $\mathrm{N}=1,778$.

The estimated Total Amount Spent on CAM for the entire population was \$253.05 (SE \$35.5). Regarding the Total Expenditures for CAM, the MDCAM groups spent statistically significantly more (\$454.83 [SE \$129.26]) than the CAM Only group, but not for the BOTH group. The CAM Only group had the smallest expenditures (\$148.43 [SE \$27.98]). 
Results

Regarding the utilization variable Estimated Number of CAM Visits, the average value for all groups was 15.81 (SE 2.68). The MDCAM group had

statistically significantly fewer visits than either of the other groups $\left(\mathrm{Mean}_{\mathrm{MDCAM}}=9.6\right.$ $\left.[\mathrm{SE} 1.41], \mathrm{Mean}_{\mathrm{BOTH}}=12.2[\mathrm{SE} 1.23], \mathrm{Mean}_{\mathrm{CAM} \text { only }}=17.45[\mathrm{SE} 3.38]\right)$. The CAM Only group had a statistically significantly greater Number of CAM visits than the BOTH group. Similarly, Number of Events with a Diagnosis and Treatment, Number of Provider Visits with a Diagnosis, and Number of Events with a General Checkup were all not statistically different between the MDCAM and BOTH groups (not shown in table).

\section{Multivariate Analyses}

Logistic regression analyses were performed to model group membership in two mutually-exclusive professional categories (ProfCAMGrp): use of BOTH conventional care and $\operatorname{CAM}(n=1,373)$; and $\operatorname{MDCAM}(n=86)$; weighted values. Multivariate modeling proceeds in two stages: modeling for financial differences between respondents; and modeling for CAM utilization differences. The analytical approach for modeling financial differences compares a base model (Model 1), drawn from Druss and Rosenheck (1999), to two elaborated models that include variables with statistically significant bivariate relationships to the DV (see Tables 6.8 \& 6.9). Table 6.11 presents a comparison between the base model and a model that includes the estimated Number of CAM Visits (ALTCVS). 
Table 6.11 Models of Professional Group Membership: Both or MDCAM

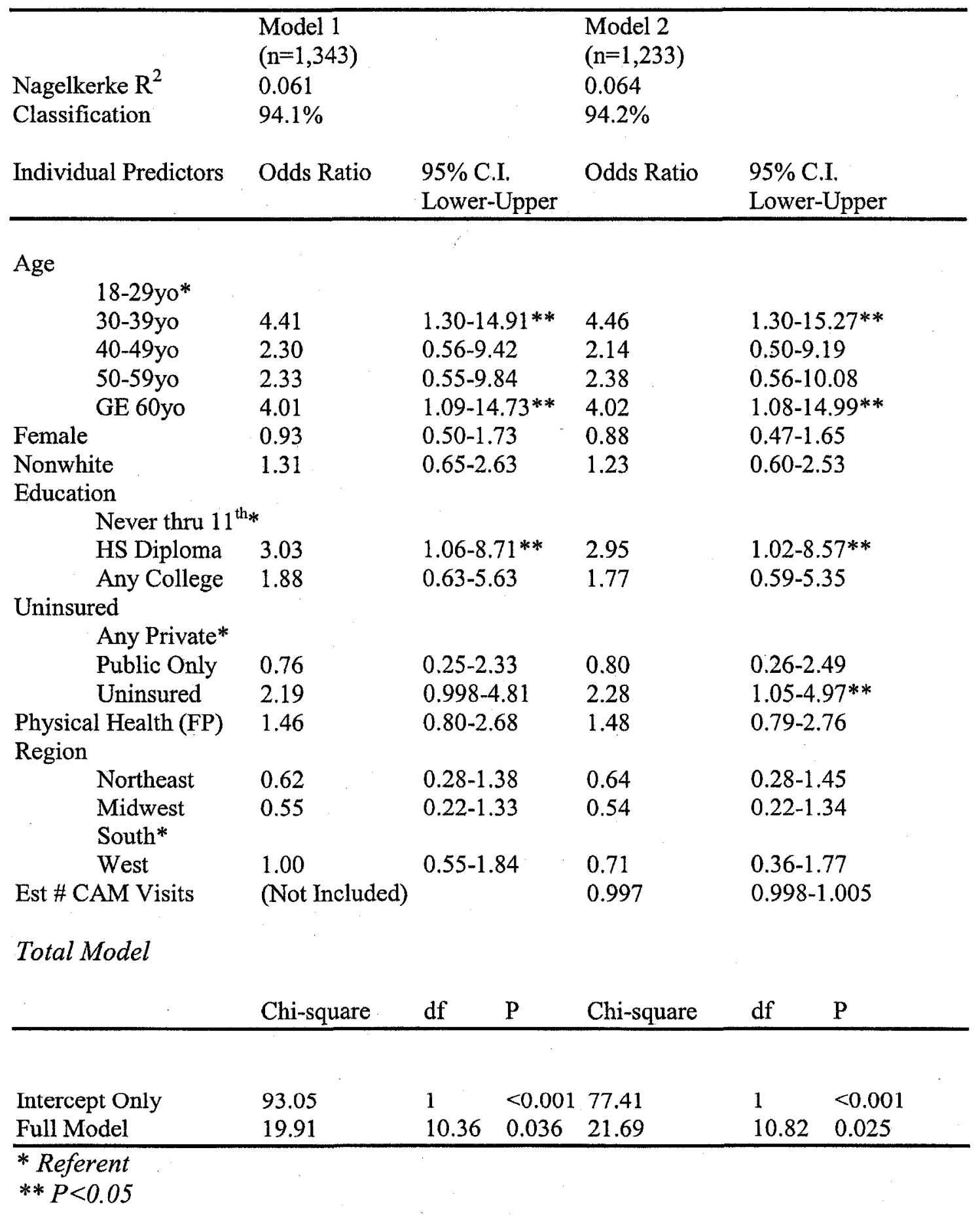


Results

The initial sample design for Model 1 included 1,168 unweighted cases.

Excluded from the analysis were the remaining 38,146 cases in the data set. The analysis was conducted in one stage, using 111 strata and 270 sampling units. The total degrees of freedom for this sampling design was 159 . The Nagelkerke $R^{2}$ for this model was .061 , indicating that the model accounted for about $6 \%$ of the variability in the dependent variable. This model accurately classified group membership in $94.1 \%$ of the cases. However, no variable in the model contributed independently to the explainable variation in the DV at a statistically significant level. Even so, the relation of the full model to the DV was statistically significant $\left(X^{2}=19.91, p=.036\right)$.

Model 2 adds the variable Number of Visits for CAM (ALTCVS). The initial sample design for Model 2 included $n=1,124$ unweighted cases, a difference from Model 1 of 44 cases (those with missing data on the variable ALTCVS, number of visits for CAM). Excluded from the analysis were the remaining 38,190 cases in the data set. The analysis was conducted in one stage, using 111 strata and 268 sampling units. The total degrees of freedom for this sampling design was 157. The Nagelkerke $\mathrm{R}^{2}$ for this model was .064 , indicating that the model accounted for about $6 \%$ of the variability in the dependent variable. This model accurately classified group membership in $94.2 \%$ of the cases. However, no variable in the model contributed independently to the explainable variation in the DV at statistically significant level. Even so, the relation of the full model to the DV was statistically significant $\left(X^{2}=21.69, p=.025\right)$. 
Results

Table 6.12 Models of Professional Group Membership: Both or MDCAM

\begin{tabular}{|c|c|c|c|c|c|c|}
\hline & $\begin{array}{l}\text { Model 1 } \\
(\mathrm{n}=1,343)\end{array}$ & & & $\begin{array}{l}\text { Model 3 } \\
(\mathrm{n}=1,233)\end{array}$ & & \\
\hline Nagelkerke $\mathrm{R}^{2}$ & 0.061 & & & 0.078 & & \\
\hline Classification & $94.1 \%$ & & & $94.1 \%$ & & \\
\hline Individual Predictors & Odds Ratio & \multicolumn{2}{|c|}{$\begin{array}{l}\text { 95\% C.I. } \\
\text { Lower-Upper }\end{array}$} & Odds Ratio & \multicolumn{2}{|c|}{$\begin{array}{l}\text { 95\% C.I. } \\
\text { Lower-Upper }\end{array}$} \\
\hline \multicolumn{7}{|l|}{ Age } \\
\hline \multicolumn{7}{|l|}{$18-29$ yo* } \\
\hline $30-39$ yo & 4.41 & \multicolumn{2}{|c|}{$1.30-14.91 * *$} & 5.03 & \multicolumn{2}{|c|}{$1.50-16.86^{* *}$} \\
\hline $40-49$ yo & 2.30 & \multicolumn{2}{|c|}{$0.56-9.42$} & 2.70 & \multicolumn{2}{|c|}{$0.63-11.60$} \\
\hline $50-59$ yo & 2.33 & \multicolumn{2}{|c|}{$0.55-9.84$} & 2.87 & \multicolumn{2}{|c|}{$0.69-11.92$} \\
\hline GE 60yo & 4.01 & \multicolumn{2}{|c|}{$1.09-14.73^{* *}$} & 4.03 & \multicolumn{2}{|c|}{$1.10-14.84^{* * *}$} \\
\hline Female & 0.93 & \multicolumn{2}{|c|}{$0.50-1.73$} & 0.96 & \multicolumn{2}{|c|}{$0.50-1.86$} \\
\hline Nonwhite & 1.31 & \multicolumn{2}{|c|}{$0.65-2.63$} & 1.20 & \multicolumn{2}{|c|}{$0.60-2.38$} \\
\hline \multirow{2}{*}{\multicolumn{7}{|c|}{$\begin{array}{l}\text { Education } \\
\text { Never thru } 11^{\text {th }} *\end{array}$}} \\
\hline & & & & & & \\
\hline HS Diploma & 3.03 & \multicolumn{2}{|c|}{$1.06-8.71 * *$} & 3.81 & \multicolumn{2}{|c|}{$1.20-12.14^{* *}$} \\
\hline Any College & 1.88 & \multicolumn{2}{|c|}{$0.63-5.63$} & 2.63 & \multicolumn{2}{|c|}{$0.76-8.78$} \\
\hline \multicolumn{7}{|l|}{ Insurance Coverage } \\
\hline Public Only & 0.76 & \multicolumn{2}{|c|}{$0.25-2.33$} & 0.63 & \multicolumn{2}{|c|}{$0.19-2.07$} \\
\hline Uninsured & 2.19 & \multicolumn{2}{|c|}{$0.998-4.81$} & 2.04 & \multicolumn{2}{|c|}{$0.90-4.63$} \\
\hline \multicolumn{3}{|l|}{ Region } & & & \multicolumn{2}{|c|}{$0.71-2.59$} \\
\hline Northeast & 0.62 & \multirow{2}{*}{\multicolumn{2}{|c|}{$\begin{array}{l}0.28-1.38 \\
0.22-1.33\end{array}$}} & 0.49 & \multicolumn{2}{|c|}{$0.23-1.05$} \\
\hline Midwest & 0.55 & & & 0.48 & $0.19-1$ & \\
\hline South* & & & & & & \\
\hline West & 1.00 & $0.55-1$ & & 0.98 & $0.55-1$ & \\
\hline Total Income & (Not Included) & & & 1.00 & $1.00-1$ & \\
\hline Total Model & & & & & & \\
\hline & Chi-square & $\mathrm{df}$ & $\mathrm{P}$ & Chi-square & $\mathrm{df}$ & $\mathrm{P}$ \\
\hline Intercept Only & 93.05 & 1 & $<0.001$ & 63.81 & 1 & $<0.001$ \\
\hline Full Model & 19.91 & 10.36 & 0.036 & 23.57 & 10.70 & 0.013 \\
\hline
\end{tabular}


Results

Table 6.12 compares Model 1 with Model 3, which includes the variable Total Income. The initial sample design for Model 3 includes 1,120 unweighted cases, a difference of 48 cases with missing income data. Excluded from the analysis were the remaining 38,194 cases in the data set. The analysis was conducted in one stage, using 111 strata and 269 sampling units. The total degrees of freedom for this sampling design was 158 . The Nagelkerke $\mathrm{R}^{2}$ for this model was .078 , indicating that the model accounted for about $8 \%$ of the variability in the dependent variable. This model accurately classified group membership in $94.1 \%$ of the cases. However, no variable in the model contributed independently to the explainable variation in the DV at a statistically significant level. Even so, the relation of the full model to the DV was statistically significant $\left(X^{2}=23.57, p=.013\right)$.

While Age had no statistically significant contribution to the explainable variation in the DV, as tested by Adjusted Wald Chi-Square, there were differences among age groups in Models 1, 2 and 3. The Age group 30-39 yrs. was 4.5 to 5 times more likely to be in the MDCAM group as compared to the 18-29 yrs. group. (Model 1: $\mathrm{OR}=4.41$ [95\% C.I.:1.3-14.91], Model 2: OR=4.46 [95\% C.I.: 1.3-15.27], Model 3: $\mathrm{OR}=5.03$ [95\% C.I.:1.5-16.86]). Similarly, the GE 60 group was about 4 times more likely to be in the MDCAM group as compared to the 18-29 yrs. group (Model 1: $\mathrm{OR}=4.01[95 \%$ C.I.:1.09-14.73], Model 2: OR=4.02 [95\% C.I.: 1.08-15.99], Model 3: $\mathrm{OR}=4.03[95 \%$ C.I.:1.1-14.84]). 
Results

Education also had no statistically significant contribution to the explainable variation in the DV, as tested by Adjusted Wald Chi-Square. There were some statistically significant differences between Education subgroups in Models 1, 2 and 3. The Education group HS Diploma was about 3 to 4 times more likely to be in the MDCAM group as compared to the Never thru 11th group. (Model 1: OR=3.03 [95\% C.I.:1.06-8.71], Model 2: OR=2.95 [95\% C.I.: 1.02-8.57], Model 3: OR=3.81 [95\% C.I.:1.2-12.14]).

Insurance Status had no independent statistically significant contributions to the explainable variation in the DV, as tested by Adjusted Wald Chi-Square. In Model 2, the Uninsured were 2.25 times more likely than those with Any Private Insurance to be in the MDCAM group (OR=2.28 [95\% C.1.: 1.05-4.97]). 
Results

Table 6.13 Models of Professional Group Membership: CAM Therapies

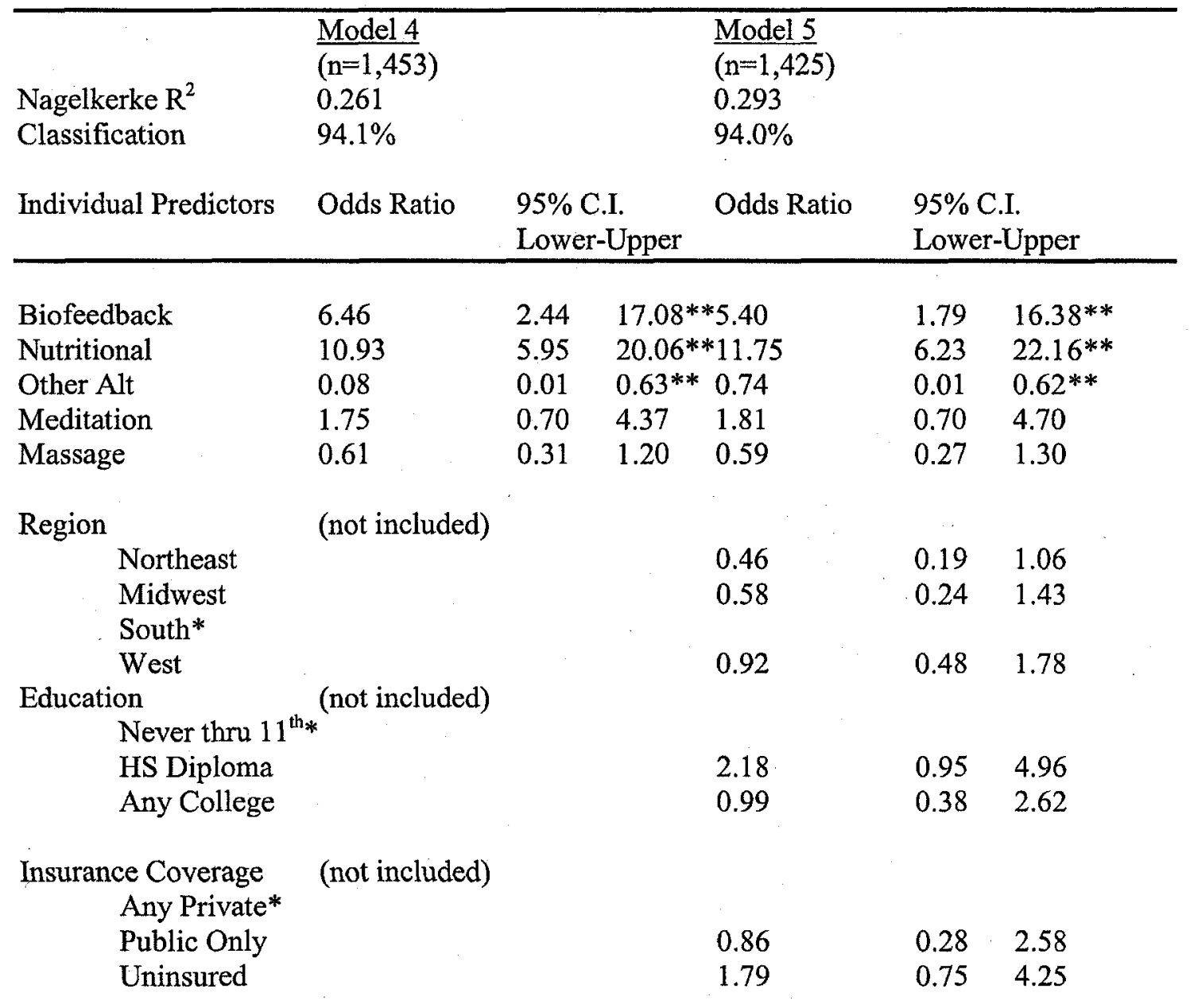

Total Model

Chi-square df $P \quad$ Chi-square $\quad$ df $\quad P$

\begin{tabular}{lllllll} 
Intercept Only & 24.30 & 1 & $<0.001$ & 17.74 & 1 & $<0.001$ \\
Full Model & 85.84 & 4.29 & $<0.001$ & 77.93 & 9.85 & $<0.001$ \\
\hline
\end{tabular}

* Referent

** $P<0.05$ 
Results

Table 6.13 compares Model 4 with Model 5, which adds Education, Insurance Coverage and Region of the country. The initial sample design for Model 4 includes 1,274 unweighted cases. Excluded from the analysis were the remaining 38,040 cases in the data set. The analysis was conducted in one stage, using 112 strata and 275 sampling units. The total degrees of freedom for this sampling design was 163 . The Nagelkerke $\mathrm{R}^{2}$ for this model was .261 , indicating that the model accounted for about $26 \%$ of the variability in the dependent variable. This model accurately classified group membership in $94.1 \%$ of the cases. Biofeedback $\left(X^{2}=14.36, \mathrm{df}=1, \mathrm{p}<.000\right)$, Nutritional Advice $\left(\mathrm{X}^{2}=60.41, \mathrm{df}=1, \mathrm{p}<.000\right)$, and Other CAM Therapy $\left(\mathrm{X}^{2}=5.82\right.$, $\mathrm{df}=1, \mathrm{p}=.016$ ) had statistically significant, independent contributions to the explainable variation in the DV. Massage Therapy and Meditation Training did not contribute to the explainable variance in the DV at a statistically significant level. The full model was statistically significant $\left(\mathrm{X}^{2}=85.84, \mathrm{p}<.000\right)$.

\section{National Projections}

The final analysis employs the MEPS unique design strength, which is the creation of national estimates for subpopulations within this representative sample of all Americans. Table 6.14 presents national projections for individual CAM therapies provided by physicians. Detail is provided on the Regional distribution of these services. Again, due to the small sample size in the MDCAM group, some regions were not populated with data for every therapy. 
Table 6.14 National Projections of MDCAM: Detail by Region*

\begin{tabular}{|c|c|c|c|c|c|}
\hline & $\begin{array}{l}\text { MDCAM } \\
\text { Total }\end{array}$ & Northeast & Midwest & South & West \\
\hline Spiritual Healing & 205,308 & $10,343(0.02)$ & $32,364(0.05)$ & $90,614(0.09)$ & $71,987(0.09)$ \\
\hline Biofeedback & 108,130 & -- & -- & $28,496(0.03)$ & $79,634(0.13)$ \\
\hline Acupuncture & 55,066 & $10,343(0.02)$ & $21,905(0.03)$ & -- & $22,818(0.04)$ \\
\hline Other Alt & 6,392 & -- & $6,392(0.01)$ & -- & -. \\
\hline Purchased Herbal & 350,163 & $23,289(0.04)$ & $28,251(0.04)$ & $184,065(0.19)$ & $114,558(0.19)$ \\
\hline Homeopathic Therapy & 61,182 & $10,343(0.02)$ & $9,528(0.02)$ & $25,710(0.03)$ & $15,600(0.03)$ \\
\hline Hypnosis & 20,644 & -- & -- & $20,644(0.02)$ & -- \\
\hline Massage Therapy & 200,107 & $8,484(0.02)$ & $28,948(0.05)$ & $38,941(0.05)$ & $123,734(0.21)$ \\
\hline Meditation Training & 166,514 & $16,309(0.03)$ & -- & $43,139(0.04)$ & $107,066(0.18)$ \\
\hline Nutritional Advice & 735,644 & $55,787(0.11)$ & $124,168(0.20)$ & $271,667(0.28)$ & $284,021(0.47)$ \\
\hline Traditional Medicine & 87,287 & $22,221(0.04)$ & $8,896(0.01)$ & -- & $56,169(0.09)$ \\
\hline
\end{tabular}

* Values are frequencies (regional percentages); Denominators for Regions were calculated as [(Regional Population 1996 + Regional Population 1998) / 2]; Data from U.S. Census Bureau. -- Indicates no data in cell

The national projected estimate for the number of Americans who received MDCAM was 992,097 (SE 149,353). For reference, recall that the regional distribution of these survey respondents is given in Table 6.2 [p. 94]. Nearly 736,000 Americans received Nutritional Advice or Lifestyle Diets from their allopathic physicians during the study period. The preponderance of this work took place in the American South and West. Just over 205,000 respondents received Spiritual Healing or Prayer from their allopathic physicians. The preponderance of this behavior occurred in the South and West. 
Discussion of Findings

Chapter 7. Discussion of Findings

The univariate statistics presented in Table 6.2 provide a general description of the study variables and also a window into the sample's overall representativeness of the United States population. Regarding the age structure of the sample, it is possible to calculate an approximate dependency ratio from these data. Dependency ratios are measures of the proportion of the population that is not engaged in economic production (due to age), in relation to the proportion that is of working age. The MEPS sample produced an approximate dependency ratio of .55, which is comparable in magnitude to a national estimate of .52 for the United States in 1998 (World Development Indicators Database, 2007). The similarity of these values lend support to the MEPS design process of poststratifying to census values. This also ensures that the general age structure of the sample was not affected by data cleaning. Similarly, the mean age reported in Table 6.2 (35.34 yrs.) is comparable, though slightly lower than, the estimates reported by the U.S. Census Bureau for both years 1996 and 1998 (35.9 and 36.2, respectively) (Population Estimates Program, Population Division, U.S. Census Bureau, 2007). The Gender distribution of 51.1\% Female and $48.9 \%$ Male provides a sex ratio of .9569 (males/females), which is comparable to .9547 (Population Estimates Program, Population Division, U.S. Census Bureau, 2007), 
Discussion of Findings

again adding confidence to the integrity of the age-sex structure of the dataset. ${ }^{1}$ Regarding Ethnicity, the estimate generated from this data identifies Whites as constituting $76.2 \%$ of the sample. The estimate for Whites from the U.S. Census Bureau is $82.65 \%$, a substantially larger percentage for the $1996-1998$ period. It is worth noting that the MEPS oversamples minorities, leading to a larger proportion within the dataset, which may account for this difference.

Regarding the variable REGION, the MEPS is comparable to the general U.S. population by design. This is a core feature of the MEPS, which imparts its value. Further, data collection post-stratifies to census estimates at the regional level, to ensure the survey's applicability to geographic population estimates (Cohen, 2002).

Regarding Education, the national estimate for the percentage of High School Graduates, produced by the American Community Survey (ACS) for 1998, was $31.6 \%$. The MEPS variable, Level of Education, provides an estimate of $27 \%$, while another variable, Highest Degree, estimates that $50.9 \%$ of the population has earned a high school diploma or GED. Regarding the percentage with Some College Education, the ACS estimates that $18.3 \%$ of the population has had at least some college, while the MEPS provides an estimate of $37.3 \%$ of the population that has had "Any College" education. Lastly, the ACS estimates that $20.9 \%$ of the population has a Bachelor's Degree or Higher, while the MEPS estimates $21.5 \%$. From these measures, it is plain that the dataset grossly approximates the general population.

\footnotetext{
${ }^{1}$ The sex ratio was calculated by averaging both the 1996 and 1998 population estimates for both genders.
} 
Discussion of Findings

Regarding Urban/Rural population distributions, the sample data closely approximates census estimates for the percentage dwelling in Metropolitan Areas in 1998 (census 80.0\%, compared to MEPS at 79.2\%) (MA-99-2, Population Estimates Program, Population Division, U.S. Census Bureau, 2007).

Regarding Employment, the MEPS estimates closely approximate national estimates. The sample produced an estimate of $65 \%$ of the U.S. population as Employed. The Bureau of Labor Statistics estimate for 1998 was $64.1 \%$ (Bureau of Labor Statistics, 2008).

Regarding Insurance Status, the MEPS estimates that $12.0 \%$ of the population was Uninsured during the period, while the national estimate for 1996 was $16.1 \%$ (Health United States, 1999, Table 129, U.S. DHHS, Public Health Service, 1999 in Budrys, 2001). Reasons for the low estimate from the MEPS are unclear.

Regarding General Health Status, the MEPS collects data on Self-Rated Health Status and both ADLs and IADLs. MEPS respondents tend to be healthier compared to estimates collected by the Behavioral Risk Factor Surveillance System Survey of the CDC (BRFSS) for 1996, with 13.1\% of the population self-rating as Fair or Poor, while the MEPS population reports $11.8 \%$. Further, only $23.9 \%$ of the BRFSS population self-rates as being in Excellent health, while the MEPS population reports $34.1 \%$ (BRFSS, 2008).

Regarding annual estimates of CAM use, these were presented on [page 51]. What is most notable is that estimates were wide-ranging with those coming from the 
Discussion of Findings

MEPS surveys being the lower-bound. The estimate presented in Table 6.2 is $4.2 \%$, which is lower, still, than the estimate published in Druss and Rosenheck (1999) of $6.5 \%$. The reason for the discrepancy is unclear; however, a quick analysis of the 1996 raw data (MEPS file HC-12) generates an estimate of 5.1\% (adjusted for complex sample design). Druss et al. report complex sampling adjustment, whereas Bausell et al. (2001) report no such adjustment. This discrepancy produces underestimates compared to other survey efforts, which indicates that the findings of this dissertation research should be taken as conservative estimates.

Druss and Rosenheck (1999) comment on the lower-than-expected estimates, suggesting that they could be a result of a focus on practitioner-based therapies and also of sampling design. The demographic distribution accessed by the MEPS is more inclusive of "less educated and poorer" respondents and also those without telephones and non-English speakers (ibid). These are distinct differences from the Eisenberg et al. $(1993,1998)$ methods, which employed telephone surveys. Bausell et al. (2001) commented on the low estimates, pointing out the same issues identified by Druss et al. They also suggested that potential differences were related to the differential response burdens of face-to-face interviewing vs. the relative anonymity of telephone interviews. Further, question phrasing may have had an impact, as well as the proportion of CAM-related questions to the overall length of each survey, with the MEPS devoting a much smaller proportion. Further still, the MEPS excluded hospitalized and institutionalized persons by design, which is a structural difference in 
Discussion of Findings

the surveys, and the MEPS used informants to report on health care utilization of other family members, thereby introducing another source of uncertainty. In assessing the potential damage to the estimates, Bausell et al. surmised that the net effect would be a bias toward false negative correlations rather than false positives, again reflecting the conservative nature of the results.

\section{Discussion of Demographics Profiles}

This analysis provides side-by-side comparisons of survey respondents, organized by professional affiliations and addresses the first hypothesis. These mutually-exclusive groups show distinctive patterns. Table 6.2 replicates an analysis of the MEPS by Druss and Rosenheck (1999:Table 1) and reinforces their findings with a larger dataset (even after extracting the MDCAM group).

Compared with individuals who used conventional services only, users of both unconventional therapies and conventional medical services were more likely to be Older, Female, White, High School Educated, Insured, in poorer Physical and Mental Health, in need of Help with ADLs, have had more Health Care Events, and have more Prescriptions. This group was less likely to live in the Northeast or South and more likely to live in the West. There were no differences in median Age, IADLs, living in the Midwest, nor in the proportion within MSAs. In contrast, Druss and Rosenheck found no health-related differences in their comparisons, whereas the BOTH group in this analysis was clearly in poorer health. 
Discussion of Findings

A central finding from comparing mutually-exclusive professional groups was that the subpopulations who received alternative medicine from a physician (MDCAM) were not different from the subpopulation that consumed BOTH mainstream and alternative care, with one exception. That is, the population characteristics, measures of health status, and geography of these two groups were similar. The one variable that set the MDCAM group apart was the Total Number of Prescriptions reported by respondents. This provides some weak support for Hypothesis 1, which predicted a difference between the two groups. While in Druss and Rosenheck, those who used BOTH CAM and conventional care did not differ in their health status, or in health care utilization from those who consumed Conventional care only, a trend emerges by extracting the MDCAM group from the BOTH group. As compared to the Conventional service group, the BOTH group is less healthy and consumes more services; the MDCAM group, though similar, exhibits greater health care utilization in the form of the greater Number of Prescriptions held by survey respondents. Measurement of the Total Number of Prescriptions held by a survey respondent is one of the core indicators included in the most widely-used scale of health care quality regarding outpatient drug utilization. This scale, referred to as a performance measure, is included in the Health Plan Employer Data and Information Set (HEDIS), a database of performance standards maintained by the National Committee for Quality Assurance (NCQA). Use of this database, as part of the quality measurement movement, increases pressure on the health care sector to set 
Discussion of Findings

high standards and to remain accountable for high quality, under penalty of bad press. Regarding pharmaceuticals, the Outpatient Drug Utilization measure is a component of the more encompassing effort of health plans to measure service utilization. The Outpatient Drug Utilization measure includes the following indicators: Total Number of Prescriptions; Average Number of Prescriptions per member per year (stratified by age group); Total Cost of Prescriptions; Average Cost of Prescriptions per member per month; and Average Number of Prescriptions per member per year (Chawla et al., 2001).

Because this measure is the only distinguishing difference between the MDCAM and Both groups, it warrants closer scrutiny. Figure 6.2 [p. 100] illustrates the distributions of the Number of Prescription Medicines variable by professional group. For each group, the tails of the distributions demonstrate wide variety, however the measures of central tendency, along with the interquartile range, minimize the effect of these extreme values. The median value for the MDCAM group is larger than the other groups, reinforcing the validity of the average value, which is also the highest of all groups. The MDCAM group has the highest number of prescription medicines of all respondents in the MEPS data for 1996 and 1998.

\section{Discussion of CAM Therapy Utilization Among CAM Professional Groups}

Table 6.4 (p. 114) compares CAM therapy utilization by three professional categories: CAM Only; BOTH CAM and Conventional care; and MDCAM. This 
Discussion of Findings

analysis offers support for Hypothesis 2. MDCAM was statistically significantly different from BOTH in that this group used more Biofeedback, Meditation, and Nutritional Advice, and less Massage and Other unspecified CAM therapies. There were some trends among these three groups that did not reach statistically significant levels. Interestingly, the MDCAM group had the lowest consumption of Acupuncture, Homeopathy, and Spiritual Healing and had the most consumption of Herbal Remedies and Traditional Medicines; again, all below statistically significant levels. This first look at the therapy consumption patterns of these market segments begins to illuminate their relationships to mainstream medicine. There is ample room for debate about the rationale for interpreting a continuum or polarization across CAM therapies as being either more or less mainstream. Indeed, Druss and Rosenheck (1999:652) decided that "visits in which unconventional therapies were provided through a physician were considered to be conventional". This strategy efficiently supported their research question, which was to determine whether unconventional therapies were used as an alternative or as a complement to mainstream health care. However, there is also a long history of typologies of CAM, which are addressed in Appendix 1.

There are some clear signals in Table 6.4. Biofeedback is clearly associated with mainstream medicine. The prevalence estimates decreased markedly from MDCAM (10.9\%), to BOTH (2\%), down to $0.2 \%$ for CAM Only. Biofeedback is a technical procedure that requires familiarity with oscilloscopes, microvoltages and 
Discussion of Findings

Skinnerian behaviorism. It had a period of popular interest in the 1960's and has persisted as a valuable technique for amplifying signals from the autonomic nervous system. The primary semantic mechanism for training in biofeedback therapy is the ubiquitous instruction for the "patient" to "relax". The main thesis for this research is that biofeedback is technical, as is allopathic medicine. Patients must acquire access to the device in order to practice, and most commonly this access requires a regular relationship with a professional (though not necessarily a physician).

Meditation was statistically significantly more prevalent in the MDCAM group, and twice as prevalent as in the BOTH group. The CAM Only group fell intermediate to these two. They may reflect the bifurcation in the practice of meditation, which has become more prominent since the 1990's. Parallel with the emergence of psychoneuroimmunology as a medical specialty, meditation has been welcomed into health care settings, even in the heart of Boston (cf., Kabat-Zinn et al., 1985; Davidson et al., 2003). However, it should be noted that the survey question was worded as follows: Training or practice of meditation, imagery or relaxation techniques. The common denominator to these therapies is the systematic pursuit of the human relaxation response.

Nutritional Advice was statistically significantly more prevalent in the MDCAM group, and more than 3.5 times as prevalent as in the BOTH group. The CAM Only group had the lowest prevalence, with more than a 4-fold difference from MDCAM. The survey question inquired about Nutritional Advice or Lifestyle Diets. 
Discussion of Findings

This can be perceived as a double-barreled question, due to the differing connotations of giving advice versus offering a diet. A core challenge to allopathic medicine has been the overemphasis on technology (Maizes et al., 2002) and the undereducation of physicians about nutrition (Committee on Nutrition in Medical Education, National Research Council, 1985:95; Goldstein, 1999). If this measure reflects the consumption of nutrition education from physicians, then this finding would be an interesting precursor to the now-formal model of integrative medicine. If, however, this variable measured the frequency of lifestyle diets obtained from physicians, this could be a measure of physicians as brokers of preexisting products. This professional behavior would not necessarily require a paradigmatic shift. However, this information is not forthcoming from these data alone.

Massage therapy was statistically significantly lower in the MDCAM group, as compared to the BOTH group. It was not different from the CAM Only group. Interestingly, it was also a nonzero value, meaning that some respondents reported receiving massage from their physicians. Recalling that these two groups did not differ on Insurance Status, this finding may help discriminate between the types of health issues associate with each group.

The variable Other CAM therapies was also statistically significantly lower in the MDCAM group. Interpretation of the meaning of the Other CAM finding is difficult. The fact that both Biofeedback and the mysterious Other CAM therapies are both strongly statistically significantly $(p<.01)$ related to the MDCAM group, yet in 
Discussion of Findings

opposite directions, establishes a form of polarity among the CAM therapies.

Additional therapies least likely to be used by MDCAM, at statistically significant levels, were Massage, Spiritual Healing. Similarly, Acupuncture was seldom used, as well as Homeopathy/Naturopathy. Each of these seldom used therapies is associated with a specific occupational role (i.e., massage therapist, priest, acupuncturist, and naturopathic physician), in which case, the response pattern across these therapies could be a map of professional jurisdictions contra allopathy.

Table 6.4 also provides a measure of the degree to which respondents believed that their physicians were involved in their CAM consumption. This was measured with two variables, Physician Referred and Physician Aware. Not surprisingly, the MDCAM group had the highest prevalence of agreement with both of these variables, while the BOTH group was intermediate and the CAM Only group had the lowest prevalence of physician involvement. The primary utility of these measures is to provide construct validity to the assertion that the MDCAM group is distinct from the BOTH group.

\section{Discussion of MDCAM Compared to Frequent and Infrequent Health Care Users}

Tables 6.5 and 6.6 (pp. 166 and 122, respectively) present comparisons of MDCAM to other CAM users, characterized by either frequent or infrequent mainstream health care utilization. These analyses compare demographics and CAM therapies by three mutually-exclusive groups; top quartile of HC utilization; bottom 
Discussion of Findings

quartile of $\mathrm{HC}$ utilization, and MDCAM. This analysis provides support for

Hypothesis 3 by establishing that consumer demographics in the MEPS are different, based on the frequency of $\mathrm{HC}$ utilization. The top and bottom quartile groups were different on 16 of 27 measures (59.3\%), yet the measures on which they were similar are also telling. They had similar numbers of $\mathrm{HC}$ Events and were nearly equally distributed across the country, with an exception in the Northeast, where there was a concentration of high consumption. Not surprisingly, high $\mathrm{HC}$ consumption was associated with being insured.

The profile for MDCAM includes the most Female, White, and Educated of the three groups. This group was the most Uninsured, which is surprising. The MDCAM group had the most respondents who rated their Mental Health as poor. Self-Rated Physical Health, needing Help with ADLs, and IADLs all fell intermediate to the high and low quartile groups. Geographically, MDCAM as a practice was least prevalent in both the Midwest and, at a statistically significant level, in the Northeast. Recalling that this is where the greatest concentration of frequent $\mathrm{HC}$ users live this can be interpreted as indicating a geographic region of medical traditionalism, supported by both professionals and consumers. It could also be taken to mean that the consumers of the Northeast were buying what the professionals are selling. While MDCAM was present in the South, in the West, the proportion was nearly double the prevalence of high and low $\mathrm{HC}$ users alike. Regarding Physician Involvement in 
Discussion of Findings

CAM, not surprisingly, the MDCAM group had the highest prevalence rates for both variables, Physician Referred and Physician Aware.

\section{Discussion of Nonparametric Profiling}

Table 6.6 presents the model variables, recoded into nonparametric ranks. As in Table 6.5, the comparison is across three groups: those in the top quartile of health care utilization; those in the bottom quartile; and the MDCAM group. This simple approach to inspecting the data yields an interesting result. Under the null hypothesis, the expected value for all cell frequencies is 8.7 . The statistically significant difference found across cell frequencies indicates some order to the relation. By inspection, we see that the MDCAM group is distinctive in at least three ways. The MDCAM group contains subpopulations with both the highest cell frequencies $(n=13$ for "pluses") and the lowest cell frequencies ( $n=3$ for "minuses"). This is interpreted as evidence that the MDCAM group is indeed distinctive from other CAM users (regardless of their utilization pattern) and provides clarification of the groups beyond the comparisons of Table 6.5. It also reinforces early utilization reports (cf., Eisenberg et al, 1993 \& 1998) that CAM is consumed by Educated (Mackenzie et al., 2003; Bausell et al., 2001; Astin, 1998a; Druss \& Rosenheck, 1999; Eisenberg et al., 1993 \& 1998) Women (Mackenzie et al., 2003, Wolsko, 2002, Bausell et al., 2001; Astin, 1998a; Druss \& Rosenheck, 1999; Eisenberg et al., 1993 \& 1998). This profile adds that the MDCAM population is Nonwhite, Uninsured, in poorer Mental Health, and 
Discussion of Findings

population lives in the South and West. The primary utility of "crudifying" these data is in the ease of positioning MDCAM relative to high and low users of health care.

Discussion of the Average Number of Health Care Visits Associated with Each CAM Therapy

Tables 6.7 and 6.8 (pp.125 and 127, respectively) examine utilization patterns across both CAM Therapies, CAM Professional Services and MDCAM. These analyses provides some support for Hypotheses 4 and 5, and illustrate what Nahin et al. (2005) observed. The scientific community attends to different therapies than the lay public. The most general finding from this analysis is that the MDCAM group has higher mainstream utilization rates than the All CAM Users group. This observation was supported through analysis of individual therapies (Table 6.7) and utilization of different CAM professionals (Table 6.8).

Table 6.8 , provides a baseline estimate of the average number of mainstream visits for the subpopulation who also visited CAM professionals. Those with the highest number of mainstream visits also visited Other CAM Professionals (unspecified), Massage Therapists, and Clergy, Spiritualists or Channelers. Those with the lowest mainstream visits saw either Nurses or Acupuncturists for CAM care. This baseline helps locate the MDCAM group by illustrating the relative correspondence of MDCAM respondents with some CAM professionals, but not others. One interesting observation is the tendency against MDCAM recipients 
Discussion of Findings

receiving Massage from their physician, but tend to visit Massage Therapists for the service. Similarly, while Spiritual Healing is offered in the MDCAM group, it is less frequent than in the Both or CAM groups, yet the MDCAM recipients tend to engage in this behavior with Clergy.

Discussion of Financial and Utilization Characteristics by Professional Groups Hypothesis 6 was supported by analysis of several measures of SES. This would lend an argument to the class relation between clients and a burgeoning specialty. This has already been discussed in relation to cosmetic surgery (Sullivan, 1993) such that elective health care is a marker for disposable income. Indeed, the Both group had the highest average income across groups. However, Table 6.9 (p. 129) finds that the MDCAM group had statistically significantly lower incomes and wages than the Both group. As Income and Wage were highly correlated, only income was entered into multivariate analysis to test its independent contribution to group membership.

Discussion of Spending and Utilization by CAM Groups.

Expenditures for CAM differed among respondents who used BOTH, CAM Only, and MDCAM (Table 6.10, p. 131), providing support for Hypothesis 7. The group with the largest average Expenditures was MDCAM, which was more than three times larger than the CAM Only group and nearly twice the expenditures of the 
Discussion of Findings

Both group. This indicates that the MDCAM group engages in spending patterns that are statistically significantly different from those who simply combine treatments from both allopathic and CAM spheres, and also from those who avoid mainstream health care altogether.

\section{Discussion of Regressions for Predicting Group Membership: Demographics}

Regression modeling took place in two stages, modeling group membership and comparing models when utilization variables were added which were found to be significant in bivariate analyses. These additional variables were Estimated Number of CAM Visits and Total Income. The base model replicates an analysis from Bausell et al., (2001: Table 3), which predicted CAM use from a demographic profile. Models $1,2 \& 3$ were all statistically significantly related to the DV, however, no individual variable held a significant relationship. Further, the utilization variable did not improve the models, nor was it significantly related to the DV, as such, Hypothesis 8 was not supported.

This indicates that the model presented in Bausell et al., (2001) fits the data sufficiently, though this analysis lacked power. Two age groups were more likely to hold MDCAM membership as compared to the 18-29 year old segment, in all three models. The 30-39 year old group and the 60 and older group were both 4-times more likely to be in the MDCAM group. Further analysis is needed to determine whether the health needs of these segments are different from one another. Similarly, those 
Discussion of Findings

with High School Education were more likely to be in the MDCAM group than those with less education, but this did not hold for those with College Education. This is consistent with the findings of Table 6.3 which described the MDCAM group as holding the greatest proportion of High School Educated respondents.

\section{Discussion of Regressions for Predicting Group Membership: CAM Therapies}

The preceding analysis was adapted to examine whether the patterns of CAM therapy use identified in bivariate analyses could predict MDCAM group membership. Two models were compared. Model 4 examined the predictive power of five CAM therapies. The full model was statistically significant, lending support to this approach. The findings of the bivariate analyses were supported illustrating that biofeedback and nutritional advice and other CAM were statistically significantly related to the MDCAM group. Both biofeedback and nutritional advice were predictive because they had a 6 and 11 fold increased likelihood, respectively, of being associated with MDCAM. Other CAM was predictive because it was less likely to be associated with MDCAM. These findings persisted with the addition of the potential confounders Region, Education and Insurance coverage; none of which was statistically related to the DV.

In comparing the demographic models to the CAM therapy models, it is interesting to note the differences in explanatory power as measured by the Naglekerke pseudo $\mathrm{R}^{2}$. This measure approximates OLS regression and calculates a 
Discussion of Findings

measure of the variance explained by the model. The demographic models accounted for between $6.1 \%$ and $7.4 \%$ of the explainable variance. The CAM therapies models accounted for between $26.1 \%$ and $29.3 \%$ of the explainable variance. This argues for the increased discriminatory power of utilization variables over demographics in this investigation. These findings are in agreement with the findings of the bivariate analyses.

\section{Discussion of Population Estimates of MDCAM Therapies}

The non-mutually-exclusive population estimates of MDCAM provided therapies describe large numbers of patients who receive unconventional treatments from their conventional doctors. This behavior was geographically distributed across all regions of the country. Nearly three-quarters of a million Americans received nutritional advice or lifestyle diets from their physicians. It is unclear whether this encapsulates megavitamin supplementation, a commonly cited CAM modality, or simply advice on eating for health. It can be inferred that this represents the least paradigmatically challenging of the MDCAM therapies because of the penetration into the NE region, which had the lowest prevalence of MDCAM. Similarly, those who reported Purchasing Herbal Supplements were found in the NE region, and was the second most prevalent form of MDCAM. Taken together, the role of food in the therapeutic milieu seems acceptable to the allopathic framework, and raises the question as to whether these treatments were, or should be considered "alternative". 
Discussion of Findings

In contrast, there is little doubt that Spiritual Healing or Prayer, and Homeopathic

Therapy are alien to the allopathic cannon. These MDCAM therapies were distributed across all regions, unlike some of the other therapies. These two variables measure boundary crossing across greater social and conceptual distances. Spiritual healing as a medical treatment represents borrowing across social institutions, that is, co-opting a core service provided by the institution of religion. Similarly, the provision of homeopathic therapy by allopathic physician represents a conflation of the paradigmatic frames held by both schools. To the extent that this is unimportant to doctors, or patients, it represents a disconnection between Abbott's levels of claimsmaking. The conceptual level claims of expertise are different for these two schools, with homeopathy advancing a veiled form of Vitalism, and allopathy advancing the power of scientific empiricism. The behavior measured by the MEPS illustrates that those abstract claims are unimportant at the level of the workplace, where clients present problems and professionals provide solutions.

Massage therapy is the only other MDCAM therapy that is distributed across all regions of the country. This is interesting for two reasons. It represents borrowing from a subordinate health profession. It also represents an ancient form of healing exchange - the laying on of hands - which mainstream medicine forsake in lieu of technology. This is a familiar criticism of the allopathic system.

The remaining MDCAM therapies were not measured in all regions of the country, illustrating practice pattern variation. Hypnosis was found only in the South, 
Discussion of Findings

and Other CAM was found only in the Midwest. Meditation training was clearly

favored in the West, yet was also present in the Northeast, where other therapies did

not penetrate. These patterns argue for regional cultures of medicine. This is not

unusual, and is more commonly found in service pricing structures which are based on

regional (often at the level of MSA) or community standards. This means that the

price of medical services depends on what the community has become accustomed to,

which gives importance to marketing and advertising. The theoretical value of this

observation, is again the disconnection between the conceptual level claims of a

unified allopathic paradigm, in the face of empirical evidence of workplace level

borrowing.

Table 7.1 Summary Table for Hypotheses

\begin{tabular}{|l|l|l|l|}
\hline Hypothesis & Table & Outcome & Comment \\
\hline 1 & 6.3 & Supported & $\begin{array}{l}\text { Groups differed, though MDCAM and Both differed only } \\
\text { by Number of Prescriptions }\end{array}$ \\
\hline 2 & 6.4 & Supported & $\begin{array}{l}\text { CAM Therapy utilization varied with professional } \\
\text { affiliation }\end{array}$ \\
\hline 4 & $6.5-6.6$ & Supported & $\begin{array}{l}\text { MDCAM is more closely aligned with high-frequency } \\
\text { health care users, compared to low frequency users. }\end{array}$ \\
\hline 5 & 6.7 & Supported & $\begin{array}{l}\text { Analysis by CAM Therapy support finding that MDCAM } \\
\text { group are high frequency health care users. }\end{array}$ \\
\hline 6 & 6.8 & Supported & $\begin{array}{l}\text { Analysis by CAM Professions support finding that } \\
\text { MDCAM group are high frequency health care users. }\end{array}$ \\
\hline 7 & 6.10 & Supported & $\begin{array}{l}\text { MDCAM is characterized by low income and wages and } \\
\text { tends to be less employed. }\end{array}$ \\
\hline 8 & $6.11-$ & $\begin{array}{l}\text { Not } \\
\text { Supported }\end{array}$ & $\begin{array}{l}\text { MDCAM has more CAM visits, tends to spend more on } \\
\text { CAM and use CAM for specific problems. }\end{array}$ \\
\hline
\end{tabular}


Chapter 8. Conclusions

The value of retrospective analysis comes, in part, from its role in clarifying the present moment. The present moment, regarding integrative medicine and more broadly, integrative health care, is full of creative alliances and business opportunities. Heralding the mixture of alternative medicine with the mainstream system remains a marketable strategy for the popular press. A recent cover story in U.S. News and World Report, for example, revisits integrative medicine and advises on how to select an "integrative medicine practitioner" (U.S. News \& World Report, Jan. 11, 2008). Taken from a critical view, this article is only a slightly-veiled advertisement for Duke University Health System and their product, The Duke Encyclopedia of New Medicine: Conventional and Alternative Medicine for All Ages (2006). The Duke University program was also the topic of a feature story on the MSNBC Nightly News program of May 5, 2008 entitled The Mind Body Connection. This news program was accompanied by an editorial on the station's website, by their chief science correspondent, Robert Bazell. The editorial identified the CAM movement as a product of "a handful of billionaires that have brought alternative medicine to many [of] the nation's major medical centers," Duke included (Bazell, 2008). The editorial conflated CAM and integrative medicine and cautioned that some stakeholders in the alternative medicine movement "see no need for their claims to be tested with 
Conclusions

scientific studies or [they] simply ignore the results" (ibid). The claims-making debate continues, and the symbolism is noteworthy.

Our social institutions embrace alternative medicine for their own purposes. Goldstein (1999) recognized a meaningful distinction between CAM as Big Business and CAM as Small Business. In the case of the former, CAM is promoted by both large manufacturing efforts (in the form of nutritional supplements) and by media conglomerates who recognize the marquee value of CAM. As Small Business, CAM is a feature of the cottage industries of healers who work within a cash-only economy, often taking political pride at their ability to sustain themselves. Since the mid-1990's, our national mindsets and colloquialisms have opened to the discourse about CAM. Integrative medicine, as a medically-sanctioned form of CAM, has been embraced not only by the U.S. government, but also by medical schools across the country by their offices of research, curriculum development and marketing.

This dissertation has addressed the cultural dynamics of alternative medicine by attending carefully to the specifics of survey analysis, and also by emphasizing the importance of context. This was provided by discussing the philosophical distinctions involved, by tracing the historical origins of CAM in this country, and by describing the explosive growth of CAM across the past 15 years.

This dissertation opened with an accounting of the increasing social trends of support for CAM, including its repackaging as integrative medicine. Re-labeling is predicted by trait theories of professionalization which identify, as a prerequisite, the 
adoption of a new name to distinguish the new work from the old. The cultural authority of medicine has laid claim to some of the CAM domain through formal jurisdictional changes (e.g., Washington State) and through workplace-level changes, (e.g., IM clinics). By appreciating the history of professional contests between medical sects, the groundwork was laid for interpreting the paradoxical behavior of MDCAM. The paradox is that physicians provided CAM at a time when they were at risk for doing so. This provides further empirical evidence that while the political discourse of marginalized medical professionals has maintained a thread of continuity for over a century, the degree of concrete organizational and legal prerogatives has fluctuated.

The analytic frame for examining these changes uses ideas from both the systems sciences and from the sociology of professions, which share a common theoretical interest in accounting for multiple levels of interaction. It was asserted that the conceptual-level differences between CAM and conventional medicine (i.e., the ontological differences) represented a philosophical boundary, and that the empirical observation of boundary-crossing at a more concrete level, would reflect something deep about the present state of health care in America. To the extent that allopathic medicine simultaneously claimed a paradigmatic distinctiveness from CAM and borrowed specific therapeutic behaviors from CAM, a measure of change could be interpreted. 
Conclusions

There are stereotypical difficulties with secondary analysis, one of them being the challenge of imposing a theoretical treatment to preexisting data. This dissertation addressed this challenge by providing several layers of context around the analysis. These layers included some philosophical discussion, the combination of a few "theories of the middle range" and a treatment of the historical foundations of alternative medicine in America. At first blush, this approach may seem distracting or tangential; however, the layers of context provide dimensions of deep correspondence with ideas and intellectual discourse that precede the analysis. What follows will strive to unpack the findings of this research along these lines of correspondence.

Preceding research has characterized the consumers of health care who use both conventional medicine and also unconventional therapies. The descriptive characteristics of these research subjects is well known and has been verified through repeated measurements. The general description includes the following attributes: white, female, educated, with higher incomes. The majority of these results found support in this analysis, thereby providing some external validation.

In the years 1996 and 1998, the MEPS included questions about alternative medicine consumption, including questions about the service providers. Heretofore, no such analysis has been made of the logical combinations that led to MDCAM. Physician-provided CAM was recognized in print by Druss and Rosenheck (1999), but this behavior was operationally defined as mainstream care. By taking the opposite 
Conclusions

view, this dissertation has pursued the possibility of early empirical measurement of professional behaviors that ultimately have been labeled as integrative medicine.

The analysis found that physicians were providing CAM during the period and the types of therapies delivered by the allopathic mainstream were surprising. For example, consider the interesting observation that an estimated 735,644 Americans received Nutritional Advice from their physicians (Table 6.14). Similarly, 205,308 received Spiritual Healing or Prayer from their physicians. This has not been previously measured; however, Barnes et al. (2004) found that these two therapies were the most popular in 2002 (as measured by the NHIS), and Nahin et al. (2005) commented in Health Affairs that these therapies were specifically overlooked by the scientific research community, as reflected by gaps in the literature. A notable difference from the prevalence estimates in Barnes et al. is the observation that 200,107 Americans received Massage Therapy from their physicians. By broadening the investigation to include MDCAM, this dissertation has illuminated different patterns of utilization not reported in other large-scale studies. This leads to the first main conclusion of the study.

\section{Conclusion \#1}

Americans received CAM services from physicians during the study period. The types of services provided were wide-ranging, from technical procedures like Biofeedback to behaviors borrowed from other social institutions and professions, like 


\section{Conclusions}

Spiritual Healing, Hypnosis and Massage. This professional behavior was present in all regions of the country. This is theoretically informative because it illustrates a divergence in values across levels within the profession; CAM is embraced in the workplace, but challenged by opinion leaders.

The second research question addressed whether the MDCAM group was unique. The litmus test for this assertion was whether the subpopulation of survey respondents who received CAM from a physician reflected a distinctive profile of demographics and utilization patterns from other respondents who used mainstream health care and CAM together.

In fact, these two groups were different, but only marginally so. Because of the small sample size, a nonparametric ranking of distribution proportions per variable was used to create an easily-appreciable profile of MDCAM users as compared to frequent and infrequent users of health care. This approach imposes a difference structure on the data. This analysis illustrated that the MDCAM group was extreme to frequent and infrequent users, lending some support for its distinctiveness. One potential outcome could have found the MDCAM group to fall intermediate to high and low users, but this was not the case. This was a promising result; however, bivariate parametric analyses indicated that the MDCAM group and the group who used both CAM and conventional medicine (i.e., Both) were similar in their ascriptive characteristics: Education; Insurance Status; overall State of Health, and Geographic Distribution. The general descriptive profile of the MDCAM group was not 
appreciably distinctive. The one variable that discriminated between MDCAM and the Both group was the Number of Prescription Medicines, with MDCAM respondents holding more. This measure is used as an indicator of the burden of disease. However, because of the legal authority that limits access to regulated drugs to licensed physicians, this measure is also an indicator of the level of attachment to the mainstream system. This is an interesting finding on its own, when set in the historical context. Recall that Druss and Rosenheck (1999) used the MEPS data to explore a pressing issue: whether unconventional therapies were being used by the American public as alternatives or as complements to mainstream care. They found that Americans were using both domains, implying that neither was under attack. Finding that MDCAM respondents hold more prescriptions indicates that this group was under more conventional medical influence than any of the other mutuallyexclusive groups of Americans under analysis. While interpreting these results, it is important to remember that pharmaceutical therapy is the hallmark of allopathic care, and has been cited as the technological achievement that lifted allopathic medicine to its heights during the Golden Age of medicine. This curious result led to an investigation of the specific diagnoses held by these respondents. Upon inspection, the list of first and second diagnoses held by those in the MDCAM group with the most prescriptions was biased heavily toward chronic illnesses and conditions (cf., Appendix 2). This list also contained several mental health-related conditions, lending 
some explanation to the comparatively large percentage of respondents who self-rated their mental health as Fair or Poor.

When compared to respondents in the top and bottom quartiles of mainstream health care utilization, the MDCAM group appears to be demographically more like those in the top quartile. People who received CAM from their physicians are frequent health care users.

The MDCAM group appears to have lost employment, perhaps due to chronic illness. As a group they are less insured, but have higher numbers of prescription medications. Those with the highest numbers of prescription medicines were also likely to receive Medicaid and/or Medicare, and one person received Champus benefits. In addition, those with high prescription medicine usage (the $80^{\text {th }}$ percentile) had an average age of $57.5+-16.5 \mathrm{yrs}$, compared to $48.8+-13$ yrs for the remainder of this high prescription group. The surprisingly young age of both of these groups lends credence to the supposition that the burden of chronic illness experienced by the MDCAM group has led them to seek pharmaceutical and CAM therapy simultaneously.

This finding is bolstered by the patterns of difference in CAM utilization illuminated by Table 6.4. Massage Therapy and Spiritual Healing or Prayer were minimally used by the MDCAM group (though not absent), while Biofeedback Training, Training or Practice of Meditation, Imagery or Relaxation Techniques and 
Nutritional Advice or Lifestyle Diets were embraced. This leads to the second main conclusion.

\section{Conclusion \#2}

The MDCAM subpopulation was similar to frequent health care users and was distinguished by the highest number of prescription medications and diagnoses of chronic illnesses. This group consumed more of some CAM therapies and avoided others. The pattern of consumption distinguished this group from its closest comparison group.

An interesting issue is raised by the utilization findings, which reflect on the research constructs employed by the MEPS and accepted by this research. The affiliation and avoidance of specific CAM therapies by the MDCAM group is a measure of distinction. These differences raise a question about the construct validity of treating CAM as a unity. Biofeedback, Relaxation Techniques and Nutritional Advice, the therapies embraced by the MDCAM group have a long history within the mainstream culture of the helping professions. Similarly, Massage Therapy and Spiritual Healing have a long history of acceptance by society at large. The empirical observation that the MDCAM group prefers some treatments over others implies a continuum. This assertion is bolstered by research on physician attitudes towards CAM. Astin (1998b) reported that physicians were both referring to, and also practicing, various forms of CAM, primarily Acupuncture and Chiropractic care, with some enthusiasm for Massage Therapy. The primary explanations for these 
professional behaviors were: (1) poor response to conventional treatment; (2) per patient's request; (3) belief in their efficacy; and (4) fewer adverse effects.

Biofeedback, Relaxation Techniques and Nutritional Advice can also be viewed as supportive coping skills that could aid in palliation or disease management. The discourse on CAM use in palliation is strong and ongoing. This dissertation provides a description of a subpopulation that is chronically ill, yet reports distinctive challenges to their activities of daily living. This group is a different market segment than those targeted by IM advertising (consumers who are healthful and proactive). Again, reinforcing the theme of specialization and internal differentiation, the MDCAM group creates a boundary within the practices labeled "CAM." This leads to the third main conclusion.

\section{Conclusion \#3}

The pattern of CAM therapy utilization by the MDCAM group implies that some therapies are more acceptable to mainstream providers than others. This raises questions about the research construct of a unified set of therapies called CAM.

\section{Theory}

One precipitator of boundary change is the boundary mechanism of borrowing (Tilly, 2004a). The operational definition of MDCAM, as an early form of integrative medicine, engenders the concept of borrowing. The empirical evidence to support this 
assertion comes from the final table (Table 6.14, p.138) of the Results section; i.e., the population prevalence estimates of CAM therapies offered by physicians show considerable variation. Some therapies are offered more than others and the geographic distribution varies by specific CAM therapy. This indicates differential preferences for some CAM therapies over others, and provides information on where borrowing occurs. This leads to the forth main conclusion.

\section{Conclusion \#4}

The theoretical construct of boundary change through borrowing has some descriptive utility concerning the relationship between CAM and allopathic medicine. The borrowing concept aids in the investigation of which CAM therapies are accepted and where the MDCAM practice is occurring.

However, the pattern of borrowing does not promote a sense of philosophical coherence. In light of Conclusions \#3 and \#4, the selection of CAM therapies is tied more closely to workplace-level consideration, consumer demand, and geography than to a conceptual-level organizing principle. This empirical observation lends credence to Bell et al. (2002) when they warn that the neologism integrative medicine connotes something deeply philosophical, and most references to IM are performing what Bell et al. labeled as "combination medicine". These authors advance a meaning for IM that includes "bio-psycho-socio-spiritual dimensions". By focusing on this distinction, Bell et al. are making a conceptual-level claim in an effort to frame the 
meaning of the label. However, the MEPS captures workplace-level supply and demand relations that also reflect a claims-making process. This process produced a set of professionals and clients that enacted CAM therapies in the context of an allopathic health care encounter. This measured behavior occurred before the label IM was coined, as attributed to Andrew Weil by Eisenberg (2005).

Regarding the system of professions, MDCAM provides an illustration of the internal differentiation process. Internal differentiation is a mechanism to absorb system disturbances. These disturbances can arise within a profession or can be a reaction to external challenges. Mainstream medicine has endured a persistent challenge for pursuing the problem-solving approach to health, rather than the health promotion approach. In the 1990 's, the popularity of CAM gave mainstream medicine an opportunity to include prevention by adopting CAM services. By borrowing specific CAM therapies, and re-labeling the work as integrative medicine, physicians were able to enact the process of client differentiation, an early stage of specialization, as a response to external threat to their jurisdiction.

Another possibility is that IM in its present form represents a structural redesign to accommodate what physicians have been doing all along. Mechanic (1979) described the private nature of the doctor's office visit, which obfuscates collegial review and emphasizes billable services. The general professional ethic of confidentiality, along with the claims-making processes that advance professional expertise and legitimate authority, erect a boundary that is difficult to penetrate. These 
Conclusions

mechanisms slowed pattern recognition of the MDCAM behavior captured by the MEPS. This assertion is supported by the general recognition that the magnitude of the CAM social movement was captured by measuring consumer behavior, not through medical chart review.

The emergence of integrative medicine is located in the doctor-patient relationship. Early concerns about cooptation were predicated on the supposition that the behaviors of allopathic medicine and CAM were mutually exclusive, and that the surprising consumption measured by Eisenberg et al. would lure physicians into the lucrative domain of CAM provision. This was a reasonable concern, due to the deprofessionalization pressures that were strengthening during the period. Through the lens of a system of professions, which disaggregates conceptual-level claims from the functional realities of the daily work, this dissertation locates the process of integration at a much earlier time than can be derived by analyzing the discourse about integrative medicine. This is a unique contribution as this research measured a subpopulation that had not been previously measured. Through the good fortune of a few specific questions embedded in a rigorous population-based survey, the prevalence and geographic distribution of MDCAM can be estimated. Nearly one million people received MDCAM during the period and this subpopulation was distributed across the U.S.

Given the professional politics of the period, this finding was unlikely to be revealed in any other way. The doctor-patient relationship is private and occurs 
behind closed doors. The privacy of the relationship is guarded by the professional traits that separate expert work from other occupations. The period addressed by this dissertation was framed by uncertainty about ethical professional behavior, making the discussion of MDCAM a risky enterprise. That period of risk and uncertainty has passed.

\section{Summary}

This dissertation contributes to the study of CAM in a small way, by tackling the difficulties of what amounts to an analysis of rare events. Often, to record rare events, vast quantities of data must be collected, to assure sufficient statistical power for detection of said events. Such is the case with MDCAM and the MEPS. It is worthwhile to comment on the magnitude of the enterprise surrounding the MEPS. The MEPS is an ongoing major research effort of the U.S. government. The MEPS solves a problem that arises from the American strategy for delivering health care: a fragmented approach that is part private, part public system of insurance and managed care, characterized by citizens moving in and out of coverage, and changing providers while providers change services and products. A sticky problem arises when trying to track costs and expenditures associated with health care. The MEPS collects data from citizens, from allopathic physicians, and from insurers, and links one to the other. In this way, the MEPS further connects elements of a system, providing a degree of feedback. The professional development of complex surveys serves the demand for 
Conclusions

population estimates as their main value. This dissertation focused on the Household Component of the MEPS, where the units of analysis are people of the United States. The survey respondents reported on their health care consumption (including the behavior of physicians) from a first-hand, empirical point of view. In this way, the survey captured a feedback relation between the physician and the patient, with some degree of accuracy, thereby providing an indirect method of measurement of physician behavior. The rationale for this methodological view is supported by three pillars of logic: (1) the concept of system implies the environment; (2) probability theory and statistical inference; and (3) the critical realist philosophy described in Byrne (1998:66) about the utility of surveys for illuminating social life.

"Marsh (1982) made the most recent serious attempt to identify what social surveys actually are. She pointed out that they deal not with abstractions from reality, as in the case with any experiment, but with reality as it actually is. In other words they deal with the complex covariation as it operates in the real world. The central idea she used to express this was the notion that the surveys generate a case/variable matrix, i.e. a table in which the rows are cases, the columns are variables and the cells formed by the intersection of rows and columns contain either the value of that variable for that case or a missing data code. When this account is taken in consideration with Bateson's seminal discussion of the social nature of the survey (1984) and the way in which the data is constructed as numbers from the real knowledge of the world held by respondents as information in the natural language of everyday life, then the non-positivist character of the enterprise can be seen for what it is.

There is a close relation between the providers of health services and those that consume them, such that one can inform on the other. Differences between 
Conclusions

subpopulations, defined by professional type, can be adequately determined through probabilistic modeling. Lastly, each datum - each observation, though they be few - of a survey respondent declaring that they received alternative medicine from an allopathic physician is "real" and valid, and presumably accurate. . By operationally defining MDCAM as early integrative medicine, this dissertation established a window of opportunity to observe and characterize a system in development. Integrative medicine has become a specialty within the system of professions and the results presented here indicate that its origin is located in workplace-level behaviors (borrowed across paradigmatic boundaries) that contradicted conceptuallevel/ideological claims that were advanced during the period.

\section{Limitations}

This dissertation has several limitations. Foremost is the age of the data. The primary weakness associated with the age of the dataset is in the relevance of the findings for impacting current health care policy. The role of CAM in American health care has gained mainstream acceptance. Research into the utility and effectiveness of CAM has normalized under the influence of governmental support. Major research efforts have been established around the country, located in prestigious universities and hospitals. The novelty of the main research finding, consumers receiving CAM from physicians, is diminished in the context of current attitudes towards CAM. 
Conclusions

Another vulnerability of this analysis stems from the limited statistical power associated with the small sample size of the MDCAM group. This subpopulation analysis runs the risk of Type II error, i.e., missing an effect when it is present in the population. The analysis failed to detect group-level differences between subpopulations, and the possibility that the failure is due to insufficient power cannot be ruled out.

A related issue is the reliability of the prevalence estimates produced by the analysis. The estimates are questionable because the small sample sizes precluded robust multivariate modeling to adjust for confounding variables. The most notable impact was in the analyses of Tables 6.7 and 6.8 . The validity of the estimates are also suspect because procedures such as split-half analysis, or hold out samples to validate models, were precluded by the small sample size of the MDCAM group. The estimates of statistical differences are vulnerable to Type I error (i.e., rejecting the null hypothesis in error) without these validation procedures.

An additional challenge to the validity of this research is the possibility of measurement error associated with the survey instrument. While the supporting documentation for the MEPS is extensive, there is no explicit mention of attempts to determine whether survey respondents held a similar mental construct for the terms doctor or physician. The actual population prevalence of MDCAM could be either smaller or larger, depending on the various understandings of these terms. Another question is whether respondents reliably share the same meaning of CAM therapy 
Conclusions

labels as were intended by the survey designers, or the researcher. In this way, all analyses are vulnerable to measurement error.

Further, secondary analysis is subject to the inherent limitations of observational studies. "Differences in survey methods such as sampling frame, item wording and timing of data collection may result in different estimates for a similar question derived from different data sources" (Bierman \& Bubolz, 2003). This dissertation is limited, to some extent, by the methodological approach. A related issue is the difficulty of applying theoretical treatment to preexisting data. The construct validity of measures is enhanced when they are conceived from within a theoretical frame.

It is of central concern to address the limits of an indirect methodology. The potential is high for logical fallacies to creep into the discussion. Of paramount concern is a variation of the ecological fallacy. The ecological fallacy is the erroneous attributions across levels of phenomena. One type of ecological fallacy is known as the reductionist fallacy and is committed when inferences drawn from the data are applied to a different level of units of analysis. It is the error of assuming that atomistic observations aggregate to sufficiently explain more macro-level observations. It ignores the possibility of synergy or level-specific explanations and is an inherent challenge to multilevel analysis. Measurement error can vary across levels, and synergistic error can emerge by correlating across levels. The methodology employed here is particularly vulnerable to this logical fallacy because 
Conclusions

of its design. To get a sense of the vulnerability this poses to the findings, two views of the magnitude of the effect will be considered. In minimizing this concern, it is important to recognize that the process of subpopulation analysis is common in epidemiology, demography, and health services research. However, this work often proceeds within paradigmatic professional cultures where the procedures are tacitly accepted and unexamined. To maximize the vulnerability, the logic of operationally defining MDCAM as measure of physician behavior can be challenged as an imposed attribution. The units of analysis were consumers of health care, not physicians. Conclusions about physician behavior are based on inference, a weaker association than direct measurement.

\section{Indications for Future Research}

Joseph Robertson, President of Oregon Health \& Sciences University, recently stated that the production of new physicians in Oregon is half the national rate and falls far short of the $30 \%$ increase in production called for by the American Association of Medical Colleges. He estimated that nursing and "all of the healthcare professions" were in a similar state (Karr, 2007). This illustrates the discourse of need that motivates this dissertation. One challenge to the production of a future health care workforce is the stigma of a health care system in crisis. The negative attitudes of physicians and nurses about their working environments is increasingly recognized by the general public. To the extent that the addition of integrative medicine, and more 
Conclusions

broadly, integrative health care, represents an expansion of the paradigmatic frame of health care, recruitment of new talent may be facilitated. These new areas of specialization may be attractive to ambitious students with an interest in health education and health promotion. Research needs to be conducted into the differential effects of these career options on students' career choices.

Further study on the role of internal differentiation in the system of professions needs to be conducted. Again, regarding health care labor shortages, one potential solution is to open the work to workers of different types. Naturopathic physicians (NDs) are a potential pool from which to draw. There are differing levels of interest among NDs for participating in the mainstream system, however. Currently, NDs enjoy DEA privileges to prescribe controlled substances. They are classified as "midlevel practitioners," along with physician assistants and nurse-practitioners. However, few NDs request a DEA number. By employing the theoretical lens of internal differentiation within professions, the processes of professional identification can be illuminated. This research would focus on attitudes and practice patterns of both practicing NDs and naturopathic medicine students, to determine the current state of interest in mainstream participation. It would also provide information for curriculum planning and policy-making. 
References

References

Abbott, A. (1988). The System of Professions: An Essay on the Division of Expert Labor. Chicago: University of Chicago Press.

Abbott, A. (1995). Things of Boundaries. Social Research, 62(4), 857-882.

Achterberg, J. (1998). Between the Lightning and Thunder: The Pause Before the Shifting Paradigm. Alternative Therapies, 4(3), 62-66.

Ajrouch, K. J. (2004). Gender, Race, and Symbolic Boundaries: Contested Spaces of Identity among Arab American Adolescents. Sociological Perspectives, 47(4), 371393.

Albert, D. P., \& Butar, F. B. (2004). Distribution, Concentration, and Health Care Implications of Naturopathic Physicians in the United States. Complementary Health Practice Review, 9(2), 103-117.

Allen, D. (2000). Doing Occupational Demarcation: The "Boundary-Work" of Nurse Managers in a District General Hospital. Journal of Contemporary Ethnography, 29(3), 326-356.

Alster, K. (1989). The Holistic Health Movement. Tuscaloosa: The University of Alabama Press.

American Medical Association (1996). Report \#4: Alternative Therapies for the Symptoms of Menopause. Committee on Scientific Affairs

American Medical Association (1997). Report \#12: Alternative Medicine. Committee on Scientific Affairs

American Medical Association (1997). Report \#13: Folk Medicine Among Ethnic Subgroups. Committee on Scientific Affairs

American Medical News (2000) CME Sleuths: Some Continuing Medical Education Classes Under Scrutiny. Retrieved Feb 26, 2003 http://www.amaassn.org/amednews/2000/old00.htm 
Angell, M., \& Kassirer, J. P. (1998). Alternative Medicine: The Risks of Untested and Unregulated Remedies. N.Engl.J Med., 339, 839-841.

Astin, J. A. (1998a). Why Patients Use Alternative Medicine: Results of a National Study. JAMA, 279(19), 1548-1553.

Astin, J. A., Marie, A., Pelletier, K., Hanson, E., \& Haskell, W. L. (1998b). A Review of the Incorporation of Complementary and Alternative Medicine by Mainstream Physicians. Arch Intern Med, 158, 2303-2310.

Astin, J. A. (2000). The Characteristics of CAM Users: A Complex Picture. In M. Kelner \& B. Wellner (Eds.), Complementary and Alternative Medicine: Challenge and Change (pp. 101-114). Toronto, CAN: Harwood Academic Publishers.

Astin, J. A., \& Astin, A.W. (2002). An Integral Approach to Medicine. Alternative Therapies, 8(2), 70-75.

Barnes, P., Powell-Griner, E, McFann, K, \& Nahin, R. (2004). CDC Advance Data Report \#343. Complementary and Alternative Medicine Use Among Adults: United States, 2002 (No. 343): CDC.

Barrett, B. (2003). Alternative, Complementary, and Conventional Medicine: Is Integration Upon Us? The Journal of Alternative and Complementary Medicine, 9(3), 417-427.

Bausell, R. B., Lee, W. L., \& Berman, B. M. (2001). Demographic and Health-Related Correlates to Visits to Complementary and Alternative Medical Providers. Med.Care, 39(2), 190-196.

Bazell R. The Mind Body Connection. In. NY: MSNBC; 2008. p. TV news feature.

Behavioral Risk Factor Surveillance System Survey Data (BRFSS) for 1996. In. CDC BRFSS, 2008: Atlanta, GA.

Bell, I. R., Caspi, O., Schwartz, G. E. R., Grant, K. L., Gaudet, T. W., Rychener, D., et al. (2002). Integrative Medicine and Systemic Outcomes Research: Issues in the Emergence of a New Model for Primary Health Care. Arch Intern Med, 162(2), 133140. 
Bierman A, Bubolz T. Secondary Analysis of Large Survey Databases. In: Max M, Lynn J, editors. Applied Nursing Research. Bethesda, MD: National Institute of Dental and Craniofacial Research; 2003. p. 1-20.

Blane D. The Use of Quantitative Medical Sociology. Sociology of Health \& Illness 2003;25(Silver):115-130.

Business Wire. (2005). Consumer-Driven Healthcare Plans and Employee Benefit Plans to Foster More Consumerism among Employees are Among Top Five Areas of Concern to Employee Benefit Specialists. (12/13/2005).

Borokowski NM, Allen WR. Does Attribution Theory Explain Physicians' Nonacceptance of Clinical Practice Guidelines? Hospital Topics: Research and Perspectives on Healthcare 2003;81(2):9-14.

Bodeker, G., \& Kronenberg, F. (2002). A Public Health Agenda for Traditional, Complementary, and Alternative Medicine. Am.J Public Health, 92(10), 1582-1591.

Bodenheimer, T., \& Grumbach, K. (1995). The Reconfiguration of US Medicine. JAMA, 274(1), 85-90.

Borgatta \& Borgatta (1992) Encyclopedia of Sociology. New York: Macmillan Publishing Company.

Brown, P. (1991). Themes in Medical Sociology. Journal of Health Politics, Policy \& Law, 16, 596-604.

Buckman, R., \& Sabbagh, K. (1995). Magic or Medicine? An Investigation of Healing $\&$ Healers. Amherst: Prometheus Books.

Budrys, G. (2005). Our Unsystematic Health Care System (2 ed.). Lanham, Maryland: Rowman \& Littlefield.

Bunge, M. (1973). Method, Model and Matter. Boston: Reidel.

Bunge, M. (1997). Mechanism and Explanation. Philosophy of the Social Sciences, 27(4), 410-465.

Bunge, M. (2004a). Clarifying Some Misunderstandings about Social Systems and their Mechanisms. Philosophy of the Social Sciences, 34(3), 371-381. 
Bunge, M. (2004b). How Does It Work? The Search for Explanatory Mechanisms. Philosophy of the Social Sciences, 34(2), 182-210.

Bureau of Labor Statistics (2008) Table A-1: Employment Status of the Civilian Population by Age and Sex. In: Access to the Historical Data for the "A" Tables: U.S. Department of Labor

Burke, A., Ginzburg, K., Collie, K., Trachtenberg, D., \& Muhammad, M. (2005). Exploring the role of complementary and alternative medicine in public health practice and training. Journal of Alternative \& Complementary Medicine, 11(5), 931-936.

Byrne, D. (1998) Complexity Theory and the Social Sciences: An Introduction. London: Routledge.

Caplow, T. (1954). The Sociology of Work: Minneapolis: University of Minnesota Press.

CBS News (2001) Debate between Relman and Weil. [Television Broadcast].

Chawla AJ, Hatzmann MR, Long SR. Developing Performance Measures for Prescription Drug Management. In: Health Care Financing Review; 2001.

Cohen, M. (1998). Complementary and Alternative Medicine: Legal Boundaries and Regulatory Perspectives. Baltimore: Johns Hopkins University Press.

Cohen, S. (2002). The Medical Expenditure Panel Survey. Eff Clin Pract, 5(E1), 152.

Committee on Nutrition in Medical Education, National Research Council (1985) 1141.

Conboy, L., Patel, S., Kaptchuk, T., Gottlieb, B., Eisenberg, D., \& Acevedo-Garcia, D. (2005). Sociodemographic Determinants of the Utilization of Specific Types of Complementary and Alternative Medicine: An Analysis Based on a Nationally Representative Survey Sample. J Altern Complement Med, 11(6), 977-994.

Conrad, P. (1992). Medicalization and Social Control. Annual Review of Sociology 18, 209-232.

Conrad, P. (2005). The Shifting Engines of Medicalization. Journal of Health and Social Behavior, 46, 3-14. 
Cooper, R., Henderson, T., \& Dietrich, C. (1998a). Roles of Nonphysician Clinicians as Autonomous Providers of Patient Care, JAMA 280(9), 795-802.

Cooper, R., Laud, P., \& Dietrich, C. (1998b). Current and Projected Workforce of Nonphysician Clinicians. JAMA 280(9), 788-794.

Crank, J. (1984). Free and Moving Boundary Problems. Oxford. Oxford University Press.

Davidson R, Kabat-Zinn J, Schumacher J, Rosenkranz M, Muller D, Santorelli S. Alterations in Brain and Immune Function Produced by Mindfulness Meditation. Psychosom Med 2003;65(4):565-70.

de Quieroz, K. (2005). Different Species Problems and Their Resolution. BioEssays, 27(12), 1263-1269.

de Quieroz, K., \& Gauthier, J. A. (1992). Phylogenetic Taxonomy. Annual Review of Ecology and Systematics, 23, 449-480.

Devitt, M. (2005). Consumer Reports Survey: Mixed Messages About Chiropractic. Dynamic Chiropractic URL: http://findarticles.com/p/articles/mi_qa3987/ is_200509/ai_n15349240/pg 1

Dorland's Illustrated Medical Dictionary, $27^{\text {th }}$ Ed. (1988) Philadelphia, PA: Harcourt Brace Jonovich, Inc.

Druss, B. G., \& Rosenheck, R. A. (1999). Association Between Use of Unconventional Therapies and Conventional Medical Services. JAMA, 282(7), 651656.

Druss, B. G., Marcus, S. C., Olfson, M., Tanielian, T., \& Pincus, H. A. (2003). Trends in Care by Nonphysician Clinicians in the United States. N.Engl.J Med., 348(2), 130137.

Egede, L. E., Ye, X., Zheng, D., \& Silverstein, M. D. (2002). The Prevalence and Pattern of Complementary and Alternative Medicine Use in Individuals with Diabetes. Diabetes Care, 25(2), 324-329.

Ehrenreich, J., \& Ehrenreich, B. (1970). The American Health Empire. New York: Random House. 
Eisenberg, D. M. (2005). Integrative Medicine: A Dissruptive Innovation? OHSU CAM Course Distinguished Lecture (transcription). Portland.

Eisenberg, D. M., Davis, R. B., Ettner, S. L., Appel, S., Wilkey, S., Van, R. M., et al. (1998). Trends in Alternative Medicine Use in the United States, 1990-1997: Results of a Follow-Up National Survey., 280(18), 1569-1575.

Eisenberg, D. M., Kessler, R. C., \& Foster, C. (1993). Unconventional Medicine in the United States. N.Engl.J Med., 328, 246-252.

Ellwood, P. M. (1988). Shattuck Lecture - Outcomes Management. N.Engl.J Med., 318(23), 1549-1557.

Ellwood, P. M., \& Enthoven, A. C. (1995). 'Responsible Choices': The Jackson Hole Group Plan for Health Reform. Health Affairs, 14(2): 24-39.

Federation of State Medical Boards of the United States. Report: Special Committee on Questionable and Deceptive Health Care Practices: author; 1997 April.

Foucault, M. (1973). The Birth of the Clinic: An Archeology of Medical Perception. New York: Vintage Books.

Geisler, E. (2005). The Measurement of Scientific Activity: Research Directions in Linking Philosophy of Science and Metrics of Science and Technology Outputs.

Scientometrics, 62(2), 269-284.

Gieryn, T. F. (1983). Boundary-Work and the Demarcation of Science from NonScience: Strains and Interests in Professional Ideologies of Scientists. American Sociological Review, 48, 781-795.

Gieryn, T. F., Bevins, G. M., \& Zehr, S. C. (1985). Professionalization of American Scientists: Public Science in the Creation/Evolution Trials. American Sociological Review, 50(3): 392-409.

Goldner, M. (1999). How Alternative Medicine Is Changing the Way Consumers and Practitioners Look at Quality, Planning of Services, and Access in the United States. Research in the Sociology of Health Care, 16, 55-74.

Goldner, M. (2000). Integrative Medicine: Issues to Consider in this Emerging Form of Health Care. In Research in the Sociology of Health Care, 17: 213-233. 
Goldner, M. (2001). Expanding Political Opportunities and Changing Collective Identities in the Complementary and Alternative Medicine Movement. Research in Social Movements, Conflicts and Change, 23, 69-102.

Goldstein, M. (1999). Alternative Health Care: Medicine, Miracle or Mirage? Philadelphia: Temple University Press.

Goldstein, M. S. (2000a). The Culture of Fitness and the Growth of CAM. In M. Kelner, Wellman, B., Pescosolido, B., Saks, M. (Ed.), Complementary and Alternative Medicine: Challenge and Change (pp. 27-38). Canada: Harwood Academic Publishers.

Goldstein, M. S. (2000b). The Growing Acceptance of Complementary and Alternative Medicine. In C. Bird, P. Conrad \& A. Fremont (Eds.), Handbook of Medical Sociology (5 ed., pp. 284-297). Upper Saddle, NJ: Prentice-Hall, Inc.

Gordon, J. (1980). The Paradigm of Holistic Medicine. In A. Hastings, J. Fadiman \& J. Gordon (Eds.), Health and the Whole Person: The Complete Guide to Holistic Medicine (pp. 3-27). Boulder: Westview Press.

Hafferty, F. W., \& Light, D. W. (1995). Professional Dynamics and the Changing Nature of Medical Work. Journal of Health and Social Behavior, 35(Extra): 132-153.

Hall, A. D., \& Fagan, R. E. (1956). Definition of a System. In W. Buckley (Ed.), Modern Systems Research for the Behavioral Scientist (pp. 81-92). Chicago: Aldine Publishing Co.

Halpern, S. (1990). Medicalization as Professional Process: Postwar Trends in Pediatrics. 30, 28-42.

Hartley, H. (2002). The System of Alignments Challenging Physician Professional Dominance: An Elaborated Theory of Countervailing Powers. Sociology of Health and Illness, 24(2), 178-207.

Haug, M. R., \& Sussman, M. B. (1969). Professional Autonomy and the Revolt of the Client. Social Problems, 17(2), 153-160.

Haug, M. R., \& Lavin, B. (1981). Practitioner or Patient - Who's in Charge? Journal of Health and Social Behavior, 22(3), 212 - 229.

Haug, M. R., \& Lavin, B. (1983). Consumerism in Medicine: Challenging Physician Authority. Beverly Hills, CA: Sage Publications. 
Health Resources and Services Administration (HRSA). (2003) Changing Demographics: Implications for Physicians, Nurses and Other Health Workers.

Hippocrates. (400 B.C.). Hippocratic Writings: On Ancient Medicine. In R. MaynardHutchins (Ed.), Great Books of The Western World (Vol. 10, pp. 1-9). Chicago: Encyclopaedia Britannica, Inc.

Hirschkorna, K. (2005). Conceptualizing Mainstream Health Care Providers' Behaviors in Relation to Complementary and Alternative Medicine. Social Science \& Medicine, 61(1), 157-170.

Horrigan, B. (2003). Introduction. In B. Horrigan (Ed.), Voices of Integrative Medicine: Conversations and Encounters (pp. 1-7). St. Louis: Churchill Livingstone.

Jayaraman, K. (1998). Landmark Healthcare, Inc. Survey of Alternative Medicine Use. Journal of Alternative and Complementary Medicine, 4(1), 118.

Kabat-Zinn J, Lipworth L, Burney R. The Clinical Use of Mindfulness Meditation for the Self-Regulation of Chronic Pain. J Behav Med 1985;8(2):163-90.

Karr M. (2007) The New Regime in the Region. Metroscape. Summer:20-25.

Kessler, R. C. (2001). The Use of Complementary and Alternative Therapies to Treat Anxiety and Depression in the United States. Am J Psychiatry, 158, 289-294.

Klarman HE. The Distinctive Economic Characteristics of Health Services. Journal of Health and Human Behavior 1963;4(1):44-49.

Kligler, B., Maizes, V., Schachter, S., Park, C., Gaudet, T., Benn, R., et al. (2004). Core Competencies in Integrative Medicine for Medical School Curricula: A Proposal. Academic Medicine, 79(6), 521-531.

Kreitzer, M., Mitten, D., Harris, I., \& Shandeling, J. (2002). Attitudes Toward CAM Among Medical, Nursing and Pharmacy Faculty and Students: A Comparative Analysis. Alternative Therapies, 8(6), 44-53.

Lafferty, W. E., Tyree, P. T., Bellas, A. S., Watts, C. A., Lind, B. K., Sherman, K. J., et al. (2006). Insurance Coverage and Subsequent Utilization of Complementary and Alternative Medicine Providers. American Journal of Managed Care, 12(7), 397-404. 
Lamont, M., \& Molnar, V. (2002). The Study of Boundaries in the Social Sciences. Annual Review of Sociology, 28(1), 167-195.

Landmark Report II. 2003. URL: http://www.landmarkhealthcare.com/ EducandresearchLMReportII.php?left=EducandresearchLMReportII

Lavin, B., Haug, M., Belgrave, L., \& Breslau, N. (1987). Change in Student Physicians' Views on Authority Relationships with Patients'. Journal of Health and Social Behavior, 28, 258-272.

Lendaris, G. G. (1986). On Systemness and the Problem Solver: Tutorial Comments. IEEE Transaction on Systems, Man and Cybernetics, SMC, 16(4), 604-610.

Lerner LJ, Kennedy BJ. The Prevalence of Questionable Methods of Cancer Treatment in the United States. CA Cancer J Clin 1992;42:181-191.

Light, D. (1995). Countervailing Powers: A Framework for Professions in Transition. In Health Professions And The State In Europe (pp. 41) London: Routledge.

Light, D. (2000). The Medical Profession and Organizational Change: From Professional Dominance to Countervailing Power. In C. Bird, P. Conrad \& A. Fremont (Eds.), Handbook of Medical Sociology (5 ed., pp. 201-216). Upper Saddle River, NJ: Prentice Hall.

Low, J. (2004). Using Alternative Therapies: A Qualitative Analysis. Toronto: Canadian Scholars Press, Inc.

Lowenberg, J. (1989). Caring and Responsibility: The Crossroads between Holistic Practice and Traditional Medicine. Philadelphia: University of Pennsylvania Press.

Mackenzie, E., Taylor, L., \& Lavizzo-Mourey, R. (1999). Experiences of Ethnic Minority Primary Care Physicians with Managed Care: A National Survey. American Journal of Managed Care, 5(10), 1251-1264.

Mackenzie, E., Taylor, L., Bloom, B., Hufford, D., \& Johnson, J. (2003). Ethnic Minority Use of Complementary and Alternative Medicine (CAM): A National Probability Survey for CAM Utilizers. Alternative Therapies, 9(4), 50-56.

Maizes V, Schneider C, Bell IR, Weil A. Integrative Medical Education: Development and Implementation of a Comprehensive Curriculum at the University of Arizona. Academic Medicine 2002;77(9):851-860. 
Mahner, M., \& Bunge, M. (2001). Function and Functionalism: A Synthetic Perspective. Philosophy of Science, 68(1), 75-94.

Marshall, G. (1998). A Dictionary of Sociology (2 ed.). New York: Oxford University Press.

McClelland MA, Westerberg KW. Material and Energy Flow in a Metal Evaporation System with Moving Boundaries. Ind. Eng. Chem. Res. 2004;43:3948-56.

McFarland, B., Bigelow, D., Zani, B., Newsom, J., \& Kaplan, M. (2002). Complementary and Alternative Medicine Use in Canada and the United States. Am.J Public Health, 92(10), 1616-1618.

Mechanic D. Physicians. In: Freeman HE, Levine S, Reeder LG, editors. Handbook of Medical Sociology. 3rd ed. Englewood Cliffs,NJ: Prentice Hall, Inc.; 1979. p. 177192.

Nahin, R. L., Pontzer, C. H., \& Chesney, M. A. (2005). Racing Toward the Integration of Complementary and Alternative Medicine: A Marathon or a Sprint? Health Affairs, 24(4), 991-993.

National Center for Complementary and Alternative Medicine. (2003-2008)., URL: http://www.nccam.org

New York Times (1990, February 9) Appeals Court Rules AMA Acted Against Chiropractors.http://query.nytimes.com/gst/fullpage.html?res=9C0CEED81FF3AA35 751C0A966958260

NIH News (2005) New Online Continuing Education Series on Complementary and Alternative Medicine. (Press Release) www.nih.gov/news/pr/jul2005/nccam-18.htm Retrieved 080427.

Norkus, Z. (2005). Mechanisms as Miracle Makers? The Rise and Inconsistencies of the "Mechanismic Approach" in Social Science and History. History and Theory, 44(3), 348-372.

O'Connor, B. (1995). Healing Traditions. Philadelphia: University of Pennsylvania Press.

Pagan, J. A., \& Pauly, M. V. (2005). Access to Conventional Medical Care and the Use of Complementary and Alternative Medicine: Do People Seek Alternative 
Therapies as a Way to Save Money, or Because They Believe that these Therapies Reflect their Personal Approach to Health Care? Health Affairs, 24(1): 255-263.

Pawluch, D. (1983). Transitions in Pediatrics: A Segmental Analysis. Social Problems, 30(4), 449-465.

Pelletier, K., \& Horrigan, B. (2003). Ken Pelletier PhD MD: Mind-Body Medicine. In B. Horrigan (Ed.), Voices of Integrative Medicine: Conversations and Encounters (pp. 45-56). St.Louis MO: Churchill Livingstone.

Pelletier, K., Astin, J. A., \& Haskell, W. L. (1999). Current Trends in the Integration and Reimbursement of Complementary and Alternative Medicine by Managed Care Organizations (MCOs) and Insurance Providers: 1998 Update and Cohort Analysis. American Journal of Health Promotion, 14(2), 125-133.

Pelletier, K., Marie, A., Krasner, M., \& Haskell, W. L. (1997). Current Trends in the Integration and Reimbursement of Complementary and Alternative Medicine by Managed Care, Insurance Carriers and Hospital Providers. American Journal of Health Promotion, 12(2), 112-122.

Pickel, A. (2004). Systems and Mechanisms: A Symposium on Mario Bunge's Philosophy of Social Science. Philosophy of the Social Sciences, 34(2), 169-181.

Pizzorno, J. (1996). Natural Medicine. In M. Michozzi (Ed.), Fundamentals of Complementary and Alternative Medicine. New York: Churchill Livingstone, Inc.

Reinhardt, U. E. (1992). The United States: Breakthroughs and Waste. Journal of Health Politics, Policy \& Law, 17(4), 637-666.

Relman, A. (1980). The New Medical-Industrial Complex. N.Engl.J Med., 202(17), 963-970.

Ritenbaugh, C., Verhoef, M., Fleishman, S., Boon, H., \& Leis, A. (2003). Whole Systems Research: A Discipline for Studying Complementary and Alternative Medicine. Altern Ther Health Med, 9(4), 32-36.

Ritzer, G., \& Walczak, D. (1986). Working: Conflict and Change (3 ed.). Englewood Cliffs, NJ: Prentice-Hall.

Ruggie, M. (2005). Mainstreaming Complementary Therapies: New Directions in Health Care. Health Affairs, 24(4), 980-990. 
Sadovnikov, S. (2004). Systemism, Social Laws, and the Limits of Social Theory: Themes Out of Mario Bunge's - The Sociology-Philosophy Connection. Philosophy of the Social Sciences, 34(4), 536-587.

Saks, M. (2001). Alternative Medicine and the Health Care Division of Labour: Present Trends and Future Prospects. Current Sociology, 49(3), 119-134.

Shuval, J., \& Mizrachi, N. (2004). Changing Boundaries: Modes of Coexistence of Alternative and Biomedicine. Qualitative Health Research, 14(5), 675-690.

Simon, S. R., Pan, R. J., Sullivan, A. M., Clark-Chiarelli, N., Connelly, M. T., Peters, A. S., et al. (1999). Views of Managed Care--A Survey of Students, Residents, Faculty, and Deans at Medical Schools in the United States. New England Journal of Medicine, 340(12), 928-936.

Snyderman, R. \& Weil, A. T. (2002). Integrative Medicine: Bringing Medicine Back to its Roots. Arch Intern Med, 162(4), 395-397.

Statistical Program For the Social Sciences (SPSS) (v.13) (2005) Chicago, Il.

Starr, P. (1982). The Social Transformation of American Medicine: The Rise of a Sovereign Profession and the Making of a Vast Industry (paper ed.): Basic Books.

Sterman, J. D. (2000). Business Dynamics: Systems Thinking and Modeling for a Complex World. Boston: Irwin McGraw-Hill.

Straus, R. (1957). The Nature and Status of Medical Sociology. American Sociological Review, 22, 200-204.

Strauss, A. L., \& Corbin, J. M. (1988). Shaping A New Health Care System: The Explosion of Chronic Illness as A Catalyst for Change. San Francisco: Jossey-Bass.

Steyer, T. E., Freed, G. L., \& Lantz, P. M. (2002). Medicaid Reimbursement for Alternative Therapies. Alternative Therapies, 8(6), 84-88.

Sullivan, D. H. (1993). Cosmetic Surgery: Market Dynamics and Medicalization. Research in the Sociology of Health Care, 10, 97-115.

Taylor, L. (1968). Occupational Sociology. New York: Oxford University Press.

Tilly, C. (2001). Mechanisms in Political Processes. Annual Review of Political Science, 4, 21-41. 
Tilly, C. (2004a). Social Boundary Mechanisms. Philosophy of the Social Sciences, 34(2), 211-236.

Trachtenberg, D. (2002). Alternative Therapies and Public Health: Crisis or Opportunity? Am.J Public Health, 92(10), 1566-1567.

U.S. Census Bureau, Population Estimates Program (2007).

http://factfinder.census.gov/jsp/saff/SAFFInfo.jsp?_pageld=sp3_pop_est

U. S. News \& World Report (2008, January 11). Integrative Medicine. Retrieved $080427 \mathrm{http}: / /$ health.usnews.com/articles/health/living-well/2008/01/11/integrativemedicine-overview.html

Van den Brink-Muinen, A., \& Rijken, P. (2006). Does Trust in Health Care Influence the Use of Complementary and Alternative Medicine by Chronically Ill People? Bmc Public Health, 6, 188): 1-9.

von Bertalanffy, L. (1968). General System Theory: Foundations, Development, Applications (Revised Edition, paperback 1973 ed.). New York: George Braziller.

Weil, A. T. (2000). The Significance of Integrative Medicine for the Future of Medical Education. The American Journal of Medicine, 108, 441-443.

Weiss, L. (1997). Private Medicine, Public Health. Boulder CO: Westview Press.

Weitz, R. (2004). The Sociology of Health, Illness and Health Care: A Critical Approach (3rd ed.). Belmont, CA: Wadsworth.

Wennberg JE. Dealing with Medical Practice Variation: A Proposal for Action. Health Affairs 1984;3:6-32.

Wetzel, M., Eisenberg, D. M., \& Kaptchuk, T. (1998). Courses Involving Complementary and Alternative Medicine as US Medical Schools. 280(9), 784-787.

White House Commission on Complementary and Alternative Medicine Policy Final Report of the White House Commission. (2002). Bethesda, Maryland.

Whitley, R. (2006). Understanding Differences: Searching for the Social Processes that Construct and Reproduce Variety in Science and Economic Organization.

Organization Studies, 27(8), 1153-1177. 
WHO. (1987). Report of the Second Meeting of Directors of WHO Collaborating Centres for Traditional Medicine. http://whqlibdoc.who.int/hq/1988/

WHO TRM_88.1.pdf

WHO. (2007). Health Statistics: Dependency Ratio per 100 by Country. Retrieved 11/25, 2007 http://www.who.int/whosis/data/Search.jsp

Whorton, J. C. (2004). From Cultism to CAM: Alternative Medicine in the Twentieth Century. In R. Johnston (Ed.), The Politics of Healing: Histories of Alternative Medicine in Twentieth-Century North America (pp. 287-306). New York: Routledge.

Wight, C. (2004). Theorizing the Mechanisms of Conceptual and Semiotic Space. Philosophy of the Social Sciences, 34(2), 283-299.

Wilensky, H. (1964). The Professionalization of Everyone? American Journal of Sociology, 70, 137-158.

Winslow, L. C., \& Shapiro, H. (2002). Physicians Want Education about Complementary and Alternative Medicine to Facilitate Communication with their Patients. Arch Intern Med, 162, 1176-1181.

Wolsko, P., Eisenberg, D. M., Davis, R. B., Ettner, S. L., \& Phillips, R. S. (2002). Insurance Coverage, Medical Conditions, and Visits to Alternative Medicine Providers: Results of a National Survey. Archives of Internal Medicine, 162(3), 281287.

World Development Indicators Database. (2007). Retrieved 11.25, 2007 http://ddpext.worldbank.org/ext/DDPQQ/member.do?method=getMembers\&userid=1\&queryId $=135$

Zodet, M. (2005). Personal Communication: SPSS and SUDAAN Comparisons. Rockville, MD: MEPS. 
Appendix A

\section{Appendix A}

\section{Typologies of CAM}

James Gordon (1980) identified seventeen distinct elements of the "paradigm of holistic medicine". These are: (1) Holistic medicine addresses itself to the physical, mental, and spiritual aspects of those who come for care; (2) Although it appreciates the predictive value of data based on statistical studies, holistic medicine emphasizes each patient's genetic, biological, and psychosocial uniqueness as well as the importance of tailoring treatment to meet each individual's needs; (3) A holistic approach to medicine and health care includes understanding and treating people in the context of their culture, their family, and their community; (4) Holistic medicine views health as a positive state, not as the absence of disease; (5) Holistic medicine emphasizes the promotion of health and the prevention of disease; (6) Holistic medicine emphasizes the responsibility of each individual for his or her health; (7) Holistic medicine uses therapeutic approaches that mobilize the individual's innate capacity for self-healing; (8) Though none would deny the occasional necessity for swift and authoritative medical or surgical intervention, the emphasis in holistic medicine is on helping people to understand and to help themselves, on education, and self-care rather than treatment and dependence; (9) Holistic medicine makes use of a variety of diagnostic methods and systems in addition to and sometimes in place of the standard laboratory examinations; (10) Physical contact between practitioner and patient is an important element of holistic medicine; (11) Good health depends on good nutrition and regular exercise; (12) Holistic medicine includes an appreciation of and attention to sensuousness and sexuality; (13) Holistic medicine views illness as an opportunity for discovery as well as a misfortune; (14) Holism includes an appreciation of the quality of life in each of its stages and an interest in improving it as well as knowledge of the illnesses that are common to it; (15) Holistic medicine emphasizes the potential therapeutic value of the setting in which health care takes place; (16) An understanding of and a commitment to change those social and economic conditions that perpetuate ill health are as much a part of holistic medicine as its emphasis on individual responsibility; (17) Holistic medicine transforms its practitioners as well as its patients.

Kristin Alster (1989) identified twelve core "statements or slogans" associated with the holistic health movement. Valuable insight can be gained into the efforts of a movement to position itself in the social sphere by recognizing the signs or social messages that are constructed to represent the movement. Here Alster broadly categorizes the slogans. Slogans related to the individual: (1) The person, like any organic whole, is more than the sum of his parts; (2) "Mind" and "Body" are artificial 
Appendix A

distinctions that interfere with our understanding of man's essential integrity. Slogans related to health: (1) Good health is more than physical well-being. It is a function of balance among the physical, mental and spiritual aspects of a person in harmony with the environment; (2) Health has positive attributes and is not simply the absence of disease; (3) Ill-health, or disease, is multicausal and cannot be assigned a single etiology; (4) Because illness signals an imbalance, it can be a learning experience, providing people with an opportunity to alter harmful behaviors. Slogans related to health care: (1) The prevention of illness and the maintenance of health are more important than the treatment of disease; (2) To be effective, health care must focus on the whole person, not just the diseased part; (3) Individuals are largely responsible for maintaining their own health; (4) Although conventional medical care is useful, and sometimes necessary, self-care is preferable in many instances; (5) The health care practitioner is not simply an expert or technician, but is an agent who helps ill persons mobilize their own healing powers; (6) Caring is a significant component of the healing process; (7) Unorthodox diagnostic techniques and therapies that elicit a positive response from the patient may be legitimate, even if their efficacy has not been confirmed by scientific testing. Low-technology, non-invasive, "natural" remedies are especially desirable.

June Lowenberg (1989) identified seven core "parameters of the new model of holistic medicine". There parameters are: (1) holism; (2) health promotion; (3) the meaning of illness; (4) individual responsibility; (5) the practitioner stance; (6) cultural diversity in healing practices; and (7) a constellation of values and meanings comprising an alternative world view or consciousness. Admittedly this work focused on ideological distinctions rather than behavioral or interactional levels of practice.

Robert Buckman, MD \& Karl Sabbagh (1995) take a skeptics approach to explaining how patients are attracted to CAM. They reduce the explanation to eleven "philosophical attractions" common to the work and beliefs of alternative healers. The philosophical features identified by these authors are: (1) the conceptualization of health as more inclusive than a narrow focus on disease; (2) employing the concepts of energies and forces with the concepts of regulation and balance; (3) emphasizing selfhealing; (4) emphasizing holism; (5) unifying hypotheses of disease are attractive because of the simplicity of their accounts; (6) emphasis on natural remedies aligning with the notion that all things natural are also good; (7) emphasis on traditional remedies imparting a sense of safety and reliability; (8) emphasis on exotic treatments and their impact on hope; (9) imparting significance to the whole person - combating depersonalization; (10) invoking the David and Goliath metaphor i.e., identifying with the disempowered; and (11) justice/equity or the idea that through significant and sincere participation (ownership) in the healing process; healing occurs more readily.

Bonnie Blair O'Conner (1995) identified nine "concepts common to many vernacular health belief systems" (Chapter 1, Table 1 p30). These concepts are: (1) distinction drawn between immediate and ultimate causes. Importance of addressing ultimate causes in healing actions; (2) definition of health in terms of balance or 
harmony (e.g., innate qualities, forces, humors; internal, external, social and spiritual); (3) concepts of blockage or transference of (some form or definition of) energy in illness etiology and in healing; (4) disease etiology includes buildup of toxins, impurities, or imbalances (hot/cold, yin/yang) in the body; (5) Vitalism, or the concept that the body has its own "life force" that promotes health and healing and is essential to wellness; (6) interpretation of some disruptive states as desirable, for example, rashes as indicating impurities or disease "coming out" of the body, or diarrhea as indicating purging of impurities or toxins (i.e., some events are not constructed as "symptoms" in the same way as they are by conventional medicine); (7) recognition of magical, spiritual, metaphysical, or supernatural causes for or aspects of illnesses, with the concomitant requirement for matching aspects of healing actions; (8) illness as one subtype of a more general category of misfortune; capacity of the healing system to address or influence the larger category as well as the specific illness; (9) contagion or transference in many forms, including magical contagion and transference of illness as a "thing," with the implication that the person "passing" it no longer has it once the recipient has acquired it. 


\section{Appendix B}

Diagnoses Associated with High Prescription Medicine Count

\begin{tabular}{|l|l|l|}
\hline Count & CCC & Condition Category Label \\
\hline 1 & 48 & Thyroid \\
\hline 2 & 49 & Diabetes Mellitus with complications \\
\hline 3 & 53 & Disorders of lipid metabolism \\
\hline 4 & 69 & Affective Disorders \\
\hline 5 & 72 & Anxiety, somatoform, dissociative and personality disorders \\
\hline 6 & 74 & Other mental conditions \\
\hline 7 & 75 & $\begin{array}{l}\text { Personal history of mental disorder, mental and behavioral problems, observation } \\
\text { and screening for mental conditions }\end{array}$ \\
\hline 8 & 88 & Glaucoma \\
\hline 9 & 95 & Other nervous system disorders \\
\hline 10 & 98 & Essential hypertension \\
\hline 11 & 109 & Acute cerebrovascular disease \\
\hline 12 & 126 & Other upper respiratory infections \\
\hline 13 & 134 & Other upper respiratory disease \\
\hline 14 & 141 & Other disorders of stomach and duodenum \\
\hline 15 & 155 & Other gastrointestinal disorders \\
\hline 16 & 156 & Nephritis, nephrosis and renal failure \\
\hline 17 & 161 & Other disease of kidneys and ureter \\
\hline 18 & 164 & Hyperplasia of prostate \\
\hline 19 & 173 & Menopausal disorder \\
\hline 20 & 175 & Other female genital disorders \\
\hline 21 & 176 & Contraceptive and procreative management \\
\hline 22 & 201 & Infective arthritis and osteomyelitis (except by TB or STD) \\
\hline 23 & 204 & Other nontraumatic joint disorders \\
\hline 24 & 205 & Spondylosis, IV disc disorders and other back problems \\
\hline 25 & 208 & Acquired foot deformities \\
\hline 26 & 211 & Other connective tissue disease \\
\hline 27 & 212 & Other bone disease and musculoskeletal deformities \\
\hline 28 & 213 & Cardiac and circulatory congenital anomalies \\
\hline 29 & 214 & Digestive congenital anomalies \\
\hline 30 & 225 & Joint disorders and dislocations, trauma-related \\
\hline 31 & 232 & Sprains and strains \\
\hline 32 & 239 & Superficial injury, contusion \\
\hline 33 & 244 & Other injuries and conditions due to external causes \\
\hline 34 & 259 & Residual codes; unclassified \\
\hline 35 & 255 & Administrative/Social admission \\
\hline & & \\
\hline
\end{tabular}

